\title{
ESTRUTURA E DINÂMICA DE UM FRAGMENTO DE FLORESTA ESTACIONAL SEMIDECIDUAL NA REGIÃO DE PIRACICABA, SP
}

HENRIQUE EDUARDO MENDONÇA NASCIMENTO

Engenheiro Florestal

Orientador: Prof. Dr. VIRGílIO MAURÍCIO VIANA

Dissertação apresentada à Escola Superior de Agricultura "Luiz de Queiroz", Universidade de São Paulo, para obtenção do título de Mestre em Ciências, Área de Concentração: Ciências Florestais

PIRACICABA

Estado de São Paulo - Brasil

Agosto - 1998 
Dados Internacionais de Catalogação na Publicação (CIP) DIVISÃo DE BIBLIOTECA E DOCUMENTAÇÃO - Campus "Luiz de Queiroz"/USP

Nascimento, Henrique Eduardo Mendonça

Estrutura e dinâmica de um fragmento de floresta estacional semidecídua na regiāo de Piracicaba, SP / Henrique Eduardo Mendonça Nascimento. - - Piracicaba, 1998.

78 p. : il.

Dissertação (mestrado) - . Escola Superior de Agricultura Luiz de Queiroz, 1998. Bibliografia.

1. Biodiversidade 2. Conservação ambiental 3. Ecologia florestal 4. Floresta tropical I. Título 
Aos Meus Pais 


\section{AGRADECIMENTOS}

Boa parte do conteúdo deste trabalho e dos meus conhecimentos sobre a ecologia de florestas tropicais foram adquiridos através das discussões e troca de idéias sempre estimulantes com Nadja Lepsch-Cunha e Samir Rolim. Sou muito grato a eles.

Expresso minha gratidão ao Virgílio Viana pela oportunidade de realização deste trabalho.

Aos colegas do Laboratório de Silvicultura Tropical da ESALQ, especialmente Édson Vidal, Denise Amador, Marcelo Marquesini e Marcus Schmidt pelas informações de temas a eles relacionados que foram importantes para minha formação profissional.

Minha estima ao Tereça (Maurício Marcon), Samir Rolim, Klaus Barreto e Girlei Cunha pelo convívio nestes quatro anos e meio de Piracicaba.

Sou muito grato ao João L. F. Batista e Aldicir Scariot que fizeram ótimos comentários e sugestões na versão inicial do trabalho.

Meus estudos foram custeados pela Fundanção de Amparo Pesquisa do Estado de São Paulo (FAPESP). 


\section{SUMÁRIO}

Página

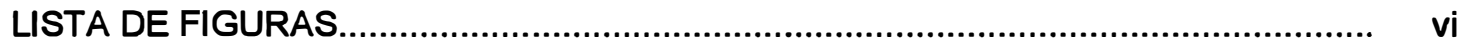

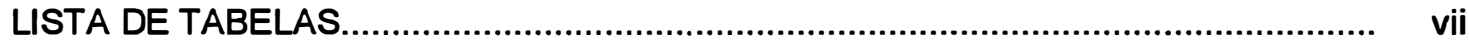

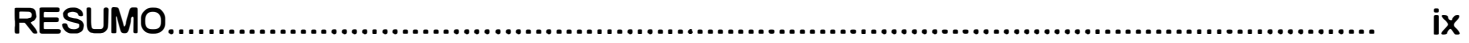

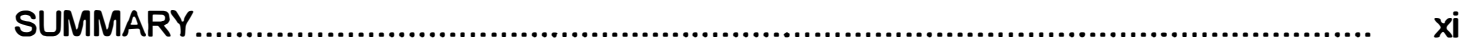

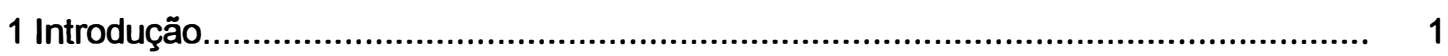

2 Revisão de Literatura...................................................................................... 3

2.1 A Fragmentação Florestal........................................................................... 3

2.2 Consequências da Fragmentação Florestal..................................................... 4

2.2.1 Efeitos de Borda.................................................................................... 4

2.2.2 Limitação do Tamanho Populacional................................................................ 5

2.2.3 Redução da Taxa de Imigração...................................................................... 7

2.2.4 Alterações nas Relações Planta-Animal......................................................... 8

CAPITULO 1 - ESTRUTURA E DINÂMICA DE POPULAÇŌES ARBÓREAS DE UM FRAGMENTO DE FLORESTA ESTACIONAL SEMIDECIDUAL NA REGIÃO DE PIRACICABA, SP

1 Introdução 10

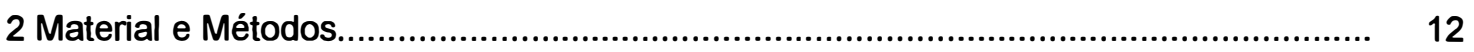

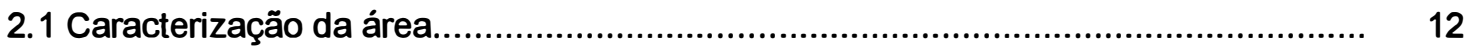

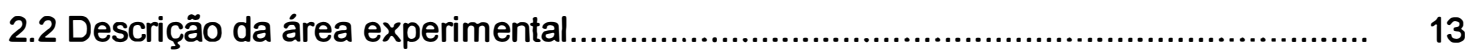

2.3 Obtenção dos dados............................................................................................ 13

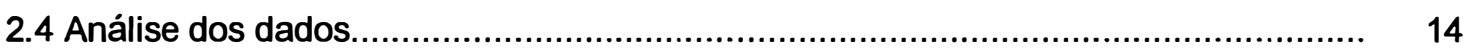

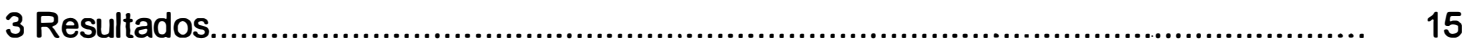

3.1 Densidade, Riqueza e Composição de Espécies em 1991.................................... 15

3.2 Comparação da Mata do Pomar com os Fragmentos Santa Rita e Capuava............ 18

3.3 Número de Individuos Mortos e Recrutados no Periodo de 1991 a 1995................ $\quad 20$

3.4 Recrutamento e Mortalidade das Classes de Densidade e dos Grupos Ecolóigicos . 20

3.5 Comparação da Diversidade e Composição Florística em 1991 e 1995................... 23

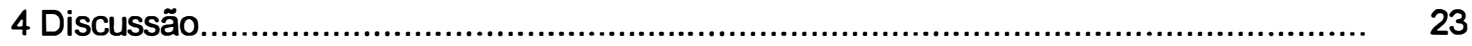

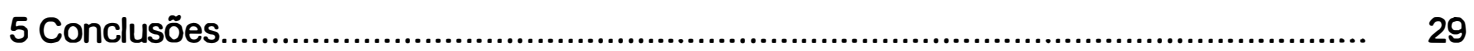

CAPITTULO 2 - ESTRUTURA E DINÂMICA DE ECO-UNIDADES EM UM FRAGMENTO DE FLORESTA ESTACIONAL SEMIDECIDUAL NA REGIÃO DE PIRACICABA, SP

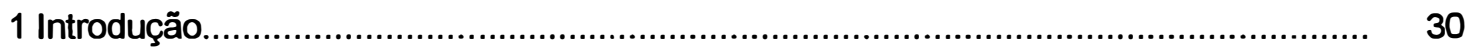

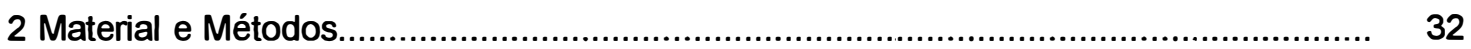

2.1 Caracterização da área............................................................................. $\quad 32$ 
2.2 Descrição da área experimental...................................................................... 33

2.3 Obtenção dos dados...........................................................................................

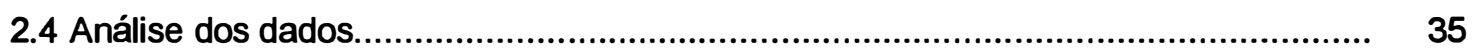

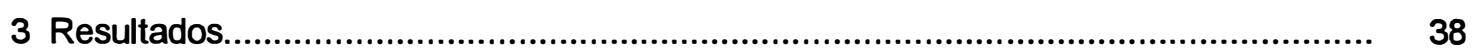

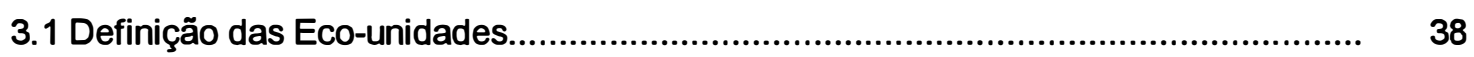

3.2 Estrutura e Dinâmica das Eco-unidades........................................................... 40

3.2.1 Riqueza e Diversidade em 1991 e 1995........................................................... 40

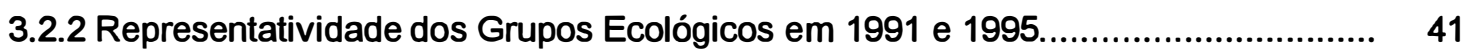

3.3 Indivíduos Jovens............................................................................................ 44

3.3.1 Densidade, Riqueza e Diversidade de Espécies em 1995 e 1996........................ 44

3.3.2 Representativdade dos Grupos Ecológicos em 1995 e 1996............................ 45

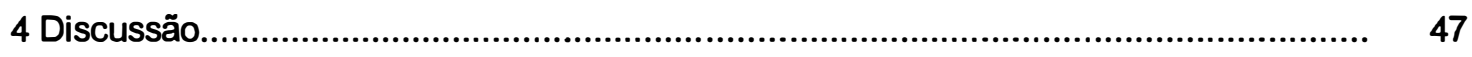

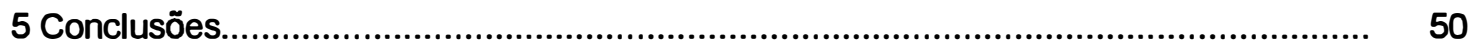

CAPÍTULO 3 - SÍNDROMES DE DISPERSÃO E SUA RELAÇÃO COM A DINÂMICA DA VEGETAÇÃO ARBÓREA EM UM FRAGMENTO DE FLORESTA ESTACIONAL SEMIDECIDUAL

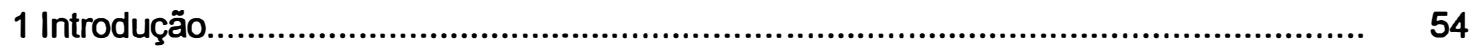

2 Material e Métodos........................................................................................ 56

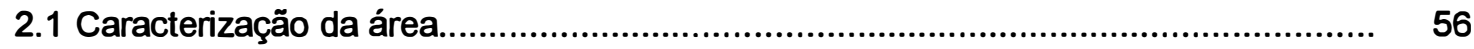

2.2 Descrição da área experimental.................................................................... 57

2.3 Obtenção dos dados............................................................................... 57

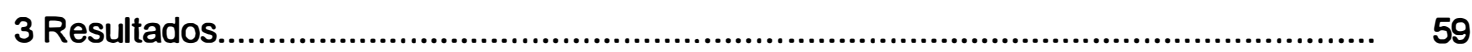

3.1 Recrutamento (Indivíduos $\geq 5 \mathrm{~cm}$ de DAP que ingressaram em 1995).................... 59

3.1.1 Proporção dos Grupos Ecológicos nas Sindromes............................................. 59

3.1.2 Número de Indivíduos Recrutados por Síndrome e Grupo Ecológico.................... 60

3.1.3 Variação Temporal do Número de Indivíduos por Síndrome (1191 a 1995)........... 61

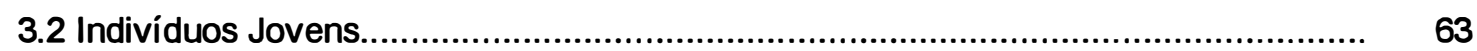

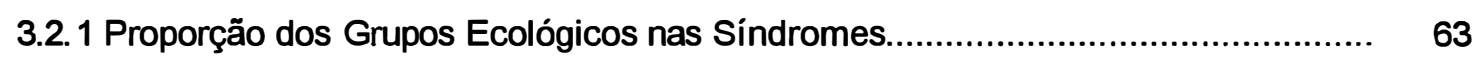

3.2.2 Número de Indivíduos Recrutados por Síndrome e Grupo Ecológico................... 64

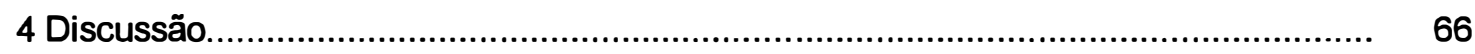

Referências Bibliográficas......................................................................... 71 


\section{LISTA DE FIGURAS}

Página

\section{Capítulo 1}

1 Croqui da Mata do Pomar mostrando a localização dos dois transectos.

2 Percentual de espécies e indivíduos para cada grupo ecológico em 1991 na Mata do Pomar. P - pioneira, OP - oportunista, T - tolerante, RS - reprodutora à sombra.

Capítulo 2

1 Croqui da Mata do Pomar mostrando a localização dos dois transectos e as parcelas de regeneração natural.

2 Dendrograma do agrupamento das eco-unidades definidas a partir da Avaliação Ecológica Rápida. Esta análise de agrupamento foi realizada com o uso das variáveis mostradas na Tabela 2, relativo ao ano de 1995.

3 Área basal relativa de cada grupo ecológico nas 4 eco-unidades em 1991 e 1995.

Capítulo 3

1 Croqui da Mata do Pomar mostrando a localização dos dois transectos e as parcelas de regeneração natural.

2 Distribuição do percentual de espécies por grupo ecológico para cada sindrome de dispersão das espécies que recrutaram entre 1991 e 1995.

3 Percentual de indivíduos recrutados por síndrome de dispersão.

$\mathrm{P}$ - pioneira, OP - oportunista, T - tolerante, RS - reprodutora à sombra.

4 Distribuição do percentual de espécies por grupo ecológico para cada síndrome de dispersão das espécies presentes nas parcelas de regeneração natural em 1995 e/ou 1996. 


\section{LISTA DE TABELAS}

Página

\section{Capitulo 1}

1 Densidade relativa e grupo ecológico por classe de densidade das espécies amostradas em 1991 na Mata do Pomar. Números entre parenteses referem-se ao número de indivíduos/ha. $P$ - pioneira; OP - oportunista; T - tolerante; RS - reprodutora à sombra. (Tabela adaptada de Tabanez et al., 1997).

2 Número de espécies e medidas de abundância de espécies arbóreas na Mata do Pomar e outros dois fragmentos. A "porcentagem de individuos das 4 espécies mais abundantes" dá o percentual de indivíduos das quatro espécies mais abundantes de cada fragmento com relação ao total de indivíduos. O "Número de espécies constituindo $50 \%$ e $70 \%$ " dá o número de espécies que contribuem com mais de $50 \%$ e $70 \%$ do total dos indivíduos. Números entre parênteses referem-se ao percentual de espécies.

3 Recrutamento e mortalidade para os grupos ecológicos pertencentes às classes 1 ( $\geq 15,5$ individuos/ha), 2 (5,2 a 13,8 individuos/ha) $e$ 3 (1,7 e 3,4 indivíduos/ha) entre 1991 e 1995.

4 Recrutamento, mortalidade e mudança do tamanho populacional para as espécies pertencentes à classe 1 ( $\geq 15,5$ individuos/ha no ano de 1991). P - pioneira, OP - oportunista, T - tolerante, RS - reprodutora à sombra.

Capitulo 2

1 Características e suas respectivas categorias usadas para identificar as diferentes eco-unidades em fragmentos de Floresta Estacional Semidecidua.

2 Percentual de área ocupada e mudanças em área basal $\left(\mathrm{m}^{2} / \mathrm{ha}\right)$, densidade (No. individuos/ha), área basal média por individuo ( $\mathrm{ABI}-\mathrm{cm}^{2} / a ́ n$ ore) para árvores $\geq 5 \mathrm{~cm}$ de DAP nas 4 eco-unidades entre 1991 e 1995. Números entre parenteses referem-se ao número de trechos de cada eco-unidade.

3 Número total de indivíduos e de espécies, número esperado de espécies $\left(E\left(S_{n}\right)\right)$ e indice de diversidade de Simpson $(1 / \lambda)$ nas 4 eco-unidades em 1991 e 1995.

4 Percentual de espécies de cada grupo ecológico nas 4 eco-unidades em 1991 e 1995. Números entre parênteses referem-se ao número 
absoluto de espécies.

5 Densidade relativa de cada grupo ecológico nas 4 eco-unidades em 1991 e 1995. Números entre parênteses referem-se ao número de indivíduos por hectare. Os valores de $\mathrm{G}$ são mostrados para os quatro grupos $(P<0,01)$.

6 Número de indivíduos por hectare recrutado nas 4 eco-unidades entre 1991 e 1995.

7 Número de indivíduos por parcela (média \pm desvio padrão), número total de espécies, número esperado de espécies $\left(E\left(S_{n}\right)\right.$ ) e índice de diversidade de Simpson $(1 / \lambda)$ para árvores $\geq 50 \mathrm{~cm}$ de altura $e<5 \mathrm{~cm}$ de DAP nas 4 eco-unidades em 1995 e 1996. Médias do número de individuo/parcela seguidas pela mesma letra, dentro do mesmo ano, não diferem estatisticamente pelo teste de Wilcoxon considerando um nivel de probabilidade $P>0,05$. Números entre parênteses referem-se aos valores absolutos da densidade.

8 Percentual de espécies de cada grupo ecológico nas 4 eco-unidades em 1995 e 1996. Números entre parênteses referem-se ao número absoluto de espécies.

9 Densidade relativa de cada grupo ecológico nas 4 eco-unidades em 1995 e 1996. Números entre parênteses referem-se à estimativa do número de indivíduos por hectare. Os valores de $\mathrm{G}$ são mostrados para os quatro grupos ecológicos (" $\mathrm{P}<0,01,0,01<\mathrm{P}<0,05$ ).

Capitulo 3

1 Percentual de indivíduos por síndromes de dispersão para o ano de 1991 e 1995.

2 Densidades relativa em 1995 e 1996 e recrutamento por síndromes de dispersão das espécies presentes nas parcelas de regeneração natural. P Pioneira, OP - oportunista, T - tolerante, RS - rep. à sombra*. Espécies nas quais os pássaros são dispersores $e^{* *}$ morcegos são um dos agentes. 


\title{
ESTRUTURA E DINÂMICA DE UM FRAGMENTO DE FLORESTA ESTACIONAL
}

\author{
SEMIDECIDUAL NA REGIÃO DE PIRACICABA, SP
}

Autor: HENRIQUE E. M. NASCIMENTO

Orientador: Prof. VIRGILIO MAURÍCIO VIANA

\section{RESUMO}

Este estudo foi realizado em um fragmento de Floresta Estacional Semidecidual de 9,5 ha localizado em Piracicaba, SP, denominado de Mata do Pomar, o qual sofreu dois incêndios em passado recente. $O$ estudo está voltado para as seguintes hipóteses: $i$ ) as espécies arbóreas e os grupos sucessionais diferenciamse com relação às taxas de recrutamento e mortalidade; ii) as eco-unidades identificadas através de uma técnica denominada de Avaliação Ecológica Rápida apresentam composição e diversidade de espécies diferenciadas; iii) as síndromes de dispersão diferem com relação ao número de indivíduos recrutados e a densidade de individuos jovens. Dessa forma, tem três objetivos: i) analisou-se o recrutamento, mortalidade e mudança do tamanho populacional das espécies arbóreas e dos grupos sucessionais num periodo de quatro anos (1991 a 1995) e também comparou a sua recente estrutura com outros dois fragmentos de Floresta Estacional Semidecidual: um fragmento de mesma área (fragmento Santa Rita-9,5 ha) e outro fragmento de tamanho cerca de nove vezes superior (fragmento Capuava-86,0 ha); ii) foram fornecidas medidas quantitativas de riqueza, diversidade e composição florística de espécies arbóreas das quatro eco-unidades identificadas neste fragmento de floresta; iii) avaliou-se a relação das síndromes de dispersão com o recrutamento (indivíduos $\geq$ $5 \mathrm{~cm}$ de DAP novos ingressos em 1995) e a densidade de indivíduos jovens (individuos $\geq 50 \mathrm{~cm}$ de altura e $<5 \mathrm{~cm}$ de DAP).

O recrutamento, mortalidade e conseqüente mudança do tamanho populacional variaram entre as espécies e grupos ecológicos. As dez espécies mais abundantes no ano de 1991, que representam a classe 1 de densidade $(\geq 15$ individuos/ha) perfizeram um alto percentual de individuos recrutados e aliado a uma baixa mortalidade tiveram um aumento pronunciado em suas populações. As espécies pioneiras e oportunistas foram os grupos que mais aumentaram em abundância no periodo. O fragmento Mata do Pomar apresentou menos da metade do número de espécies queAencontrada nos fragmentos Santa Rita e Capuava, embora tenha o mesmo tamanho do fragmento Santa Rita. Além disso, ocorre uma alta dominância local de poucas espécies no fragmento Mata do Pomar. Diferentes padrões de riqueza, diversidade e composição florística foram encontrados entre as quatro eco-unidades identificadas ("capoeira baixa"-CB, "capoeira alta tipo 1"-CA1, "capoeira alta tipo 2"-CA2 e "mata madura"-MM). A riqueza e diversidade foram maiores na $C A 2$ e $M M$ que na $C B$ e CA1. Espécies pioneiras foram bem representadas na CB e CA1, espécies oportunistas na CA2 e espécies tolerantes e reprodutoras à sombra na $\mathrm{MM}$. A zoocoria e a anemocoria compreenderam o maior número de espécies. A zoocoria foi melhor representada pelo grupo das espécies pioneiras e reprodutoras à sombra, enquanto que a anemocoria pelas espécies 
oportunistas. O número de indivíduos recrutados e a densidade de regeneração natural foram relacionados tanto aos grupos sucessionais como aos modos de dispersão, ou seja, embora encontrado um grande número de espécies e de indivíduos que independem de vetores animais para a dispersão de sementes (anemocóricas e autocóricas), as espécies e os indivíduos foram em maior número pioneiras e oportunistas.

As principais conclusões obtidas deste estudo foram: i) é provável que as espécies tolerantes e reprodutoras à sombra diminuam ainda mais as suas densidades, implicando no aumento da dominância local das espécies pioneiras e oportunistas e conseqüentemente de espécies anemocóricas e autocóricas e portanto reduzindo a diversidade; ii) as eco-unidades identificadas através da Avaliação Ecológica Rápida foram significativamente correlacionada aos diferentes estados de conservação da estrutura florestal e, portanto, podem ser usadas para definir estratégias de restauração em fragmentos de Floresta Estacional Semidecidual; iii) as estratégias de conservação da biodiversidade em fragmentos de Floresta Estacional Semidecidual no interior do Estado de São Paulo devem considerar o histórico de perturbações na identificação de prioridades. 


\title{
STRUCTURE AND DYNAMICS OF A SEMIDECIDUOUS SEASONAL FOREST
}

\author{
FRAGMENT IN THE PIRACICABA REGION, SÃO PAULO STATE, BRAZIL.
}

\author{
Author: HENRIQUE E. M. NASCIMENTO \\ Adviser: Prof. VIRGíLIO MAURÍCIO VIANA
}

\section{SUMMARY}

This study was conducted in a 9.5-ha semideciduous seasonal forest fragment located in Piracicaba region, São Paulo State, Brazil. This fragment is named "Mata do Pomar", where two woodfires occurred in the recent past. The study adresses the following hypotheses: i) tree species and sucessional groups differ in relation to recruitment and mortality rates; ii) eco-units identitfied through Rapid Ecological Assessment method have different tree species composition and diversity; iii) dispersal syndromes differ in relation to the number of recruited individuals and sampling density. Then, it has three objectives: i) it was analysed the recruitment and mortality of tree species and successional groups in a 4-yr period (1991 and 1995) and also compared its recent tree structure with a fragment of same size ("Santa Rita" fragment-9.5 ha) and a fragment of 86 ha ("Capuava" fragment); ii) it was described changes in richness, diversity and floristic composition of tree species in four forest eco-unit identified in this fragment; iii) it was evaluated the relationship among the dispersal syndromes with the tree recruitment (individual $\geq 5 \mathrm{~cm}$ DBH recruited in 1995 ) and sapling density (individuals $>50 \mathrm{~cm}$ of height and $<5 \mathrm{~cm} \mathrm{DBH}$ ).

Different patterns of recruitment, mortality and populational change were found among tree species and ecological groups. The ten species most abundant in 1991 (class 1 - > 15 individuals/ha ) had high recruitment and low mortality, which resulted in a pronounced population increase. Pioneer and gap-opportunist species presented a greater increase in plant density than shade-tolerant canopy and shade-tolerant understory species. The fragment has $\mathbf{5 0 \%}$ less tree species than "Santa Rita" and "Capuava" fragments, although with the same size of "Santa Rita" fragment. Further, the "Mata do Pomar" fragment has a high local dominance by few species. Different patterns of floristic composition, richness and diversity were found for the four identified eco-units ("capoeira baixa"-CB, "capoeira alta tipo 1"-CA1, "capoeira alta tipo 2"-CA2, "mata madura"-MM). Richness and diversity were higher in CA2 and MM than $\mathrm{CB}$ and CA1. Pioneer species were well represented in the CB and CA1, gapopportunist in the CA2; shade-tolerant canopy species and shade-tolerant understory species in MM. For saplings, density, richness and diversity were lower in "low capoeira" and this eco-unit was well represented by pioneer and gap-opportunistic species. CA1, despite having the same richness and diversity of CA2 and MM, had lower density and it was well represented by pioneer and gap-opportunistic species. In contrast, shade-tolerant canopy species and shade-tolerant understory species were well represented in MM. The higher number of species belong to zoocory and anemocory syndromes. The zoocory was well represented in pioneer and shadetolerant understory groups and the anemocory by the gap-opportunist group. The number of individuals recruited and sapling density were related with both 
successional groups and dispersal modes, i.e, the majority of the species and individuals were not dependent of animal dispersal, but were mainly represented by pioneer and gap-opportunist species.

The main conclusions of this study were: i) it is likely that the density of shadetolerant overstory and shade-tolerant understory groups will decrease, increasing the local dominance of pioneer and opportunistic species and autocoric and anemocoric species, thus reducing tree diversity; ii) the eco-units identified through the Rapid Ecological Assessment method were significantly correlated to different forest structures and thus can be used in defining conservation strategy and management of semideciduous seasonal forest fragments; iii) the strategies of conservation biodiversity in semideciduous seasonal forest fragments in the São Paulo State should consider the anthropogenic disturbance in the identification of conservation priorities. 


\section{INTRODUÇÃO}

Em várias partes do mundo, o interesse pelos efeitos da destruição e fragmentação do habitat tem atualmente estimulado um grande número de estudos de comunidades e espécies em paisagens fragmentadas. A consequente perda da diversidade biológica em todos os seus niveis - genético, espécies, comunidades e ecossistemas, tem sido a principal justificativa da preocupação que domina atualmente na comunidade científica. Embora no presente momento haja mais espécies na Terra do que em qualquer outro tempo geológico, a atual taxa de extinção de espécies é maior do que no passado (Primack, 1993).

A partir de recentes décadas, os conservacionistas têm voltado para uma maior atenção nas florestas tropicais por duas razões cruciais: a primeira, embora esses ecossistemas representem apenas $7 \%$ da área terrestre da Terra, contêm mais da metade do número de espécies e a segunda, as florestas tropicais estão sendo destruídas em taxas alarmantes (Wilson, 1988). As principais causas da destruição e fragmentação das florestas tropicais incluem a conversão do uso da terra voltado para a agricultura e pecuária e a exploração de recursos madeireiros (Primack, 1993). Num período de nove anos, de 1981 à 1990, as florestas tropicais sofreram uma perda de 154 milhões de hectares, o que representa uma taxa de $7,3 \%$, ou $0,81 \%$ ao ano (Whitmore, 1997).

Embora as taxas de desmatamento tenha se acelerado enormemente a partir de décadas recentes, o processo da destruição e fragmentação das florestas tropicais não é novo. Em algumas regiões tropicais, grandes áreas de floresta foram desmatadas há muitos anos atrás. Estes desmatamentos do passado oferecem oportunidades de estudo de processos de longo prazo que não podem ser estudados em áreas desmatadas recentemente, tal como o destino dos diferentes grupos de espécies em fragmentos isolados, e, consequentemente, contribuirá para propostas 
mais seguras de conservação para as regiões que atualmente vem sendo fragmentadas (Corlett \& Turner, 1997).

A Floresta Estacional Semidecidua no interior do Estado de São Paulo é um exemplo claro deste processo. Este ecossistema está representado atualmente por pequenos fragmentos bastante isolados, imersos numa paisagem dominada pela agricultura e grandes centros urbanos. A fragmentação iniciou-se há várias décadas e os fragmentos que ainda restam vêm sofrendo, ao longo destes vários anos, as conseqüências peculiares advindas da própria fragmentação florestal, e os efeitos danosos da paisagem na qual estão inseridos: incêndios periódicos, caça e agrotóxicos advindos de práticas agrícolas (Viana, 1995; Viana \& Tabanez, 1996; Viana et al., 1997). Além disso, estes remanescentes são também resultado da exploração seletiva de madeira até recentemente. Como exemplo, a região de Piracicaba representa um excelente laboratório para estudos dos efeitos da fragmentação de longo prazo. Atualmente, apenas $2,1 \%$ da sua cobertura florestal nativa ainda persiste. Os 102 fragmentos florestais que compõe esta paisagem são isolados, altamente perturbados e na maioria $(87,8 \%)$ menores que 50 ha (Viana et al., 1997).

Nesta dissertação, o Capítulo 1 avaliou o impacto das perturbações antrópicas em um fragmento de floresta estacional semidecídua de 9,5 ha localizado em Piracicaba, SP. Este Capítulo analisou a estrutura e a dinâmica da comunidade arbórea neste fragmento e compara a sua recente estrutura com outros dois fragmentos de floresta estacional semidecidua: um fragmento de mesma área e outro fragmento de tamanho cerca de nove vezes superior. São discutidos os principais processos que podem levar à extinção local de espécies arbóreas em fragmentos isolados há muitos anos. O Capítulo 2 analisou a estrutura e a dinâmica das diferentes unidades estruturais, ou eco-unidades, que podem ser encontradas dentro de um fragmento. As eco-unidades foram identificadas com uso de uma técnica de diagnóstico denominada de Avaliação Ecológica Rápida. Este estudo define quais são as áreas mais prioritárias dentro de um fragmento do ponto de vista de estratégias de recuperação de fragmentos florestais. O Capítulo 3 avaliou os efeitos da fragmentação florestal sobre um processo ecológico, a dispersão de sementes. 
Este estudo 'relacionou as síndromes de dispersão de árvores com o recrutamento (índivíduos $\geq 5 \mathrm{~cm}$ de DAP ingressos em 1995) e a densidade de indivíduos jovens (indivíduos $\geq 50 \mathrm{~cm}$ de altura e $<5 \mathrm{~cm}$ de DAP) presentes em parcelas de regeneração natural. Seu principal objetivo foi avaliar se a fragmentação afeta o padrão da dispersão de sementes.

\section{REVISÃO BIBLIOGRÁFICA}

\section{1 - A Fragmentação Florestal}

A fragmentação florestal é o processo pelo qual áreas contínuas de floresta são reduzidas em tamanho e subdivididas em dois ou mais fragmentos florestais devido à destruição do habitat (Lovejoy et al., 1986). A fragmentação florestal então produz uma série de fragmentos florestais rodeados por uma matriz de vegetação e/ou uso da terra diferenciados (Saunders et al., 1991). O efeito da fragmentação sobre a biodiversidade pode ser um resultado direto de desmatamentos não aleatórios de uma determinada área florestal, o que implica na falta de representatividade de um determinado micro-habitat e/ou um grupo de espécies em fragmentos isolados, ou um resultado indireto, resultante de uma série de causas e efeitos (Zuidema et al., 1996). Em outras palavras, a maior ou menor redução do tamanho da floresta implica não apenas no maior ou menor tamanho dos fragmentos que comporão a paisagem, como também no maior ou menor grau de isolamento. Ambos os efeitos, por sua vez, influenciam numa maior ou menor quantidade de regiōes que sofrem influências da vizinhança dos fragmentos (bordas). O tamanho dos fragmentos também se relaciona diretamente à perda de micro-habitat e/ou de espécies (Zuidema et al., 1996). Consequentemente, as paisagens fragmentadas diferem de acordo com a maior ou menor intensidade destes fatores (Primack, 1993). Estes fatores podem causar a redução ou a eliminação de populações e mudanças nas interações entre as espécies de planta e animal, resultando, em última análise, na perda da biodiversidade (Zuidema et al., 1996).

Os fragmentos florestais contêm muitas espécies na época do isolamento. No entanto, o número de espécies diminuirá através do tempo em virtude de uma série de fatores. Os principais processos que leva à extinção local de espécies em 
fragmentos isolados incluem: os efeitos de borda, a limitação do tamanho populacional, a redução da imigração de espécies entre os fragmentos e a ruptura da relação planta-animal (Turner, 1996). Estes processos são descutidos abaixo.

\section{2 - Consequências da Fragmentação Florestal}

\subsection{1 - Efeitos de Borda}

Os fragmentos florestais diferem da floresta original de duas importantes formas: os fragmentos têm uma maior quantidade de borda e o centro dos fragmentos é mais próximo a uma borda do que as grande florestas continuas (Primack, 1993). A fragmentação expõe então os organismos que estão dentro de um fragmento às condições diferenciadas dos ecossistemas que os rodeiam, os chamados efeitos de borda (Murcia, 1995). A quantidade de área que é afetada pelos efeitos de borda depende do tamanho, forma, tipo de vizinhança e do grau de isolamento dos fragmentos (Viana et al., 1992). Existem três tipos de efeitos de borda nos fragmentos isolados: os efeitos abióticos, que envolvem mudanças microclimáticas resultante da proximidade da matriz estruturalmente dissimilar; os efeitos bióticos diretos implica em mudanças na abundância e distribuição das espécies e se diferenciam entre as espécies de acordo com à tolerância próximo às bordas; e os efeitos bióticos indiretos que acarreta mudanças nas interações entre as espécies, tais como predação, competição, herbivoria e na polinização e dispersão de plantas (Murcia, 1995). Comparado à floresta, os cultivos agrícolas e as pastagens permitem maior radiação solar no solo durante o dia e mais alta reradiação para a atmosfera durante a noite. Consequentemente, as temperaturas diurnas em pastos e cultivos são mais alta próximo ao solo e diariamente há uma maior flutuação de temperatura (Primack, 1993, Murcia, 1995). Então, a diferença no microclima entre os dois lados da borda cria um gradiente de temperatura e umidade, que é mais forte próximo à borda e diminui em direção ao interior do fragmento (Primack, 1993, Murcia, 1995). Em fragmentos florestais da Amazônia, tais efeitos microclimáticos foram evidentes a uma distância de cerca de 40 metros da borda do fragmento (Kapos, 1989).

As mudanças no ambiente físico causados pelo efeitos abióticos pode diretamente afetar a estrutura florestal. As espécies de plantas e animais diferem com 
relação ás mudanças do microclima, resultando em mudanças na composição, abundância e na distribuição das espécies ao longo do gradiente borda-interior (Primack, 1993; Murcia, 1995). Algumas espécies de plantas mostram menores densidades ou são ausentes próximo às bordas enquanto outras mostram maiores densidade (veja Sork, 1983; Casenave et al., 1995). As espécies de planta de subbosque são as mais prováveis de terem suas densidade imediatamente diminuídas enquanto que as espécies intolerantes á sombra tendem a aumentarem suas densidades (Primack, 1993). Por exemplo, Casenave et al. (1995) mostrou que todas as espécies de planta que tinham as maiores densidades próximo à borda eram colonizadoras ou pioneiras, típicas de áreas degradadas.

A matriz desmatada de uma paisagem fragmentada é freqüentemente dominada por espécies agricolas. Estas espécies podem se beneficiar do microclima alterado da região de borda dos fragmentos e portanto competir de com as espécies nativas (Janzen, 1983; Lovejoy et al., 1986; Laurance 1991b). Em fragmentos rodeados por pastagens, Laurance (1991b) encontrou espécies não florestais invadindo a uma distância de $\mathbf{5 0 0}$ metros da borda.

\subsection{2 - Limitação do Tamanho Populacional}

Uma das conseqüências imediatas da fragmentação e do isolamento do habitat é a redução do tamanho populacional (Young et al., 1996). Atualmente, os efeitos demográficos e genéticos da limitação do tamanho populacional com a fragmentação ainda é bastante teórico, embora alguns resultados empíricos têm sido publicados (Turner, 1996, Zuidema et al., 1996). Fragmentos menores manterão menores populações de uma dada espécie do que os fragmentos maiores (Turner, 1996). Consequentemente, as espécies que naturalmente apresentam pequenas densidades e/ou que têm distribuições amplamente esparsadas ou bastante agrupadas serão as mais prováveis de terem pequenas populações em fragmentos florestais.

A drástica redução da população pode resultar em um tamanho populacional abaixo do seu mínimo viável. A população mínima viável (MVP) dependerá do ciclo de vida da espécie, características demográficas e do sistema de cruzamento (Schaffer, 
1981). As pequenas populações são mais propensas à extinção do que as grandes populações devido às quatro fontes de variação ao acaso: as estocasticidades demográfica, genética e ambiental, e as catástrofes naturais (Shafer, 1981; Gilpin \& Soulé, 1986). A estocasticidade demográfica refere-se à variação aleatória em parâmetros populacionais, tais como as taxas de nascimento e mortalidade e a razão entre machos e fêmeas. Se uma pequena população experimentar uma baixa taxa de natalidade em duas gerações sucessivas, a probabilidade de sobrevivência da população pode ser diminuída. A estocasticidade genética refere-se aos processos genéticos aleatórios, tal como a deriva genética, que podem levar à perda de variação genética e consequentemente, a uma reduzida capacidade da população resistir aos alelos letais recessivos ou responder às mudanças das condições ambientais nas gerações subseqüentes. A estocasticidade ambiental é a variação aleatória dos processos ambientais que podem afetar uma população, tais como, a variação em temperatura, precipitação, recurso alimentar, aumento da população de predadores e competição. As catástrofes naturais, tais como a seca e o fogo, ocorrem em intervalos irregulares e pode ter um grande efeito na sobrevivência de uma população.

Além das pequenas populações estarem sujeitas à extinção local em fragmentos isolados devido às flutuações ao acaso, as espécies que experimentam estrangulamentos populacionais pode sofrer a endogamia (acasalamento entre aparentados), o que resulta na depressão endogâmica e perda de heterozigosidade e consequentemente reduz o "fitness" (Barrett \& Kohn, 1991). Por exemplo, como boa parte das espécies arbóreas tropicais de baixa densidade apresentam sistema de cruzamento exogâmico, e são auto-incompatíveis, com polinizadores voando a grandes distâncias, o isolamento populacional ocasionado pela fragmentação tende a aumentar seus níveis de endogamia e consequentemente espera-se que ocorra alto grau de depressão endogâmica e perda de heterozigosidade (Lepsch-Cunha, no prelo). Embora os efeitos genéticos da diminuição do tamanho populacional possam ser obscuros para as espécies de vida longa, as flutuações demográficas e ambientais e as catástrofes naturais podem representar os principais mecanismos de extinção local e regional em populações isoladas. 


\subsection{3 - Redução da Taxa de Imigração}

A fragmentação do habitat cria barreiras aos processos naturais de dispersão e colonização de muitas espécies de animal e consequentemente das espécies de plantas dependentes dos animais para dispersão de suas sementes (Primack, 1993). Este efeito diferem entre as espécies animais, dependendo da mobilidade, grau de especialização em recurso alimentar e de habitat e mecanismo de dispersão (Laurance, 1991a; Estrada et al., 1993). Quando os animais são capazes de migrar entre fragmentos isolados, os efeitos da redução do tamanho populacional pode ser parcialmente ou grandemente atenuado (Estrada et al., 1993). Além disso, a deficiência de animais que se movem entre fragmentos pode restringir a migração de espécies de planta quando os animais são dispersores e fluxo gênico se os animais são polinizadores (Turner, 1996). Desta forma, a extinção local poderá ser evitada quando indivíduos são substituídos por outras populações isoladas, ou seja, quando uma metapopulação é estabelecida (Hanski, 1994).

A migração é um importante fenômeno para a manutenção de espécies de baixa densidade em um local. Os estudos de longo prazo de comunidades arbóreas tropicais têm mostrado que há "turnover" na composição de espécies raras maior do que para as espécies comuns, ou seja, em uma determinada parcela, algumas espécies se extinguem e outras colonizam ao longo do tempo (Hubbell \& Foster, 1986; Primack \& Hall, 1992). Portanto, uma considerável fraçằo da diversidade em uma determinada parcela é mantida pelas populações transitórias de espécies raras (Turner, 1996). Conforme as espécies raras já existentes em um fragmento bastante isolado desaparecerem, novas espécies não substituirão as anteriores devido a uma insuficiência na imigração de novos propágulos (Primack \& Hall, 1992), ocasionando a diminuição de diversidade arbórea em fragmentos e favorecendo a extinção local e regional de espécies com populações pequenas. As estratégias de conservação de espécies arbóreas tropicais devem priorizar estas espécies (Laurance et al., 1997).

\subsection{4 - Ruptura da relação planta-animal}

A perda de espécies nativas e a introdução de espécies exóticas em fragmentos isolados, rompem ou modificam processos ecológicos, tais como as 
interações predador-presa, planta-dispersor e planta-dispersor. As florestas tropicais, por exemplo, é freqüentemente associada como um ecossistema com uma grande dependência de relações mutualísticas para sua a estabilidade. Muitas espécies de planta em florestas tropicais são dependentes de animais como agente dispersores de sementes ou pólen ou de ambos (Howe \& Smallwood, 1982; Bawa, 1990). Desta forma, se certas espécies de animais ou de plantas são localmente extintas, uma mudança na estrutura da comunidade é altamente provável, o que pode, em última análise, levar a mais mudanças e a mais extinções em fragmentos florestais isolados (Turner, 1996). Gilbert (1980) usou os termos "elos móveis" para descrever os animais que têm uma significante contribuição na persistência de espécies de planta, tais como os polinizadores e dispersores e "espécies-chaves", que são aqueles organismos, geralmente as plantas, que são críticos para a sobrevivência dos "elos móveis". Por exemplo, Howe (1984) afirma que a extinção local de Casearia corymbosa na Costa Rica poria em risco as populações de algumas espécies de pássaros. Esta espécie é referida como "espécie-chave" pois fornece recurso alimentar para a avifauna em épocas de escassez de alimento na floresta (Howe, 1984). Se estas espécies de pássaros fossem extintas ou reduzissem seus tamanhos populacionais, o recrutamento de outras espécies de árvores que produzem frutos em outras épocas do ano estaria ameaçado (Howe, 1984, 1990). Resultados empíricos têm mostrado que a fragmentação afeta a relação planta-polinizador (Jennersten, 1988; Aizen \& Feinsinger, 1994). Por exemplo, Aizen e Feinsinger (1994) avaliaram os niveis de polinização e produção de frutos em espécies de plantas em fragmentos menores de 10 ha e em florestas contínuas, na Argentina. Oito das dezesseis espécies avaliadas mostraram um declínio significativo nos niveis de polinização em função da redução do tamanho do fragmento. Diminuição significativa na produção de frutos com a redução do tamanho do fragmento foi encontrada em cinco das quinze espécies avaliadas (Aizen \& Feinsinger 1994).

Os processo descritos acima podem resultar na redução do tamanho populacional e na extinção local de espécies em fragmentos isolados. Atualmente, existe uma forte evidência que o risco de extinção de espécies em um determinado fragmento varia entre os diferentes taxa. A aplicação do modelo da Biogeografia de 
Ilhas em paisagens continentais fragmentadas vem sendo questionada por alguns pesquisadorés devido à duas particularidades: o tempo esperado da ocorrência do declínio no número de espécies e o posterior equilíbrio entre extinção e colonização; e, a mais importante, a seqüência de espécies, ou seja, os taxa (animais e vegetais) mais prováveis de serem inicialmente extintas (Lynam, 1997). Além disso, a previsão da taxa de extinção de espécies baseada na relação espécie-área, está sendo considerada uma inadequada abordagem para planos de conservação (Zuidema et al., 1996). Esta relação prevê uma taxa de extinção muito maior conforme as áreas de florestas vão sendo diminuídas, do que os estudos empíricos atuais têm registrados (veja Simberloff, 1992; Corlett \& Turner, 1997). De fato, existe uma forte evidência que o risco de extinção de espécies em um determinado fragmento varia entre os diferentes taxa. As plantas são mais persistentes em fragmentos florestais e os vertebrados, tais como os mamiferos e pássaros, devido às suas maiores necessidades de área para sobrevivência aọ longo prazo e de terem vida mais curta em relação às muitas espécies de plantas, são mais vulneráveis à fragmentação (Corlett \& Turner, 1997). Ao contrário da alta persistência de plantas no geral, a perda de espécies de plantas não tem sido distribuída uniformemente entre as diferentes formas de vida. Devido que a maioria das espécies arbóreas tem tempo de vida mais longo que animais e outros grupos de plantas, estão menos sujeitas a desaparecerem mais rapidamente de fragmentos floretais (Corlett \& Turner, 1997). Por exemplo, em Singapura, Corlett \& Turner (1997) estimaram que mais da metade das espécies de epífitas e orquídeas foram extintas, enquanto que três quartos das espécies de ánores e arbustos ainda persistem, mesmo com apenas $0,2 \%$ de cobertura vegetal nativa ainda existente. Particularmente, a família orchidaceae, devido possivelmente a uma maior sensibilidade às mudanças microclimáticas, tem sofrido a mais alta taxa de extinção, com $86 \%$ das espécies extintas até o momento (Corlett \& Turner, 1997). Especificamente em um único fragmento de 4 ha, também em Singapura, Turner et al. (1996) registraram a extinção de $42,3 \%$ de espécies arbóreas, contra $66,7 \%$ de epífitas e $85,7 \%$ de ervas, em um período de 100 anos de monitoramento. 


\section{CAPITULO 1}

\section{ESTRUTURA E DINÂMICA DE POPULAÇÕES ARBÓREAS DE UM FRAGMENTO DE FLORESTA ESTACIONAL SEMIDECÍDUA.}

\section{INTRODUÇÃO}

Em várias regiōes tropicais, o processo da fragmentação florestal é uma realidade atual que vem ocorrendo a partir de décadas recentes em função das altas taxas de desmatamento (Whitmore, 1997). A velocidade destes desmatamentos está acontecendo em uma escala de tempo que é inaudita na história ecológica e geológica das florestas tropicais, e portanto, têm profundos efeitos sobre esses ecossistemas (Bierregaard et al., 1992; Primack, 1993). Diante disso, as conseqüências da fragmentação do habitat são atualmente o principal tema abordado na biologia da conservação com respeito tanto às regiōes tropicais como temperadas (Primack, 1993).

Estudos suficientes já foram realizados para concluir satisfatoriamente que a destruição e a conseqüente fragmentação dos habitat é a maior ameaça à biodiversidade. Várias conseqüências advindas da fragmentação, tais como os efeitos de borda (Janzen, 1986; Lovejoy et al., 1986; Kapos, 1989; Bierregaard et al., 1992; Laurance, 1991b), impedimento ou redução na taxa de migração entre fragmentos (Becker et al., 1991; Bierregaard et al., 1992; Silva et al., 1996; Bierregaard \& Stouffer, 1997), diminuição do tamanho efetivo populacional com conseqüente perda da variabilidade genética (Menges, 1991a; Young et al., 1996; Nason et al., 1997; LepschCunha, no prelo) e invasão de espécies exóticas (Janzen, 1983, 1986) são os principais mecanismos de deterioração de uma paisagem composta de fragmentos florestais (Turner, 1996). A intensidade destes fatores dependerá das características da paisagem na qual os fragmentos estão inseridos. Logo, o tamanho, a forma, 
número de fragmentos e o tipo de vizinhança influenciará no número de espécies capazes de sobreviver em um fragmento florestal (Saunders et al., 1991; Viana et al., 1992). Devido ao mutualismo existente entre plantas e animais em florestas tropicais, tais como planta-polinizador e planta-dispersor, é sensato imaginar um amplo ciclo de extinções que ocorrerão com a fragmentação florestal (Howe, 1984; Bawa, 1990, Aizen \& Feinsinger, 1994).

Embora estes fatores sejam grandes ameaças à extinção de espécies em fragmentos florestais, o aumento da pressão humana sobre o ecossistema em paisagens fragmentadas contribui a um impacto negativo (Turner, 1996). Existe uma tendência de simplificar o processo da fragmentação como uma paisagem desmatada contendo fragmentos de florestas não perturbados. Em regiōes nas quais o processo de fragmentação se iniciou há muitas décadas, perturbações antrópicas constantes representam uma importante ameaça à biodiversidade (Viana et al., 1992; Viana, 1995; Turner, 1996). A Floresta Estacional Semidecidual no interior do Estado de São Paulo é um exemplo claro deste processo. Este ecossistema está representado atualmente por pequenos fragmentos bastante isolados, imersos numa paisagem dominada pela agricultura e grandes centros urbanos A fragmentação iniciou-se há várias décadas e os fragmentos que ainda restam vêm sofrendo, ao longo destes vários anos, as conseqüências peculiares advindas da própria fragmentação florestal, e os efeitos danosos da paisagem na qual estão inseridos: incêndios periódicos, caça e agrotóxicos advindos de práticas agrícolas (Viana, 1995; Viana \& Tabanez, 1996; Viana et al., 1997). Além disso, estes remanescentes são também resultado da exploração seletiva de madeira até recentemente. Como exemplo, a região de Piracicaba representa um excelente laboratório para estudos dos efeitos da fragmentação de longo prazo. Atualmente, apenas $2,1 \%$ da sua cobertura florestal nativa ainda persiste. Os 102 fragmentos florestais que compõe esta paisagem são isolados, altamente perturbados e na maioria $(87,8 \%)$ menores que 50 ha (Viana et al., 1997).

Neste trabalho é apresentado os resultados obtidos de um estudo de quatro anos de acompanhamento analisados com relação à estrutura e dinâmica de populações arbóreas de um fragmento de Floresta Estacional Semidecidual de 9,5 
ha, denominado de Mata do Pomar, localizado em Piracicaba-SP (22 $47^{\prime} \mathrm{S}$ e $47^{\circ}$ $49^{\prime} \mathrm{W}$ ). Além destes resultados, foi realizada uma análise comparativa da estrutura deste fragmento com outro fragmento de tamanho semelhante (fragmento Santa Rita) e um outro fragmento com tamanho nove vezes superior (fragmento Capuava). O fragmento Mata do Pomar sofreu dois grandes incêndios recentemente (15-20 anos), enquanto que para os outros dois não se tem relato de perturbações antrópicas em grandes proporções.

Este estudo foi organizado a fim de responder as seguintes questões: i) a estrutura do fragmento está tendendo à uma maior dominância de espécies de início de sucessão e das espécies mais abundantes, acarretando a diminuição da diversidade? e ii) a perda da diversidade arbórea em fragmentos florestais isolados há muitas décadas está mais relacionada às perturbações antrópicas do que a outros fatores advindos da fragmentação, tais como tamanho dos fragmentos, isolamento, vizinhança, etc.? São discutidos os principais processos que podem levar à extinção local de espécies arbóreas em fragmentos florestais isolados. A hipótese central deste estudo é que as espécies arbóreas se diferenciam com relação às taxas de rtcrutamento e mortalidade. Se a fragmentação e as perturbações antrópicas afetam diferentemente o recrutamento e a mortalidade das espécies arbóreas, então as predições são: i) as espécies mais comuns e as espécies de início de sucessão apresentarão um maior aumento no tamanho populacional que as espécies tipicas de comunidades mais maduras e ii) que as perturbações antrópicas são as principais causas da perda de diversidade arbórea em fragmentos florestais.

\section{MATERIAL E MÉTODOS}

\section{1 - Caracterização da área}

O municipio de Piracicaba localiza-se na depressão periférica do Estado de São de Paulo, apresentando relevo suavemente ondulado, com altitude em torno de 500 metros, situando-se nas coordenadas $22^{\circ} 47^{\prime} \mathrm{S}$ e $47^{\circ} 49^{\prime} \mathrm{W}$. Segundo levantamento feito no Departamento de Meteorologia da Escola Superior de Agricultura Luiz de Queiroz (ESALQ/USP), para o periodo de 1990-1996, a 
pluviosidade média anual foi de cerca $1430 \mathrm{~mm}$, distribuidas irregularmente durante 0 ano. $O$ período de maior precipitação coincide com o periodo mais quente, de outubro a março (média de $184 \mathrm{~mm}, 25^{\circ} \mathrm{C}$ ), e o periodo de menor precipitação coincide com o periodo mais frio, de abril a setembro (média de $50 \mathrm{~mm}, 17^{\circ} \mathrm{C}$ ).

A vegetação natural da região é classificada pelo Sistema Fitogeográfico Brasileiro como Floresta Estacional Semidecidual (IBGE, 1992). Caracteriza-se pela mistura de espécies vegetais caducifólias, que perdem suas folhas no periodo seco, e perenifólias. Entre as espécies arbóreas típicas de dossel destacam-se: Aspidosperma polyneuron, Astronium graveolens, Balfourodendron riedelianum, . Chorisia speciosa, Cariniana legalis' e C. estrellensis. No sub-dossel tem-se Esenbeckia febrifuga, Galipea multiflora, Metrodorea nigra, Trichilia catigua, T. elegans e $T$. pallida como as espécies mais representativas.

\section{2 - Descrição da área experimental}

O fragmento Mata do Pomar, com cerca de 9,5 ha, è uma reserva localizada dentro do campus da ESALQ/USP. Em mapa datado de 1894, este fragmento era parte de uma maior área de floresta, que progressivamente foi sendo derrubada em diferentes épocas para dar lugar às culturas de café, cana-de-açúcar e algodão e à instalação dos edifícios da ESALQ (Catharino, 1989).

A Mata do Pomar fragmento sofreu, nas três últimas décadas, dois grandes incêndios, com o último ocorrido entre 15 e 20 anos atrás, queimando cerca de 20$30 \%$ de sua área, além de ter havido extração madeireira em passado relativamente recente, há cerca de 30 anos (Tabanez et al., 1997).

\section{3 - Obtenção dos dados}

Os dados usados neste trabalho foram obtidos em dois períodos, com o uso de dois transectos perpendiculares entre si, com 10 metros de largura, que vão de uma borda à outra do fragmento (Figura 1). Os dois transectos correspondem à uma área amostral de $5805 \mathrm{~m}^{2}$ (6,3\% da área total do fragmento). No ano de 1991, todas as árvores com DAP (diâmetro à altura do peito) igual ou superior a $5 \mathrm{~cm}$ foram mapeadas, etiquetadas, identificadas, e tiveram seus DAP's medidos. Os resultados 
deste primeiro levantamento são encontrados em Tabanez et al. (1997). Em 1995, todas as árvores anteriormente existentes foram novamente medidas e os novos ingressos tiveram medidos seus DAP's, etiquetados, mapeados e identificados.

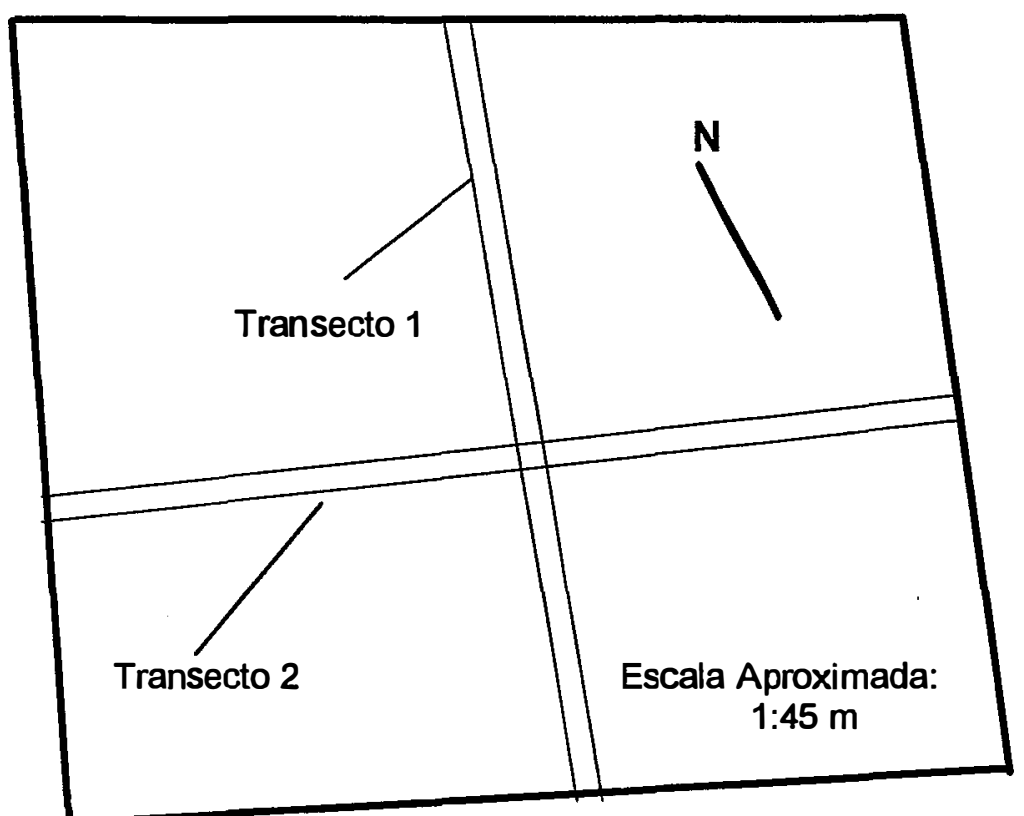

Figura 1 - Croqui da Mata do Pomar mostrando a localização dos dois transectos.

\section{4 - Análise dos dados}

As espécies encontradas no fragmento foram agrupadas em categorias sucessionais segundo a classificação proposta por Viana (1989). Este autor agrupou as espécies em quatro grupos: pioneiras, oportunistas, tolerantes e reprodutoras à sombra. As pioneiras são espécies que normalmente têm sementes de grande longevidade e que exigem a formação de clareiras para germinação e dependem destas durante todo o seu ciclo de vida. As oportunistas são espécies com sementes que não requerem clareiras para germinar, com plântulas que sobrevivem à sombra, mas que dependem de aberturas do dossel para atingir o estágio reprodutivo. As tolerantes têm sementes que também não necessitam de clareiras para germinar, as plantas podem crescer até o estágio juvenil sem a presença de clareiras, mas dependem destas para alcançar o estágio reprodutivo. As reprodutoras à sombra têm sementes que não necessitam de clareiras para germinar, crescem até o estágio adulto 
sob sombra e se reproduzem nesta mesma condição.

As espécies foram enquadradas nestas categorias sucessionais baseado em classificações realizadas por diversos autores e por observações de campo. É importante salientar que esta não é uma classificação definitiva, sendo apenas uma tentativa de comparar os diferentes grupos com respeito à mudança populacional no período de estudo. A pequena quantidade de informações referentes à biologia de muitas espécies tropicais limita o enquadramento preciso das espécies em grupos ecológicos. Isso tem resultado numa classificação diferenciada entre autores para algumas espécies.

A comunidade foi dividida em três classes arbitrárias de densidade, a saber: a classe 1 de densidade representa as espécies com $>15,5$ individuos/ha $(\geq 9$ indivíduos no levantamento), a classe 2, as espécies com 5,2 a 13,8 indivíduos/ha (3 a 8 indivíduos no levantamento) e a classe 3, 1,7 e 3,4 indivíduos/ha ( 1 e 2 indivíduos no levantamento). O objetivo de tal divisão é de obter uma melhor visualização do recrutamento e da mortalidade do gradiente que vai das espécies de maiores densidades para as de menores densidades.

$\mathrm{O}$ ínidice de diversidade de Shannon ( $\left.\mathrm{H}^{\prime}\right)$ foi calculado a fim de comparar a diversidade da comunidade do ano de 1991 com a sua estrutura mais recente, a do ano de 1995. A solução do índice de Shannon é dada pela seguinte equação:

$$
H^{\prime}=-\sum p_{i} \ln p_{i}
$$

onde:

$p_{i}=$ é a proporção $i_{t h}$ espécie da comunidade.

In = logaritmico neperiano de base $e$.

O teste $t$ foi utilizado a fim de verificar se há ou não diferença significativa dos valores do índice de Shannon entre os dois períodos (veja Magurran, 1988).

\section{RESULTADOS}

\section{1 - Densidade, Riqueza e Composição de Espécies em 1991.}

Em 1991 foram registradas 49 espécies dentre os 517 indivíduos (cerca de 891 ind./ha) $\geq 5 \mathrm{~cm}$ de DAP na Mata do Pomar. Tanto as espécies quanto os individuos estão distribuídos desigualmente nos quatro grupos ecológicos aqui 
considerados (Figura 2). Embora o número de espécies oportunistas (20) fosse maior que 0 das espécies pioneiras (13), as espécies pioneiras representaram $65,2 \%$ do total dos indivíduos contra apenas $22,2 \%$ das espécies oportunistas (Figura 2). A maior abundância e o maior número de espécies dos dois grupos anteriores implicou numa baixa representatividade do grupo das espécies tolerantes e reprodutoras à sombra.

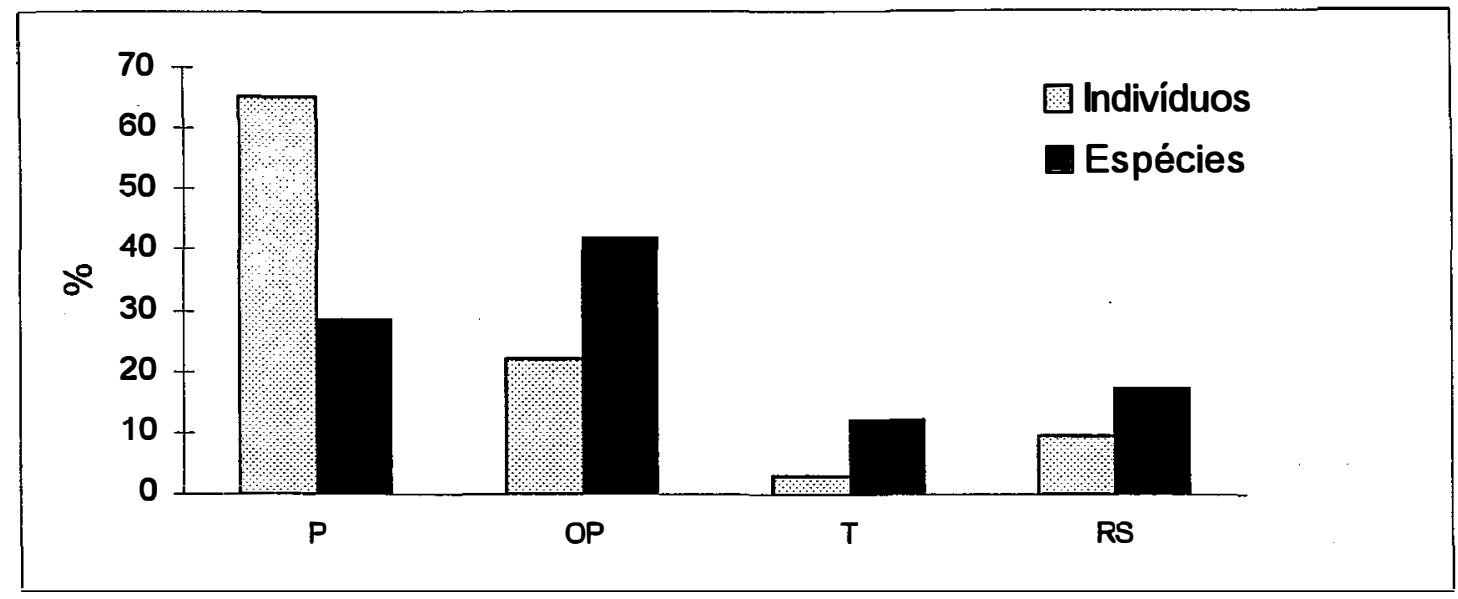

Figura 2 - Percentual de espécies e individuos para cada grupo ecológico em 1991 na Mata do Pomar. P - pioneira, OP - oportunista, T - tolerante, RS - reprodutora à sombra.

A alta abundância das espécies pioneiras na Mata do Pomar é representada pelas quatro espécies mais comuns no fragmento pertencentes à classe 1 de densidade: Bauhinia forficata, Aloysia virgata, Urera baccifera e Trema micrantha (Tabela 1). Estas espécies perfizeram $62,0 \%$ do total dos indivíduos em 1991, sendo que somente as duas espécies mais comuns, $B$. forficata e $A$. virgata, compreenderam aproximadamente $40 \%$ do total dos indivíduos (Tabela 1). Particularmente, a espécie mais abundante no fragmento, $B$. forficata, foi 2 e 1,7 vezes mais abundante que a quarta ( $T$. micrantha) e terceira espécie ( $U$. baccifera). Em contrapartida, 17 espécies apresentaram apenas 1 indivíduo no levantamento, as quais representaram $34,7 \%$ do total das espécies e apenas $3,2 \%$ do total dos indivíduos. 
Tabela 1 - Densidade relativa e grupo ecológico por classe de densidade das espécies amostradas em 1991 na Mata do Pomar. Números entre parênteses referem-se ao número de individuos/ha. $\mathrm{P}$ - pioneira; OP - oportunista; $\mathrm{T}$ - tolerante; RS - reprodutora à sombra. (Tabela adaptada de Tabanez et al., 1997).

\begin{tabular}{c|c|c|c|c}
\hline Espécie & Família & $\begin{array}{c}\text { Densidade } \\
\text { Relativa }\end{array}$ & $\begin{array}{c}\text { Densidade } \\
\text { Relativa } \\
\text { Acumulada }\end{array}$ & $\begin{array}{c}\text { Grupo } \\
\text { Ecológico }\end{array}$ \\
\hline
\end{tabular}

Classe 1 ( $\geq 15,5$ individuos/ha)

\begin{tabular}{l|l|c|c|c}
\hline Bauhinia forficata & Caesalpinaceae & $20,5(182,6)$ & P & P \\
\hline Aloysia virgata & Verbenaceae & $19,2(170,5)$ & 39,7 & $\mathrm{P}$ \\
\hline Urera baccifera & Urticaceae & $12,1(108,5)$ & 51,8 & $\mathrm{P}$ \\
\hline Trema micrantha & Ulmaceae & $10,2(91,3)$ & 62,0 & $\mathrm{P}$ \\
\hline Croton floribundus & Euphorbiaceae & $4,7(41,3)$ & 66,7 & $\mathrm{OP}$ \\
\hline Metrodorea nigra & Rutaceae & $3,5(31,0)$ & 70,2 & $\mathrm{RS}$ \\
\hline Bastardiopsis densiflora & Malvaceae & $3,3(29,3)$ & 73,5 & OP \\
\hline Machaerium stipitatum & Fabaceae & $2,5(22,4)$ & 76,0 & OP \\
\hline Lonchocarpus muhelbergianus & Fabaceae & $2,1(18,9)$ & 78,1 & OP \\
\hline Lonchocarpus guilleminianus & Fabaceae & $1,7(15,5)$ & 79,8 & OP \\
\hline
\end{tabular}

Classe 2 (5,2 a 13,8 indivíduos/ha)

\begin{tabular}{l|l|c|c|c}
\hline Acacia polyphylla & Mimosaceae & $1,4(12,1)$ & 81,2 & OP \\
\hline Centrolobium tomentosum & Fabaceae & $1,4(12,1)$ & 82,6 & OP \\
\hline Holocalyx balansae & Mimosaceae & $1,4(12,1)$ & 84,0 & $\mathrm{~T}$ \\
\hline Nectandra megapotamica & Lauraceae & $1,1(10,3)$ & 85,1 & OP \\
\hline Guazuma ulmaefolia & Sterculiaceae & $1,1(10,3)$ & 86,2 & $\mathrm{P}$ \\
\hline Trichilia catigua & Meliaceae & $1,1(10,3)$ & 87,3 & $\mathrm{RS}$ \\
\hline Piptadenia gonoacantha & Mimosaceae & $0,9(8,6)$ & 88,2 & OP \\
\hline Trchilia pallida & Meliaceae & $0,9(8,6)$ & 89,1 & $\mathrm{RS}$ \\
\hline Inga sp. & Mimosaceae & $0,9(8,6)$ & 90,0 & Não class. \\
\hline Galipea multiflora & Rutaceae & $0,8(6,8)$ & 90,8 & $\mathrm{RS}$ \\
\hline Chrysophyllum gonocarpum & Sapotaceae & $0,8(6,8)$ & 91,4 & $\mathrm{RS}$ \\
\hline Campomanezia guazumifolia & Myrtaceae & $0,6(6,8)$ & 92,0 & $\mathrm{RS}$ \\
\hline Guarea macrophylla & Meliaceae & $0,6(5,2)$ & 92,6 & $\mathrm{RS}$ \\
\hline Gallesia integrifolia & Phytolaccaceae & $0,6(5,2)$ & 93,2 & $\mathrm{~T}$ \\
\hline
\end{tabular}


Tabela 1 - continuação

\begin{tabular}{|c|c|c|c|c|}
\hline \multicolumn{5}{|c|}{ Classe 3 (1,7 e 3,4 indivíduos/ha) } \\
\hline Chorisia speciosa & Bombacaceae & $0,4(3,4)$ & 93,6 & OP \\
\hline Croton salutaris & Euphorbiaceae & $0,4(3,4)$ & 94,0 & OP \\
\hline Balfourodendron riedelianum & Rutaceae & $0,4(3,4)$ & 94,4 & OP \\
\hline Crecopia ololeuca & Cecropiaceae & $0,4(3,4)$ & 94,8 & $P$ \\
\hline Eugenia cf. moraviana & Myrtaceae & $0,4(3,4)$ & 95,2 & RS \\
\hline Matayba elaegnoides & Sapindaceae & $0,4(3,4)$ & 95,6 & OP \\
\hline Solanum granulosum-leprosum & Solanaceae & $0,4(3,4)$ & 96,0 & $P$ \\
\hline Casearia sylvestris & Flacourtiaceae & $0,4(3,4)$ & 96,4 & $\bar{P}$ \\
\hline Schizolobium parahyba & Caesalpinaceae & $0,2(1,7)$ & 96,8 & $\mathrm{OP}$ \\
\hline Croton urucurana & Euphorbiaceae & $0,2(1,7)$ & 97,0 & $P$ \\
\hline Citronella megaphylla & Icacinaceae & $0,2(1,7)$ & 97,2 & $\mathrm{~T}$ \\
\hline Indeterminada 1 & - & $0,2(1,7)$ & 97,4 & \\
\hline Pseudobombax cf. grandiflorum & Bombacaceae & $0,2(1,7)$ & 97,6 & $\mathrm{OP}$ \\
\hline Cordia trichotoma & Boraginaceae & $0,2(1,7)$ & 97,8 & $\mathrm{OP}$ \\
\hline Vernonia polyanthes & Compositae & $0,2(1,7)$ & 98,0 & $P$ \\
\hline Enterolobium contortisiliquum & Mimosaceae & $0,2(1,7)$ & 98,2 & OP \\
\hline Terminalia triflora & Combretaceae & $0,2(1,7)$ & 98,4 & OP \\
\hline Zanthoxylum rhoifolium & Rutaceae & $0,2(1,7)$ & 98,6 & $P$ \\
\hline Copaifera langsdorffii & Fabaceae & $0,2(1,7)$ & 98,8 & $\mathrm{~T}$ \\
\hline Machaerium vestitum & Fabaceae & $0,2(1,7)$ & 99,0 & OP \\
\hline Cestrum laevigatum & Solanaceae & $0,2(1,7)$ & 99,2 & $P$ \\
\hline Piper cf. aduncum & Piperaceae & $0,2(1,7)$ & 99,4 & $P$ \\
\hline Patagonula americana & Boraginaceae & $0,2(1,7)$ & 99,6 & OP \\
\hline Ficus sp. & Moraceae & $0,2(1,7)$ & 99,8 & $\mathrm{~T}$ \\
\hline Aspidosperma aff. ramiflorum & Apocynaceae & $0,2(1,7)$ & 100 & $\mathbf{T}$ \\
\hline
\end{tabular}

\section{2 - Comparação da Mata do Pomar com os Fragmentos Santa Rita e Capuava.}

A abundância acentuada de poucas espécies na Mata do Pomar é revelada quando comparada com outros dois fragmentos de Floresta Estacional Semidecidual de igual tamanho (fragmento Santa Rita, 9,5 ha) e maior tamanho (fragmento 
Capuava, 86 ha), ambos também localizados no municipio de Piracicaba (Tabela 2). Nestes fragmentos também foi utilizado o mesmo método de levantamento (transectos) e igual limite mínimo de DAP ( $\geq 5 \mathrm{~cm}$ ). Na Mata do Pomar, além do número de espécies ser menos da metade daquele registrado nos outros dois fragmentos, as 3 espécies mais comuns $(6,1 \%$ do total de espécies) constituem aproximadamente $50 \%$ do número total de individuos e as 6 espécies mais comuns $(12,2 \%)$ contribuem aproximadamente com $70 \%$ dos individuos. Ao contrário, no fragmento Santa Rita, 10 espécies (9,8\%) abrangem $50 \%$ dos indivíduos e 21 espécies $(20,6 \%)$ abrangem $70 \%$ do total de individuos. No fragmento Capuava, $13 \mathrm{e}$ 27 espécies $(10,2 \%$ e $21,1 \%)$ constituem $50 \%$ e $70 \%$ do total de indivíduos, respectivamente (Tabela 2). Além disso, nos fragmentos Santa Rita e Capuava, as quatro espécies mais abundantes nestes contribuem com apenas $30,6 \%$ e $23,2 \%$ do total dos individuos, respectivamente (Tabela 2).

Tabela 2 - Número de espécies e medidas de abundância de espécies arbóreas na Mata do Pomar e outros dois fragmentos. A "\% individuos das 4 espécies mais abundantes" dá o percentual de individuos das quatro espécies mais abundantes de cada fragmento com relação ao total de indivíduos. O "Número de espécies constituindo $50 \%$ e $70 \%$ " dá o número de espécies que contribuem com mais de $50 \%$ e $70 \%$ do total dos indivíduos. Números entre parênteses referem-se ao percentual de espécies.

\begin{tabular}{c|c|c|c|c|c|c}
\hline Fragmento & $\begin{array}{c}\text { Tamanho } \\
\text { (ha) }\end{array}$ & $\begin{array}{c}\text { Area } \\
\text { amostral } \\
\text { (ha) }\end{array}$ & $\begin{array}{c}\bar{N}^{\circ} \text { de } \\
\text { Espécies }\end{array}$ & $\begin{array}{c}\text { \% individuos das 4 } \\
\text { espécies mais } \\
\text { abundantes }\end{array}$ & \multicolumn{2}{|c|}{$\begin{array}{c}\text { No. de espécies constituindo } \\
50 \%\end{array}$} \\
\hline $\begin{array}{c}\text { Mata do } \\
\text { Pomar }\end{array}$ & 9,5 & 0,58 & 49 & 62,0 & $3(6,1)$ & $6(12,2)$ \\
$\begin{array}{c}\text { Santa Rita } \\
\text { Capuava }^{2}\end{array}$ & 9,5 & 0,71 & 102 & 30,6 & $10(9,8)$ & $21(20,6)$ \\
\hline
\end{tabular}

Fonte: 'Viana \& Tabanez (1996) e Lab. Silvicultura Tropical-ESALQ (não publicado); ${ }^{2}$ Tabanez (1995)

As densidades das quatro espécies mais abundantes na Mata do Pomar são de 182,60 ind./ha (B. forficata), 170,54 ind./ha (Aloysia virgata), 108,52 ind./ha (U. baccifera) e 91,3 ind./ha ( $T$. micrantha), bem superiores às encontradas nos outros dois fragmentos. No fragmento Santa Rita ocorreu apenas $B$. forficata (3,91 ind./ha) e $T$. micrantha $(3,91$ ind./ha) e na Capuava, $B$. forficata $(26,61$ ind./ha) e $U$. baccifera (20,86 ind./ha). Os fragmentos Santa Rita e Capuava, apresentam duas espécies em comum das quatro espécies mais abundantes de cada um deles. Nestes fragmentos 
nenhuma das quatro espécies são pioneiras. No fragmento Santa Rita as quatro espécies mais comuns abrangem uma espécie oportunista (Astronium graveolens), duas espécies tolerantes (Securinega guaraiuva e Aspidosperma pyricollum) e uma espécie reprodutora à sombra (Metrodorea nigra) e no fragmento Capuava duas espécies oportunistas (Astronium graveolens e Croton floribundus) uma espécie tolerante (Aspidosperma polyneuron) e uma espécie reprodutora à sombra (Metrodorea nigra) (Tabanez, 1995 e dados extraídos do Laboratório de Silvicultura Tropical - ESALQ/USP).

\section{3 - Número de Individuos Mortos e Recrutados no periodo de 1991 a 1995.}

No intervalo de 1991 à 1995 a mortalidade absoluta de árvores foi de 97 indivíduos, que corresponde à 41,8 árvores mortas/ha/ano. No entanto, em 1995, o número de árvores novas na classe $\geq 5 \mathrm{~cm}$ de DAP foi de 199 indivíduos, mais de duas vezes superior à mortalidade, correspondendo à 85,7 árvores novas/ha/ano. Isto implicou numa razão recrutamento/mortalidade de 2,05. A diferença entre recrutamento e mortalidade elevou a densidade para 1066,3 ind./ha (total de 619 indivíduos) em 1995, representando um acréscimo de 19,2\% na densidade total.

\section{4 - Recrutamento e Mortalidade das Classes de Densidade e dos Grupos Ecológicos.}

Vinte e seis espécies (53\% do total das espécies) presentes em 1991 apresentaram recrutamento em 1995. As espécies mais abundantes em 1991, representadas pela classe 1 de densidade, foram as responsáveis por um alto recrutamento comparativamente às classes 2 e 3 . Somente a classe 1 deteve $79,9 \%$ dos individuos recrutados, ao passo que as classes 2 e 3 detiveram apenas $6,5 \%$ e $9,0 \%$, respectivamente (Tabela 3 ). Além disso, todas as espécies pertencentes à classe 1 recrutaram no período de estudo, enquanto que 53,8\% e $33,3 \%$ das espécies pertencentes às classes 2 e 3, respectivamente, obtiveram recrutamento (Tabela 3).

Exceto uma espécie reprodutora à sombra (Metrodorea nigra), as demais espécies deste grupo e as espécies tolerantes estão representadas por populações menores, pertencentes às classes 2 e 3 (Tabela 1). Ambas as classes congregam 6 
espécies tolerantes e 7 espécies reprodutoras à sombra (Tabela 3). Além do baixo recrutamento nessas duas classes de densidade, as espécies pioneiras e oportunistas foram as responsáveis por um alto recrutamento, especialmente na classe 3 (Tabela 3). Essas espécies compreenderam 74,2\% dos individuos recrutados nas duas classes, com 38,7\% (total de 12 indivíduos) para as espécies pioneiras e $35,5 \%$ (total de 11 individuos) para as espécies oportunistas. 0 maior recrutamento de espécies pioneiras na classe 3 não está relacionado ao fato desta classe congregar um grande número destas espécies. Apenas três espécies recrutaram, sendo que uma única espécie pioneira, Cecropia ololeuca, que tinha 2 individuos em 1991, foi responsável por $70 \%$ do recrutamento na classe 3 . O mesmo é válido para as espécies oportunistas. Ao contrário, as espécies tolerantes obtiveram um baixo Tabela 3 - Recrutamento e mortalidade para os grupos ecológicos pertencentes às classes 1 ( $\geq 15,5$ individuos/ha), 2 (5,2 a 13,8 individuos/ha) e 3 (1,7 e 3,4 individuos/ha) entre 1991 e 1995.

\begin{tabular}{|c|c|c|c|c|c|c|}
\hline \multirow{2}{*}{$\begin{array}{l}\text { Grupo } \\
\text { Ecol. }\end{array}$} & \multirow{2}{*}{$\begin{array}{l}\text { No. Total } \\
\text { Espécies }\end{array}$} & \multirow{2}{*}{$\begin{array}{l}\text { No. Espécies } \\
\text { que recrutaram }\end{array}$} & \multicolumn{2}{|c|}{ Recrutamento } & \multicolumn{2}{|c|}{ Mortalidade } \\
\hline & & & Absoluto & $\%$ do total & Absoluta & $\%$ do total \\
\hline \multicolumn{7}{|c|}{ Classe 1} \\
\hline$P$ & 4 & 4 & 128 & 64,3 & 68 & 69.3 \\
\hline OP & 5 & 5 & 30 & 15,1 & 5 & 5,1 \\
\hline $\mathrm{T}$ & 0 & 0 & 0 & 0 & 0 & 0 \\
\hline RS & 1 & 1 & 1 & 0,5 & 4 & 4,1 \\
\hline TOTAL & 10 & 10 & 159 & 79,9 & 77 & 78,5 \\
\hline \multicolumn{7}{|c|}{ Classe 2} \\
\hline$P$ & 1 & 1 & 2 & 1,0 & 1 & 1,0 \\
\hline OP & 4 & 2 & 4 & 2,0 & 3 & 3,1 \\
\hline $\mathrm{T}$ & 2 & 1 & 1 & 0,5 & 2 & 2,1 \\
\hline RS & 6 & 3 & 6 & 3,0 & 5 & 5,1 \\
\hline TOTAL & 13 & 7 & 13 & 6,5 & 11 & 11,3 \\
\hline \multicolumn{7}{|c|}{ Classe 3} \\
\hline$P$ & 8 & 3 & 10 & 5,0 & 5 & 5,1 \\
\hline OP & 11 & 4 & 7 & 3,5 & 2 & 2,1 \\
\hline $\mathrm{T}$ & 4 & 1 & 1 & 0,5 & 2 & 2,1 \\
\hline RS & 1 & 0 & 0 & 0 & 0 & 0 \\
\hline TOTAL & 24 & 8 & 18 & 9,0 & 9 & 9,3 \\
\hline
\end{tabular}


recrutamento comparativamente aos outros grupos. Das 6 espécies tolerantes presentes nas duas classes, duas espécies, Holocalyx balansae e Citronela megaphylla, com 7 individuos e 1 individuo em 1991, respectivamente, recrutaram apenas 1 indivíduo no período cada uma. Além disso, as espécies pioneiras e oportunistas apresentaram maior ganho em densidade do que as espécies tolerantes e reprodutoras à sombra, resultado de uma maior diferença entre recrutamento e mortalidade para os dois primeiros grupos (Tabela 3).

A quarta espécie mais abundante em 1991, Trema micrantha, teve sua população drasticamente reduzida no periodo, apresentando uma alta mortalidade comparativamente às outras espécies. Apenas dois individuos sobreviveram, o que fez com que esta espécie fosse responsável por $52,0 \%$ do total das ánores mortas (Tabela 4). $O$ alto recrutamento na classe 1 foi principalmente ocasionado pelas três espécies pioneiras mais abundantes em 1991 ( $B$. forficata, $A$. virgata, $U$. baccifera) e uma espécie oportunista (Croton floribundus). Somente estas quatro espécies compreeenderam $72,5 \%$ do recrutamento do periodo, que, conjuntamente a uma baixa mortalidade, tiveram um aumento pronunciado em suas populações (Tabela 4). Apenas $B$. forficata e $A$. virgata foram responsáveis por $52,9 \%$ do recrutamento. Com exceção de Metrodorea nigra e Bastardiopsis densiflora, todas as outras espécies nessa classe apresentaram um aumento em suas populações (Tabela 4).

Tabela 4 - Recrutamento, mortalidade e mudança do tamanho populacional para as espécies pertencentes à classe 1 ( $\geq 15,5$ indivíduos/ha no ano de 1991). $\mathrm{P}$ - pioneira, $\mathrm{OP}$ - oportunista, $\mathrm{T}$ - tolerante, $\mathrm{RS}$ - reprodutora à sombra.

\begin{tabular}{l|c|c|c|c|c|c|c|c}
\hline \multicolumn{1}{c|}{ Espécie } & GE & \multicolumn{1}{|c|}{$\begin{array}{l}\text { Ind/ha } \\
\text { (1991) }\end{array}$} & $\begin{array}{c}\text { Recrutamento } \\
\text { Absoluto \%total }\end{array}$ & $\begin{array}{c}\text { Mortalidade } \\
\text { Absoluta \%total }\end{array}$ & $\begin{array}{c}\text { Ind/ha } \\
(1995)\end{array}$ & $\begin{array}{c}\text { Mudança } \\
\text { (\%) }\end{array}$ \\
\hline Bauhinia forficata & P & 182,6 & 59 & 29,6 & 1 & 1,0 & 282,5 & 54,7 \\
Aloysia virgata & P & 170,5 & 46 & 23,3 & 9 & 9,2 & 234,3 & 37,4 \\
Urera baccifera & P & 108,5 & 21 & 10,6 & 7 & 7,1 & 132,6 & 18,2 \\
Trema micrantha & P & 91,3 & 2 & 1,0 & 51 & 52,0 & 6,9 & $-92,4$ \\
Croton floribundus & OP & 41,3 & 18 & 9,0 & 0 & 0 & 72,4 & 75,0 \\
Metrodorea nigra & RS & 31,0 & 1 & 0,5 & 4 & 4,1 & 25,8 & $-16,7$ \\
Bastardiopsis densiflora & OP & 29,3 & 2 & 1,0 & 4 & 4,1 & 25,8 & $-11,8$ \\
Machaerium stipitatum & OP & 22,4 & 5 & 2,5 & 1 & 1,0 & 29,3 & 30,8 \\
Lonchocarpus muhelbergianus & OP & 18,9 & 2 & 1,0 & 0 & 0 & 22,4 & 18,5 \\
L. guilleminianus & OP & 15,5 & 3 & 1,5 & 0 & 0 & 20,7 & 33,4 \\
\hline \hline
\end{tabular}


Além do alto recrutamento das espécies pioneiras e oportunistas no período de estudo, outras espécies destes grupos, inexistentes no levantamento de 1991, surgiram em 1995. Três espécies pioneiras, Alcornea urucurana, Solanum swartzinum e Zanthoxylum aff. chiloperone, com 2 indivíduos, 1 e 1 individuo, respectivamente, e duas novas espécies oportunistas, Seguieria langsdorffii e Astronium graveolens, com 2 individuos e 1 individuo, respectivamente, foram encontradas em 1995. Duas espécies pioneiras, Vernonia polyanthes e Piper cf. aduncum, e duas espécies tolerantes, Aspidosperma aff. ramiflorum e Copaifera langsdorffii, todas com 1 indivíduos em 1991, não foram encontradas no levantamento de 1995.

\section{5 - Comparação da Diversidade e Composição Florística em 1991 e 1995.}

Houve diferença altamente significativa dos valores do índice de diversidade Shannon de 1991 e 1995 ( $P<0,001)$. A comunidade era significativamente mais diversa em 1991 (índice de Shannon=2,75) do que em 1995 (2,59).

Como conseqüência do maior ganho de indivíduos no periodo, o grupo das espécies pioneiras e 0 grupo das oportunistas apresentaram aumento nas suas abundâncias em 1995, ao passo que os grupos das tolerantes e reprodutoras à sombra apresentaram uma diminuição. Em 1995, as espécies pioneiras foram responsáveis por $66,7 \%$ do total dos indivíduos, as espécies oportunistas, $24,3 \%$, e as espécies tolerantes e reprodutoras à sombra por apenas $2 \%$ e $7 \%$, respectivamente. À exceção de $T$. micrantha, a alta representatividade das espécies pioneiras em 1995 é ainda explicada pelas três espécies pioneiras mais comuns em 1991, B. forficta, $A$. virgata e $U$. baccifera, que continuaram sendo as três espécies mais comuns em 1995.

\section{DISCUSSÃO}

Este estudo exemplifica o processo ao longo do qual a estrutura florestal em fragmentos florestais é condicionada a um alto nivel de degradação a partir de perturbações antrópicas. Além da baixa riqueza de espécies comparativamente aos outros dois fragmentos (Tabela 2), a alta densidade de espécies pioneiras, conseqüência da elevada abundância de poucas espécies, encontrada na Mata do Pomar é um bom indicador para tal estado de degradação. Em fragmentos de 
Floresta Estacional Semidecidual na região de Piracicaba, espécies pioneiras são encontradas em baixa densidade (Tabanez, 1995; Viana \& Tabanez, 1996). Estas espécies estão geralmente associadas com perturbações antrópicas recentes e, como um grupo, apresenta um baixo número de espécies e uma baixa abundância em florestas onde a intervenção humana é leve (Denslow, 1996). Em florestas maduras estas espécies têm maior probabilidade de serem encontradas apenas em grandes clareiras $\left(>200 \mathrm{~m}^{2}\right)$, formadas a partir de distúrbios naturais, as quais ocupam apenas cerca de $1-2 \%$ das áreas de florestas (Martinez-Ramos, 1985).

Embora quatro anos possa ser considerado um curto período de tempo para uma análise mais precisa de mudanças demográficas de comunidades tropicais, os resultados mostram evidências que diferenciam de outros estudos que avaliaram a dinâmica de populações de árvores tropicais. Dois importantes aspectos merecem ser avaliados. O primeiro diz respeito ao alto recrutamento e a alta razão recrutamento/mortalidade ocorridos na Mata do Pomar comparado a outros estudos. Para a maioria das florestas tropicais estudadas, o recrutamento de árvores adultas não ultrapassa o limite de 10 árvores/ha/ano para indivíduos $>10 \mathrm{~cm}$ de DAP, e a densidade mantém-se praticamente constante no período de tempo analisado, resultado de uma razão recrutamento/mortalidade próxima à 1 (veja revisão em Swaine et al., 1987; Rankin-de-Merona et al., 1990). Em um fragmento de 10 ha recém-isolado na Amazônia, Bierregaard et al. (1992) encontraram um recrutamento de cerca de 8 ánores/ha/ano e uma razão próxima à 1 para árvores $>10 \mathrm{~cm}$ de DAP. Embora haja um aumento significativo no recrutamento quando considerada a mesma classe de tamanho deste estudo (indivíduos $>5 \mathrm{~cm}$ de DAP), ainda fica distante do encontrado na Mata do Pomar. Por exemplo, Uhl et al. (1988a), na Amazônia, encontraram 40,5 ánores/ha/ano e uma razão de 1,28 e Nascimento et al. (1996) encontraram no fragmento Santa Rita, mencionado acima, 34,5 árvores/ha/ano e uma razão de 1,68. A razão recrutamento/mortalidade para a Mata do Pomar poderia ter sido maior se não houvesse a alta mortalidade de $T$. micrantha. Conforme apontado por Rankin-de-Merona et al. (1990), a razão pode variar de acordo com a estrutura inicial, composição de espécies e as diferentes intensidades de perturbações às quais a comunidade eventualmente está sujeita. $O$ segundo, que está relacionado ao 
apresentado acima, diz respeito ao alto recrutamento e a baixa mortalidade de $B$. forficata, $A$. virgata, $U$. baccifera e $C$. floribundus (Tabela 3 ). Estas espécies foram as principais responsáveis pelo alto recrutamento e pela elevada razão recrutamento/mortalidade ocorrida no periodo, especialmente as duas primeiras. Alguns estudos têm demonstrado uma baixa mudança no tamanho populacional das espécies mais comuns, resultado de um equilíbrio entre recrutamento e mortalidade (Swaine et al., 1987; Primack \& Hall, 1992). Por exemplo, na Malásia, oito das trinta e duas espécies mais comuns que apresentaram uma maior mudança populacional, variaram suas densidades entre um declínio de 3,6\% e um aumento de 2,9\% (Manokaran \& Kochummen, 1987). Comparando a Mata do Pomar com um fragmento similar, o Santa Rita, as duas espécies mais comuns deste fragmento, Astronium graveolens e Securinega guaraiuva, apresentaram aumento de $9,2 \%$ e $2,1 \%$, respectivamente (Viana et al., 1997).

A análise comparativa entre a Mata do Pomar e os dois fragmentos, Santa Rita e Capuava, revela evidências bastantes claras que implicam na conservação da biodiversidade em fragmentos de Floresta Estacional Semidecidual do interior do Estado de São Paulo. Estes três fragmentos têm o mesmo tipo de vizinhança (monocultura agricola) e apresentam semelhante isolamento de outras áreas florestadas. Então, devido ao fato da Mata do Pomar apresentar um baixo número de espécies com relação aos fragmentos Santa Rita e Capuava, sendo que o fragmento Santa Rita tem o mesmo tamanho da Mata do Pomar, e também a menor dominância das espécies mais comuns que os fragmentos Santa Rita e Capuava apresentam comparado à Mata do Pomar (Tabela 2), nos leva às seguintes conclusões: i) a perda da diversidade arbórea em fragmentos de floresta isolados há muitas décadas está muito mais relacionado à freqüência e intensidade das pertubações antrópicas que eventualmente estes fragmentos estão sujeitos e ii) as poucas espécies que inicialmente são beneficiadas por estas pertubações continuam a exercer um alto grau de dominância local.

Este fenômeno de uma ou poucas espécies tornarem-se dominantes em fragmentos de floresta tropical isolados por longo tempo também foi registrado em um fragmento de 4 ha em Sígapura (Turner et al., 1996). Neste caso, uma espécie 
arbórea, Calophyllum ferrugineum, representou $26,2 \%$ do total dos individuos do fragmento. Dessa forma, é provável que $B$. forficata, $A$. virgata, $U$. baccifera e $C$. floribundus, tornar-se-ão as espécies ainda mais comuns na Mata do Pomar, enquanto que as outras espécies, especialmente as tolerantes e reprodutoras à sombra, mais raras. Esta previsão está também baseada no fato de que somente em áreas restritas dentro da Mata do Pomar, que ocupam cerca de $16 \%$ da área total dos transectos, apresentam condições mais apropriadas para o estabelecimento destes grupos de espécies (Nascimento \& Viana, submetido), o que, dessa forma, tornará a vulnerabilidade destas espécies ainda maior.

O maior número de espécies arbóreas encontrado nos fragmentos Santa Rita e Capuava não implica na manutenção da diversidade arbórea nestes fragmentos a longo prazo. Atualmente, a aplicação do modelo da Biogeografia de llhas em paisagens continentais fragmentadas vem sendo questionada por alguns pesquisadores devido à duas particularidades: o tempo esperado da ocorrência do declínio no número de espécies e o posterior equilíbrio entre extinção e colonização; e, a mais importante, a seqüência de espécies, ou seja, os taxa (animais e vegetais) mais prováveis de serem inicialmente extintas (Lynam, 1997). Além disso, a previsão da taxa de extinção de espécies baseada na relação espécie-área, está sendo considerada uma abordagem inadequada para planos de conservação (Zuidema et al., 1996). Esta relação prevê uma taxa de extinção muito maior conforme as áreas de florestas vão sendo diminuidas, do que os estudos empiricos atuais têm registrados (veja Simberloff, 1992). De fato, existe uma forte evidência que o risco de extinção de espécies em um determinado fragmento varia entre os diferentes taxa. As plantas são mais persistentes em fragmentos florestais e os vertebrados, tais como os mamíferos e pássaros, devido às suas maiores necessidades de área para sobrevivência ao longo prazo e de terem vida mais curta em relação às muitas espécies de plantas, são mais vulneráveis à fragmentação (Laurance, 1997a). Ao contrário da alta persistência de plantas no geral, a perda de espécies de plantas não tem sido distribuida uniformemente entre as diferentes formas de vida. Devido que a maioria das espécies arbóreas tem tempo de vida mais longo que animais e que outros grupos de plantas, estão menos sujeitấs a desaparecerem mais rapidamente de fragmentos florestais 
(Laurance, 1997a). Por exemplo, em Singapura, Corlett \& Turner (1997) estimaram que mais da metade das espécies de epífitas e orquídeas foram extintas, enquanto que três quartos das espécies de árvores e arbustos ainda persistem, mesmo com apenas $0,2 \%$ de cobertura vegetal nativa ainda existente. Particularmente, a família orchidaceae, devido possivelmente a uma maior sensibilidade às mudanças microclimáticas, tem sofrido a mais alta taxa de extinção, com $86 \%$ das espécies extintas até o momento (Corlett \& Turner, 1997). Especificamente em um único fragmento de 4 ha, também em Singapura, Turner et al. (1996) registraram a extinção de $42,3 \%$ de espécies arbóreas, contra $66,7 \%$ de epífitas e $85,7 \%$ de ervas, em um período de 100 anos de monitoramento.

Uma das conseqüências imediatas da destruição e fragmentação do habitat é a redução do tamanho populacional e o aumento do isolamento populacional, com a divisão de uma determinada população em duas ou mais sub-populações, cada uma restrita a uma determinada área (Young et al., 1996). A teoria da conservação afirma que uma determinada espécie para sobreviver deverá ter uma população mínima viável, ou seja, apresentar o menor tamanho populacional capaz de vencer os efeitos das estocasticidades demográfica, genética e ambiental e das catástrofes naturais (Shafer, 1981). Em comunidades arbóreas tropicais, as espécies que naturalmente ocorrem em baixas densidades e que são amplamente esparsadas terão pequenos tamanhos populacionais em fragmentos, e portanto deverão ser mais susceptíveis à extinção local devido às variações ambientais, demográficas e genéticas, tal como a deriva genética, e catástrofes naturais (como ocorreu na Mata do Pomar). $O$ fato de que a maioria das espécies arbóreas tropicais de baixa densidade apresentam sistema de cruzamento predominantemente exogâmico, e auto-incompatíveis, com polinizadores voando a grandes distâncias, o isolamento populacional ocasionado pela fragmentação tende a aumentar seus niveis de endogamia e conseqüentemente espera-se que ocorra alto grau de depressão endogâmica e perda de heterogozidade (Lepsch-Cunha, no prelo). Embora os efeitos genéticos da diminuição do tamanho populacional e a ruptura de imigração entre isolados fragmentos possam ser obscuros para as espécies de vida longa, as variações demográficas e ambientais e as catástrofes naturais podem representar os principais mecanismos de extinção local e 
regional em populações isoladas (Lande, 1988; Menges, 1991b). Espécies que podem persistir por um longo periodo de tempo devido à grande longevidade, mesmo que não haja reprodução ou recrutamento, foram denominadas por Janzen (1986) como "mortas-vivas".

Em paisagens altamente fragmentadas, onde os fragmentos estão inseridos numa matriz inóspita ao fluxo de animais, muitas espécies de vertebrados e invertebrados não atravessam, mesmo à curtas distâncias, áreas abertas (Powell \& Powell, 1987; Becker et al., 1991; Bierregaard et al., 1992; Silva et al., 1996). Este efeito diferein entre as espécies animais, dependendo da mobilidade, grau de especialização em recurso alimentar e de habitat e mecanismo de dispersão (Laurance, 1991a; Estrada et al., 1993). Portanto, a deficiência de animais que se movem entre fragmentos pode restringir a migração de certas espécies de planta quando os animais são dispersores e também o fluxo gênico se os animais são polinizadores (Turner, 1996). Desta forma, a extinção local poderá ser evitada quando individuos são substituidos por outras populações isoladas, ou seja, quando uma metapopulação é estabelecida (Hanski, 1994).

A migração é um importante fenômeno para a manutenção de espécies de baixa densidade em um determinado local. Os estudos de longo prazo de comunidades arbóreas tropicais têm mostrado que há "turnover" na composição de espécies raras maior do que para as espécies comuns, ou seja, em uma determinada parcela, algumas espécies de baixa densidade se extinguem e outras colonizam ao longo do tempo (Hubbell \& Foster, 1986; Primack \& Hall, 1992). Portanto, uma considerável fração da diversidade em uma determinada parcela é mantida pelas populações transitórias de espécies raras. Dessa forma, conforme as espécies raras já existentes em um fragmento bastante isolado desaparecerem, novas espécies não substituirão as anteriores devido a uma insuficiência na imigração de novos propágulos (Primack \& Hall, 1992), ocasionando a diminuição de diversdidade arbórea em fragmentos isolados e favorecendo a extinção local e regional de espécies com populações pequenas. As estratégias de conservação de espécies arbóreas devem priorizar este grupo de espécies (Laurance et al., 1997) 


\section{CONCLUSÕES}

O fragmento Mata do Pomar passou por um processo de redução da diversidade de espécies arbóreas no periodo de 1991 à 1995. Esta redução está relacionada diretamente ao aumento significativo do tamanho populacional das espécies de maiores densidades no período. Caso seja mantido este processo, o fragmento diminuirá sua capacidade de suporte de populações de plantas e animais. São necessárias, então, ações de manejo conservacionistas dentro e no entorno do fragmento com o objetivo de reverter ou atenuar o atual processo de emprobecimento biológico.

Embora as regiões que ainda apresentam grandes áreas intactas de florestas $\operatorname{devAm}$ ser as áreas de maior interesse para consenvação atual da biodiversidade tropical, em localidades altamente fragmentadas, os pequenos fragmentos ainda podem sustentar uma boa porção da diversidade de espécies tropicais por longos periodos, como é caso da Floresta Estacional Semidecidual do interior do Estado de São Paulo. Algumas espécies, especialmente os grandes mamiferos e algumas espécies de pássaros, são as mais susceptiveis à extinção a curto prazo em função da fragmentação. Todavia, o mostrado neste estudo revela que mesmo fragmentos bastante pequenos podem manter alta diversidade de espécies arbóreas após décadas, a menoś que estejam protegidos de fortes perturbações antrópicas. Quatro pontos relevantes justificam a sua conservação: i) a presença destes fragmentos melhora significativamente a diversidade da paisagem, ii) estes fragmentos são benéficos para os animais migratórios, fornecendo alimento e abrigo em periodos especificos do ano, iii) os pequenos fragmentos são os locais mais apropriados para fornecer um número significante de espécies e diversidade genética para estratégias de conservação ex situ. e iv) estes fragmentos funcionam como fonte de recolonização de áreas vizinhas. 


\section{CAPITULO 2}

\section{ESTRUTURA E DINÂMICA DE ECO-UNIDADES EM UM FRAGMENTO DE FLORESTA ESTACIONAL SEMIDECIDUAL NA REGIÃO DE PIRACICABA, SP}

\section{INTRODUÇÃO}

Em função do processo acelerado de degradação e fragmentação das florestas tropicais em todo o mundo e a busca de alternativas para o seu manejo e recuperação, há uma necessidade de utilização de um método para avaliar o estado de conservação destas florestas. A Avaliação Ecológica Rápida (REA-rapid ecological assessment) é um método diagnóstico utilizado para inferir sobre o estado de conservação de florestas naturais baseado em usos de indicadores, tais como características da estrutura florestal e luminosidade (Abate, 1992; Koop et al., 1994). A Avaliação Ecológica Rápida pressupõe que i) os indicadores escolhidos devem permitir que o método seja constante ao longo de todo o trabalho de diagnóstico, ii) os indicadores devem fornecer dados relevantes, ou seja, refletir os diferentes graus de conservação, e iii) que o método possa ser facilmente utilizado por pessoas sem conhecimentos teóricos (Koop et al., 1994). Isto implica que os indicadores utilizados na Avaliação Ecológica Rápida possam ser facilmente reconheciveis. A principal vantagem da Avaliação Ecológica Rápida é a redução do tempo e custo para a avaliação do estado de consenvação de áreas de interesse, sem a necessidade, portanto, de inventários detalhados (Abate, 1992; Koop et al., 1994).

Os processos dinâmicos que ocorrem em florestas tropicais produzem através do tempo uma estrutura de grande heterogeneidade espacial, em que a densidade, área basal, altura do dossel e a camada de copa variam à curtas distâncias (Lieberman et al., 1989; Whitmore, 1989; Lieberman \& Lieberman, 1994). Essa heterogeneidade é resultado do regime de distúrbios e do subseqüente processo de sucessão secundária (Martinez-Ramos, 1985; Denslow, 1987). As florestas tropicais são então caracterizadas como um mosaico composto por manchas de diferentes 
idades ou estágios sucessionais, conceito inicialmente proposto por Aubréville em 1938 (Richards, 1979). Oldeman $(1983,1989)$ considerou a floresta tropical como um mosaico constituído por eco-unidades de diferentes tamanhos e composição de espécies. As eco-unidades são identificadas a partir da combinação de dois parâmetros: a sua área (eco-unidades pioneiras, secundárias e primárias ou maduras) e arquitetura das árvores (eco-unidades em inovação, agradação, equilíbrio e degradação), resultando então em vários tipos de eco-unidades que compõem o mosaico silvático (Oldeman, 1989). Atualmente, o conceito de eco-unidades vem sendo empregado por alguns autores com modificações, em função da utilização da Avaliação Ecológica Rápida. Estas modificações objetivam um diagnóstico mais rápido e simples, seja do ponto de vista de caracterização do estado de consenvação e degradação de florestas naturais, ou seja para a avaliação de diferentes sistemas de manejo florestal (veja Koop et al. 1994, Tabanez, 1995; Viana \& Tabanez, 1996; Viana et al., 1997; Uhl et al., 1997; Vidal et al., 1997). Estas modificações em geral simplificam o conceito mais amplo de eco-unidades proposto por Oldeman.

A Floresta Estacional Semidecidual do interior do estado de São Paulo é um exemplo claro do processo de degradação e fragmentação de ecossistemas tropicais no mundo. A fragmentação deste ecossistema iniciou-se há várias décadas e os pequenos $e$ isolados fragmentos que ainda restam sofrem, ao longo desses vários anos, as conseqüências peculiares advindas da própria fragmentação florestal e, além disso, experimentam os efeitos da paisagem na qual estão inseridos: incêndios periódicos, caça e agrotóxicos advindos de práticas agrícolas (Viana, 1995). A Avaliação Ecológica Rápida permitiu caracterizar nestes fragmentos a existência de diferentes eco-unidades, que indicam diferentes graus de consenação da estrutura florestal que ocorrem dentro de um determinado fragmento florestal (Tabanez, 1995; Viana \& Tabanez, 1996; Viana et al., 1997). Estes autores identificaram quatro ecounidades, as quais denominaram de capoeira baixa, bambuzal, capoeira alta e mata madura. A capoeira baixa é uma eco-unidade semelhante a clareiras naturais, sem ou com poucas ánores, mas geralmente coberta por cipós e arbustos escandentes. Esta é a eco-unidade mais degradada, com vegetação arbórea menos desenvolvida. Bambuzal é uma eco-unidade caracterizada pelo alto domínio de espécies de bambu 
de médio diâmetro (em torno de $5 \mathrm{~cm}$ de DAP) e baixa densidade de espécies arbustivo-arbórea. A capoeira alta é uma eco-unidade com vegetação arbórea relativamente desenvolvida, sem um dossel contínuo, presença de cipós na maioria das árvores e também com sub-bosque dominado por cipós. A mata madura é caracterizada por uma vegetação mais desenvolvida, com dossel contínuo a 20-25 metros de altura, presença de individuos arbóreos emergentes e baixa densidade de cipós.

Poucas informações quantitativas sobre a estrutura e dinâmica de populações arbóreas nestas eco-unidades estão disponiveis. Neste trabalho, é apresentado os resultados obtidos de um estudo de quatro anos de acompanhamento analisados com relação à estrutura e dinâmica de eco-unidades encontradas em um fragmento de Floresta Estacional Semidecidual de 9,5 ha, localizado no municipio de Piracicaba.

O estudo foi organizado a fim de responder às seguintes questões: i) as características da estrutura da vegetação utilizadas para definir as eco-unidades, também refletem diferenças na composição, riqueza e diversidade de espécies arbóreas nas diferentes eco-unidades? e ii) como a composição, riqueza e diversidade de espécies arbóreas variam no tempo nas diferentes eco-unidades? A hipótese é que as eco-unidades aqui identificadas apresentam composição e diversidade de espécies diferenciadas , como também a variação da composição e diversidade no periodo de tempo diferem entre as eco-unidades. Se as ecounidades apresentam estrutura e dinâmica diferenciadas, então as predições são: i) os grupos das espécies de início de sucessão terão uma maior abundância e dominância na capoeira baixa e capoeira alta, enquanto as espécies típicas de comunidades maduras na mata madura e ii) o uso da Avaliação Ecológica Rápida é um método viável para a identificação de diferentes estados de conservação em fragmentos de Floresta Estacional Semidecidual.

\section{MATERIAL E MÉTODOS}

\section{1 - Caracterização da área}

O municipio de Piracicaba localiza-se na depressão periférica do estado de São de Paulo, apresentando relevo suavemente ondulado, com altitude em torno de 500 metros, situando-se nas coordenadas $22^{\circ} 47^{\prime} \mathrm{S}$ e $47^{\circ} 49^{\prime} \mathrm{W}$ (Figura 1). Segundo 
levantamento feito no Departamento de Meteorologia da Escola Superior de Agricultura Luiz de Queiroz (ESALQ/USP), para o periodo de 1990-1996, a pluviosidade média anual foi de cerca $1430 \mathrm{~mm}$, distribuidas irregularmente durante o ano. O periodo de maior precipitação coincide com o periodo mais quente, de outubro a março (média de $184 \mathrm{~mm}$ ), e o período de menor precipitação coincide com o periodo mais frio, de abril a setembro (média de $50 \mathrm{~mm}$ ). A temperatura média do periodo mais quente foi de $25^{\circ} \mathrm{C}$ e do periodo mais frio, $17^{\circ} \mathrm{C}$, para o intervalo de 1990 à 1996. A vegetação natural da região é classificada pelo Sistema Fitogeográfico Brasileiro como Floresta Estacional Semidecidual (IBGE, 1992). Caracteriza-se pela mistura de espécies caducifólias, que perdem suas folhas no periodo seco, e perenifólias. Entre as espécies típicas de dossel destacam-se: Aspidosperma polyneuron, Astronium graveolens, Balfourodendron riedelianum, Chorisia speciosa, Cariniana legalis e C. estrellensis. No sub-dossel tem-se Esenbeckia febrifuga, Galipea multiflora, Metrodorea nigra, Trichilia catigua, T. elegans e $T$. pallida como as espécies mais representativas.

A paisagem de Piracicaba está atualmente dominada pela monocultura da cana-de-açúcar, onde a vegetação original foi reduzida a pequenos fragmentos. Apenas $2,1 \%$ da cobertura florestal nativa ainda persiste, distribuidos em cerca de 102 fragmentos, sendo que os pequenos fragmentos (menor que $50 \mathrm{ha}$ ) compreendem $89,9 \%$ do total (Viana et al., 1997).

\section{2 - Descrição da área experimental}

O fragmento em estudo está localizado dentro do campus da ESALQ/USP. Sua área é de aproximadamente 9,5 ha. Esta floresta é uma área de reserva da ESALQ, conhecida como Mata do Pomar. Em mapa datado de 1894, este fragmento era parte de uma maior área de floresta, que progressivamente foi sendo derrubada em diferentes épocas para dar lugar às culturas de café, cana-de açúcar e algodão e à instalação dos edifícios da ESALQ (Catharino, 1989).

Este fragmento sofreu, nas três últimas décadas, dois grandes incêndios, tendo o último ocorrido entre 15 e 20 anos atrás, queimando cerca de $20-30 \%$ de sua área, além de ter havido extração madereira em passado relativamente recente, há cerca de 30 anos (Tabanez et al., 1997). 


\section{3 - Obtenção dos dados}

Os dados usados neste trabalho foram obtidos em dois periodos (1991 e 1995), com o uso de dois transectos perpendiculares entre si, com 10 metros de largura, que vão de uma borda à outra do fragmento (Figura 1). Os dois transectos correspondem à uma área amostral de $5805 \mathrm{~m}^{2}$ (6,3\% da área total do fragmento). No ano de 1991, todas as árvores com DAP (diâmetro à altura do peito) igual ou superior a $5 \mathrm{~cm}$ foram mapeadas, etiquetadas, identificadas, e tiveram seus DAP's medidos. Os resultados deste primeiro levantamento são encontrados em Tabanez et al. (1997). Em 1995, Todas as árvores anteriormente existentes foram novamente medidas e os novos ingressos tiveram medidos seus DAP's, etiquetados, mapeados e identificados.

Para o estudo de individuos jovens (arvoretas), parcelas de $3 \times 3 \mathrm{~m}\left(9 \mathrm{~m}^{2}\right)$ foram instaladas a 1 metro da picada que divide os transectos ao meio (Figura 1). Nessas parcelas, alocadas sistematicamente em intervalos regulares, todos os indivíduos arbóreos maiores ou igual a $50 \mathrm{~cm}$ de altura e menores que $5 \mathrm{~cm}$ de DAP foram levantados em dois periodos. O primeiro levantamento foi realizado em dezembro de 1995 e o segundo, em dezembro de 1996, correspondendo a um intervalo de 1 ano. $O$ número de parcelas para cada eco-unidade variou de acordo com a área ocupada de cada eco-unidade nos transectos.

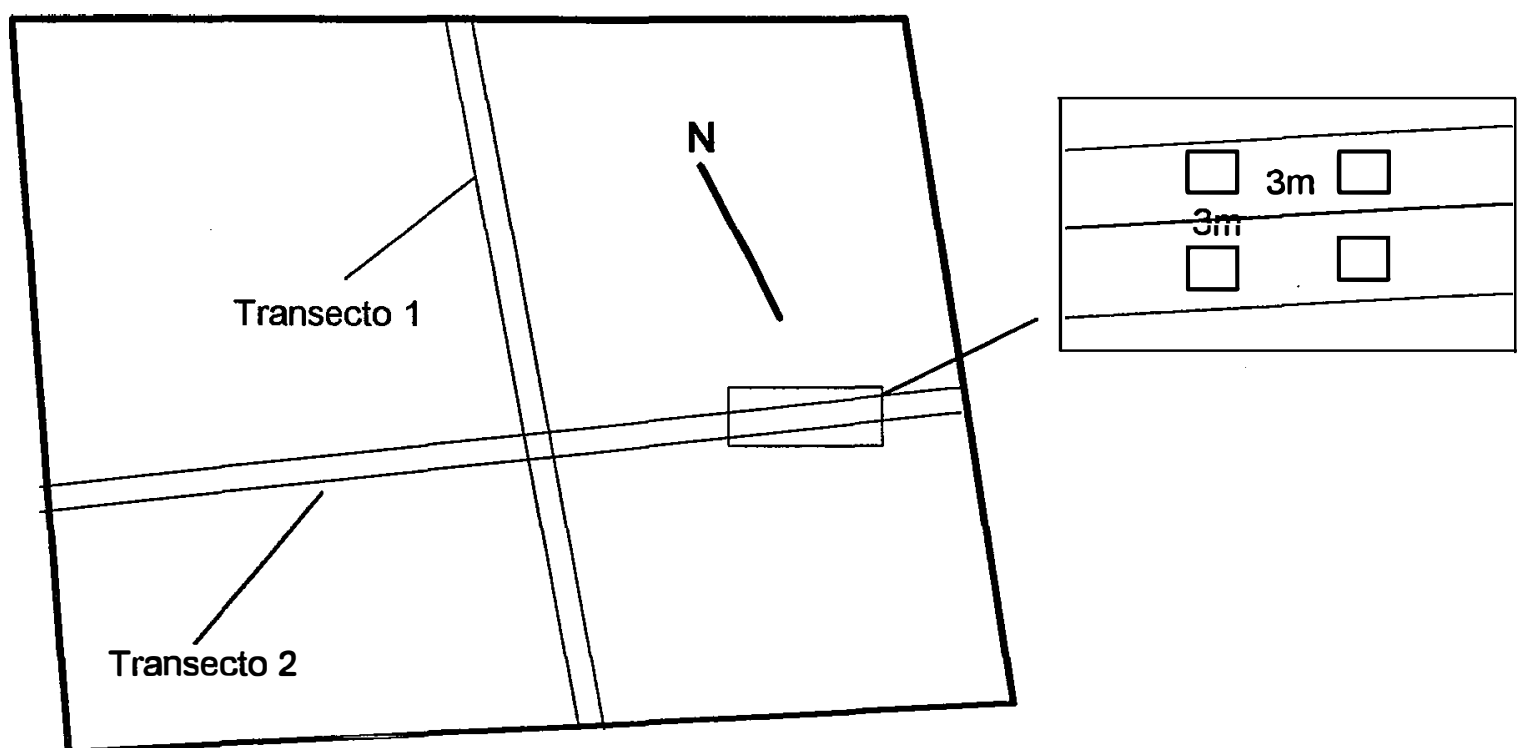

Figura 1 - Croqui da Mata do Pomar mostrando a localização dos dois transectos e as parcelas de regeneração natural. 
As eco-unidades foram identificadas através de caminhadas ao longo dos transectos. Os indicadores utilizados para identificar as eco-unidades são mostrados na Tabela 1. Cada transecto, portanto, pode conter diferentes números de trechos correspodentes às diferentes eco-unidades. Para obter a área de cada trecho, multiplicou-se o comprimento do trecho com a largura do trensecto (10 metros).

Tabela 1 - Características e suas respectivas categorias usadas para identificar as diferentes eco-unidades em fragmentos de Floresta Estacional Semidecidual.

\begin{tabular}{|c|c|c|c|c|}
\hline \multirow[b]{2}{*}{ Características } & \multicolumn{4}{|c|}{ Eco-unidade } \\
\hline & $\begin{array}{c}\text { Capoeira } \\
\text { Baixa } \\
\text { (CB) }\end{array}$ & $\begin{array}{l}\text { Bambuzal } \\
\text { (BB) }\end{array}$ & $\begin{array}{c}\text { Capoeira } \\
\text { Alta } \\
\text { (CA) }\end{array}$ & $\begin{array}{c}\text { Mata } \\
\text { Madura } \\
\text { (MM) }\end{array}$ \\
\hline $\begin{array}{l}\text { Freqüência de árvores de grande } \\
\text { porte (> } 15 \mathrm{~m} \text { de altura) }\end{array}$ & baixa & baixa & média & alta \\
\hline Densidade Arborea (> $5 \mathrm{~cm}$ DAP) & baixa & média & alta & alta \\
\hline Dossel & $\begin{array}{c}\text { não } \\
\text { contínuo }\end{array}$ & $\begin{array}{c}\text { não } \\
\text { contínuo }\end{array}$ & $\begin{array}{c}\text { não } \\
\text { contínuo }\end{array}$ & continuo \\
\hline Luminosidade & alta & média & média & baixa \\
\hline $\begin{array}{l}\text { Densidade e Cobertura Foliar de } \\
\text { Cipós }\end{array}$ & alta & baixa & média & baixa \\
\hline Densidade de bambus & baixa & alta & baixa & baixa \\
\hline
\end{tabular}

\section{4 - Análise dos dados}

Para as eco-unidades idenficadas a partir da Avaliação Ecológica Rápida, foi calculada a área basal $\left(\mathrm{m}^{2} / \mathrm{ha}\right)$, densidade (No. individuos/ha) e área basal média por indivíduo ( $\left.\mathrm{cm}^{2} / a ́ r v o r e\right)$. A partir destas variáveis, foi realizada uma análise de agrupamento das eco-unidades, utilizando o método da média de grupo (UPGMA) e a Distância Euclidiana Média como coeficiente de dissimilaridade, utilizando o programa "Cluster.bas" (Ludwig \& Reynolds, 1988).

Um problema que freqüentemente surge em comparar diferentes comunidades com relação ao número de espécies é que nem sempre é possivel assegurar o mesmo tamanho amostral, já que o número de espécies é muito sensivel com o aumento da amostra (Magurran, 1988). Como cada eco-unidade apresenta diferentes áreas dentro do fragmento, então a comparação da riqueza de espécies entre elas torna-se 
imprecisa. Dessa forma, foi comparada a riqueza de espécies entre as eco-unidades utilizando um método estatístico conhecido por rarefação ("rarefaction"). Este método permite estimar o número esperado de espécies em amostras de tamanho comum, com o mesmo número de indivíduos, sendo considerado como um índice que avalia a riqueza de espécies em diferentes situações (Ludwig \& Reynolds, 1988; Magurran, 1988; Krebs, 1989). A solução é dada pela seguinte equação:

$$
E\left(S_{n}\right)=\sum\left\{1-\left[\left(\begin{array}{l}
N-N i \\
n
\end{array}\right) /\left(\begin{array}{l}
N \\
n
\end{array}\right)\right]\right\}
$$

onde:

$E\left(S_{n}\right)=$ número esperado de espécies em uma amostra padrão com $n$ individuos.

$n=$ valor do tamanho da amostra ( $n^{\circ}$ individuos) escolhido para padronização.

$\mathrm{N}_{\mathrm{i}}=$ número de individuos da $i_{t h}$ espécie.

$\mathbf{N}=$ número total de individuos registrados $=\Sigma \mathrm{N}_{\mathrm{i}}$.

Os resultados do número esperado de espécies nas diferentes eco-unidades foram obtidos com o uso do programa "Rarefact.bas" desenvolvido por Ludwig \& Reynolds (1988).

A diversidade de espécies, que considera não só a riqueza de espécies como também a abundância proporcional entre as espécies, é medida por vários indices. Neste trabalho foi utilizado o indice de diversidade de Simpson. Este indice apresenta uma baixa sensibilidade ao tamanho da amostra, conseqüência da maior importância com respeito à abundância das espécies mais comuns e menor sensibilidade à riqueza de espécies (Ludwig \& Reynolds, 1988; Magurran, 1988). A solução é dada pela seguinte equação:

$$
\lambda=\sum p_{i}^{2}
$$

onde:

$p_{i}=$ proporção de indivíduos da $i_{t h}$ espécie na comunidade.

Quanto maior o valor de $\lambda$ menor a diversidade. Portanto, este indice é usualmente expresso como $1 / \lambda$, que, desta forma, indicará que quanto menor o valor, menor será a diversidade e vice-versa. (Magurran, 1988).

As espécies encontradas no fragmento foram agrupadas em categorias 
sucessionais segundo a classificação proposta por Viana (1989). Este autor agrupou as espécies em pioneiras, oportunistas, tolerantes e reprodutoras à sombra. As pioneiras são espécies que normalmente têm sementes de grande longevidade e que exigem a formação de clareiras para germinação e dependem destas durante todo o seu ciclo de vida. As oportunistas são espécies com sementes que não requerem clareiras para germinar, com plântulas que sobrevivem à sombra, mas que dependem de aberturas do dossel para atingir o estágio reprodutivo. As tolerantes têm sementes que também não necessitam de clareiras para germinar, as plântulas podem crescer até o estágio juvenil sem a presença de clareiras, mas dependem destas para alcançar o estágio reprodutivo. As reprodutoras à sombra têm sementes que não necessitam de clareiras para germinar, crescem até o estágio adulto sob sombra e se reproduzem nesta mesma condição.

As espécies foram enquadradas nestas categorias sucessionais baseado no enquadramento em outras categorias realizado por diversos autores e por observações de campo. É importante salientar que esta não é uma classificação definitiva, sendo apenas uma tentativa de comparar as diferentes eco-unidades com respeito proporção de cada grupo ecológico. A pequena quantidade de informações referentes à biologia de muitas espécies tropicais limita o enquadramento preciso das espécies em grupos ecológicos. Isso tem resultado numa classificação diferenciada entre autores para algumas espécies.

Foi calculada a abundância e a área basal relativa de cada grupo ecológico com relação à abundância total e a área basal total de cada eco-unidade, a fim de comparar as diferentes eco-unidades com respeito à abundância e dominância, respectivamente, de cada grupo ecológico. Ambas, abundância e dominância, retratam a quantidade do ambiente físico utilizado pelas espécies, sendo que cada uma tende a dar maior importância de acordo com o tamanho da planta adulta (Batista, 1994). Dessa forma, densidade é mais importante com respeito às espécies de pequeno porte, tais como as espécies reprodutoras à sombra, enquanto que a área basal o é para as espécies oportunistas e tolerantes.

Foi assumido que as freqüências esperadas de cada grupo ecológico, em termos de abundância, nas diferentes eco-unidades são proporcionais à área 
ocupada por cada eco-unidade. Aplicou-se, então, um teste de frequências G (“goodness of fit”) para testar se a distribuição das freqüências observadas dos grupos ecológicos nas diferentes eco-unidades se ajustam à distribuição das freqüências esperadas (Sokal \& Rohlf, 1981). Esta análise foi feita tanto para o levantamento dos transectos como para a regeneração natural nos dois períodos.

Para as densidades obtidas no levantamento da regeneração natural, foi utilizada uma análise de variância não-paramétrica de Kruskal-Wallis, seguida pelo teste de médias não-paramétrico de Wilcoxon. Este tipo de análise estatística é uma forma alternativa de análise, já que os dados não obedeceram as pressuposições obrigatórias de uma análise de variância paramétrica (Sokal \& Rohlf, 1981).

\section{RESULTADOS}

\section{1 - Definição das Eco-unidades.}

A Mata do Pomar, em função da forte intensidade de pertubações antrópicas (especialmente os incêndios ocorridos recentemente), apresenta densidade alta de duas espécies pioneiras, Bauhinia forficata e Aloysia virgata, que foram beneficiadas por essas pertubações. Em determinados trechos, ocorre uma densidade mais acentuada dessas espécies, que podem ser facilmente reconhecidas durante a Avaliação Ecológica Rápida. Assim, além das quatro eco-unidades já propostas, está sendo proposto aqui uma sub-divisão da eco-unidade capoeira alta, representativa dessas áreas. Para este estudo, a capoeira alta propriamente dita (CA) passa então a ser denominada de capoeira alta tipo 2 (CA2) e a nova eco-unidade, denominada de capoeira alta tipo 1 (CA1), apresenta uma fisionomia semelhante à CA2. O que deferencia ambas é a densidade destas duas espécies. Desse modo, a inclusão de mais um indicador (densidade de espécies pioneiras) na Avaliação Ecológica Rápida poderá ser sugerida futuramente.

A análise de agrupamento representada pelo dendrograma abaixo (Figura 2) demonstra que a definição qualitativa de eco-unidades que vem sendo proposta pode ser explicada a partir de algumas características utilizadas na sua definição. Algumas dessas características, em termos quantitativos, são mostradas na Tabela 2. Dois grupos estão claramente separados: o grupo 1, formado pela mata madura (MM) e 
grupo 2, formado pelas eco-unidades mais degradadas, capoeira baixa (CB), capoeira alta tipo 1 (CA1) e capoeira alta tipo 2 (CA2) (Figura 2). Dentro deste segundo grupo, apesar da baixa distância de dissimilaridade, a CB diferencia-se da CA2 e CA1. Nesta

Tabela 2 - Percentual de área ocupada e mudanças em área basal $\left(\mathrm{m}^{2} / \mathrm{ha}\right)$, densidade (No. individuos/ha), área basal média por indivíduo ( $\mathrm{ABI}-\mathrm{cm}^{2}$ /ánore) para árvores $\geq 5$ $\mathrm{cm}$ de DAP nas 4 eco-unidades entre 1991 e 1995. Números entre parênteses referemse ao número de trechos de cada eco-unidade.

\begin{tabular}{cc|cc|cc||cc}
\hline & Área Ocupada & \multicolumn{2}{|c|}{ Área Basal } & \multicolumn{2}{c|}{ Densidade } & \multicolumn{2}{c}{ ABI } \\
Eco & $(\%)$ & 1991 & 1995 & 1991 & 1995 & 1991 & 1995 \\
\hline CB & $12,45(2)$ & 3,90 & 4,49 & 734,34 & 706,65 & 49,57 & 54,23 \\
CA1 & $52,05(3)$ & 8,46 & 11,72 & 1019,9 & 1190,43 & 84,88 & 101,35 \\
CA2 & $19,29(3)$ & 10,49 & 12,92 & 949,14 & 1228,57 & 149,18 & 151,62 \\
MM & $16,19(2)$ & 27,07 & 32,87 & 801,87 & 893,10 & 339,99 & 351,90 \\
\hline \hline
\end{tabular}

análise de agrupamento utilizamos as variáveis: área basal, área basal média por indivíduo e densidade. No entanto, obsena-se na Tabela 2 que a área basal apresenta uma amplitude de variação semelhante da CB para a CA2 e CA1 e da CA2 e CA1 para a MM, e a área basal por indivíduo apresenta variação relativamente alta para as eco-unidades, tendo ambas um alto poder discriminatório quando comparadas à densidade que tem valores pouco discriminatórios para as quatro ecounidades. Conforme Bassab et al. (1990), o fator que mais influencia o resultado de uma análise de agrupamento é a escolha de variáveis, sendo desejável que estas sejam discriminatórias e relevantes ao problema, devendo ser eliminadas aquelas que não o são. Conseqüentemente, a inclusão de outras variáveis discriminatórias não utilizadas, como por exemplo, cobertura foliar devido a cipós e intensidade luminosa, resultaria numa expectativa de agrupamentos mais definidos das eco-unidades (distâncias maiores), através desse método de quantificação multivariada. 


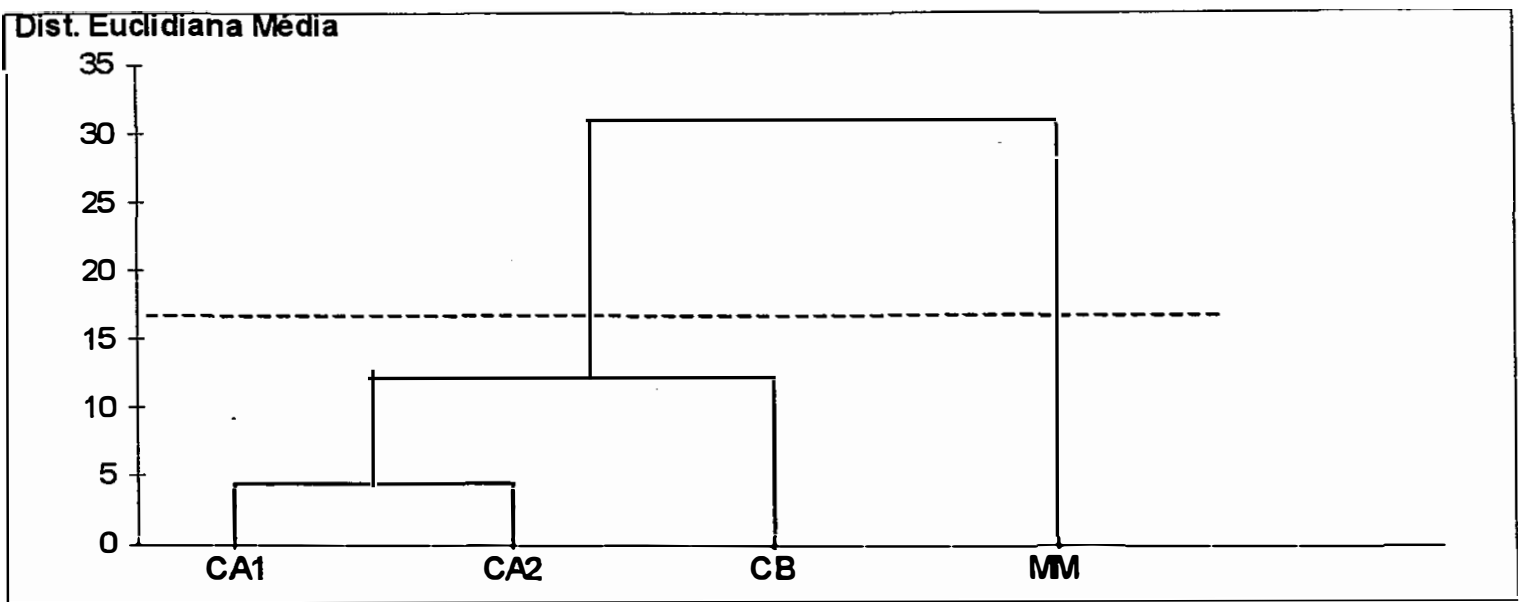

Figura 2 - Dendrograma do agrupamento das eco-unidades definidas a partir da Avaliação Ecológica Rápida. Esta análise de agrupamento foi realizada com o uso das variáveis mostradas na Tabela 2, relativo ao ano de 1995.

As eco-unidades variaram em suas extensões, sendo a metade da área ocupada pela CA1 (Tabela 2). A eco-unidade bambuzal não foi encontrada.

\section{2 - Estrutura e Dinâmica das Eco-unidades para indivíduos $>=5 \mathrm{~cm}$ de DAP}

\subsection{1 - Riqueza e Diversidade em 1991 e 1995.}

As diferenças na riqueza de espécies entre as eco-unidades podem ser constatadas pelo número esperado de espécies para ambos os anos (Tabela 3). Em 1991 e 1995, adotamos os números padrões de 57 individuos e de 55 indivíduos, respectivamente, que são referentes ao número mínimo de indivíduos obtido pela CB. Para a CA1, em ambos os anos, o número esperado de espécies caiu bruscamente, ficando próximo da $\mathrm{CB}$. Ao contrário, para a $\mathrm{CA} 2$ e $\mathrm{MM}$, a queda do número esperado de espécies foi mais suave. Estas variações no número esperado de espécies entre as eco-unidades são explicadas pelo índice de diversidade de Simpson (Tabela 3). Como relatado acima, este índice apresenta uma maior importância com respeito à abundância das espécies mais comuns, sendo menos sensivel à riqueza de espécies. Portanto, embora o número total de espécies na $\mathrm{CA} 1$ foi quase três vezes o número total de espécies na CB em ambos os anos, os índices de Simpson estão próximos e apresentam valores muito baixos em relação à CA2 e MM (Tabela 3). 
Tabela 3 - Número total de individuos e de espécies, número esperado de espécies $\left(E\left(S_{n}\right)\right)$ e indice de diversidade de Simpson $(1 / \lambda)$ nas 4 eco-unidades em 1991 e 1995.

\begin{tabular}{ccc|cc|cc|cc}
\hline \hline & \multicolumn{2}{|c|}{ No. total indivíduos } & \multicolumn{2}{|c|}{ No. total espécies } & $\mathrm{E}\left(\mathrm{S}_{57}\right)$ & $\mathrm{E}\left(\mathrm{S}_{55}\right)$ & \multicolumn{2}{|c}{$1 / \lambda$} \\
$\mathrm{Eco}$ & 1991 & 1995 & 1991 & 1995 & 1991 & 1995 & 1991 & 1995 \\
\hline $\mathrm{CB}$ & 57 & 55 & 11 & 12 & 11 & 12 & 5,0 & 4,2 \\
$\mathrm{CA} 1$ & 302 & 354 & 31 & 31 & 15 & 13 & 5,9 & 4,7 \\
$\mathrm{CA} 2$ & 81 & 112 & 29 & 29 & 24 & 21 & 15,4 & 12,9 \\
MM & 74 & 87 & 24 & 24 & 23 & 21 & 16,9 & 13,8 \\
\hline \hline
\end{tabular}

\subsection{2 - Representatividade dos Grupos Ecológicos em 1991 e 1995}

O número de espécies em cada grupo ecológico é mostrado no Apêndice 1. As espécies pioneiras e oportunistas perfizeram o maior número de espécies, com 16 e 21 espécies, compreendendo $32 \%$ e $42 \%$ do total das espécies, respectivamente. $O$ grupo das tolerantes foi o mais pobre em espécies, sendo representado por apenas 5 espécies.

As eco-unidades diferenciam-se bastante quanto à composição de espécies (Tabela 4). A CB e CA1 foram bem representadas por espécies pioneiras e oportunistas, com $72,8 \%$ e $80 \%$ do total de espécies em 1991 e $100 \%$ e $86,7 \%$ em 1995, respectivamente. A CA1 abrangeu 11 das 16 espécies pioneiras registradas e 15 das 21 espécies oportunistas registradas. Ao contrário, na MM houve uma melhor representatividade das espécies tolerantes e reprodutoras à sombra, embora as espécies oportunistas terem sido em maior número. Esta ecounidade abrangeu 4 espécies tolerantes e 7 espécies reprodutoras à sombra, do total de 5 espécies tolerantes e 8 espécies reprodutoras à sombra registradas no fragmento. A CA2, embora apresentou riqueza e diversidade de espécies semelhante à MM, foi melhor representada por espécies pioneiras e oportunistas e menos representada por espécies tolerantes e reprodutoras à sombra, comparativamente à MM. Ambas, $\mathrm{CB}$ e CA1, apresentaram ganho de seis novas espécies oportunistas, ao passo que três espécies tolerantes e duas espécies reprodutoras à sombra desapareceram dessas eco-unidades no periodo (Tabela 4). 
1991 e 1995. Números entre parênteses refere-se ao numero absoluto de espécies.

\begin{tabular}{ccc|cc|cc|cc}
\hline & \multicolumn{2}{c|}{ Pioneiras } & \multicolumn{2}{c|}{ Oportunistas } & \multicolumn{2}{c|}{ Tolerantes } & \multicolumn{2}{c}{ Rep. à Sombra } \\
Eco & 1991 & 1995 & 1991 & 1995 & 1991 & 1995 & 1991 & 1995 \\
\hline CB & $36,4(4)$ & $33,3(4)$ & $36,4(4)$ & $66,7(8)$ & $18,2(2)$ & 0 & $9,1(1)$ & 0 \\
CA1 & $36,7(11)$ & $36,7(11)$ & $43,3(13)$ & $50,0(15)$ & $3,3(1)$ & 0 & $16,7(5)$ & $13,3(4)$ \\
CA2 & $25,0(7)$ & $24,1(7)$ & $46,4(13)$ & $48,3(14)$ & $7,1(2)$ & $6,9(2)$ & $21,4(6)$ & $20,7(6)$ \\
MM & $17,4(4)$ & $17,4(4)$ & $34,8(8)$ & $34,8(8)$ & $17,4(4)$ & $17,4(4)$ & $30,4(7)$ & $30,4(7)$ \\
\hline \hline
\end{tabular}

A representatividade das espécies pioneiras e oportunistas na $\mathrm{CB}$ e CA1 pode ser sentida não apenas em número de espécies, mas pelo fato de que estas espécies, especialmente as pioneiras, serem responsáveis pela alta dominância e abundância nestas eco-unidades em 1991 e 1995 (Figura 3, Tabela 5). As espécies pioneiras compreenderam $86 \%$ e $84 \%$ da densidade total e $69 \%$ e $74 \%$ da área basal total da CB, em 1991 e 1995, respectivamente. Na CA1, essas espécies compreeenderam $76 \%$ e $77 \%$ da densidade total e $60 \%$ e $64 \%$ da área basal total.

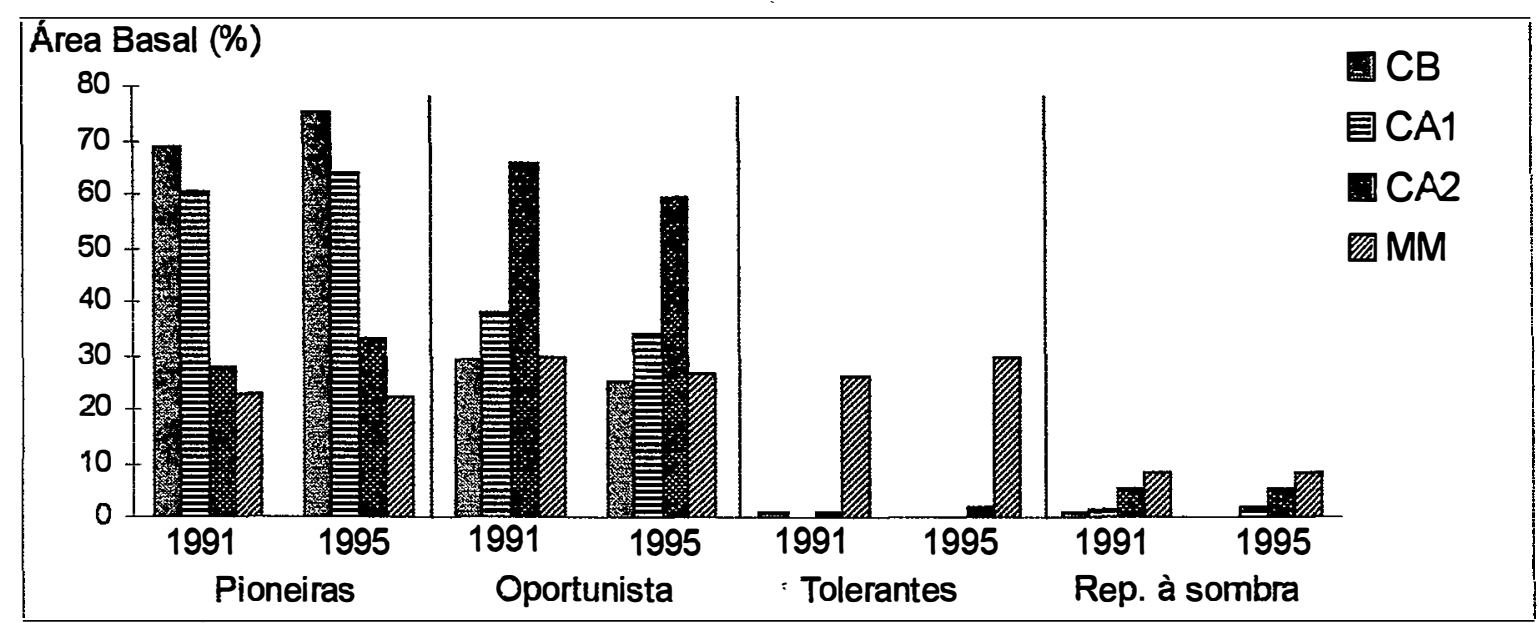

Figura 3 - Área basal relativa de cada grupo ecológico nas 4 eco-unidades em 1991 e 1995.

As espécies tolerantes e reprodutoras à sombra foram melhores representadas na MM, com relação à abundância para as espécies reprodutoras (Tabela 5) e dominância para as espécies tolerantes (Figura 3). Apenas 8 e 9 indivíduos das espécies tolerantes obtiveram o mesmo percentual de área basal quando comparado 
aos 22 e 23 individuos das espécies oportunistas presentes nesta eco-unidade em 1991 e 1995, respectivamente (Figura 3). Ao contrário, as espécies oportunistas foram responsáveis pela maior ocupação do espaço na $\mathrm{CA} 2$, revelado pela alta abundância e dominância destas espécies (Figura 3, Tabela 5). De fato, em termos de abundância, as distribuições observadas dos grupos ecológicos diferiram das distribuições esperadas, para ambos os periodos (Teste $G, P<0,01$, Tabela 5).

Tabela 5 - Densidade relativa de cada grupo ecológico nas 4 eco-unidades em 1991 e 1995. Números entre parênteses refere-se ao número de indvíduos por hectare. Os valores de $G$ são mostrados para os quatro grupos $(P<0,01)$.

\begin{tabular}{ccc|cc|cc|cc}
\hline & \multicolumn{2}{c}{ Pioneiras } & \multicolumn{2}{c|}{ Oportunistas } & \multicolumn{2}{c|}{ Tolerantes } & \multicolumn{2}{c}{ Rep. à Sombra } \\
Eco & 1991 & 1995 & 1991 & 1995 & 1991 & 1995 & 1991 & 1995 \\
\hline CB & 85,9 & 83,6 & 7,0 & 16,4 & 3,5 & 0 & 3,5 & 0 \\
& $(680,5)$ & $(638,9)$ & $(55,55)$ & $(125,0)$ & $(27,8)$ & & $(27,8)$ & \\
CA1 & 75,8 & 76,6 & 19,9 & 19,8 & 0,3 & 0 & 3,31 & 2,54 \\
& $(757,7)$ & $(896,7)$ & $(198,5)$ & $(231,6)$ & $(3,3)$ & & $(33,0)$ & $(29,8)$ \\
CA2 & 43,2 & 45,5 & 37,0 & 41,1 & 3,7 & 3,6 & 13,6 & 9,8 \\
& $(312,5)$ & $(455,5)$ & $(267,9)$ & $(410,7)$ & $(26,8)$ & $(35,7)$ & $(98,2)$ & $(98,2)$ \\
MM & 26,7 & 35,3 & 29,7 & 27,1 & 10,8 & 10,6 & 29,7 & 27,1 \\
& $(202,1)$ & $(319,15)$ & $(234,04)$ & $(244,7)$ & $(85,10)$ & $(95,74)$ & $(234,0)$ & $(244,7)$ \\
\hline$G$ & 63,46 & 50,37 & 13,53 & 15,67 & 17,41 & 20,84 & 32,76 & 43,86 \\
\hline \hline
\end{tabular}

Das onze espécies pioneiras identificadas na $\mathrm{CA} 1$, apenas quatro delas perfizeram $71,85 \%$ do total de individuos em 1991. Dessas quatro espécies, Aloysia virgata e Bauhinia forficata, que serviram para definir a CA1, totalizaram $30,79 \%$ e 22,52\% dos individuos, respectivamente, seguida por Urera baccifera com 10,26\% e Trema micrantha com $8,28 \%$. Estas mesmas espécies também foram as responsáveis pela alta densidade na CB, totalizando $85,97 \%$ dos individuos em 1991. Da mesma forma, com excessão de T. micrantha, que teve sua população drasticamente reduzida no periodo, as outras três espécies continuaram sendo as responsáveis pelas altas densidades em ambas as eco-unidades em 1995. Na CA1, 72,11\% dos individuos foram destas três espécies e na $C B, 81,82 \%$, para 1995. Este fato, portanto, corrobora com as estimativas do número esperado de espécies e de diversidade para a CA1 e CB mostrados acima. Na CA2, estas espécies foram responsáveis por 39,5\% e 41,08\% e na MM, $24,32 \%$ e $26,44 \%$ da densidade total em 1991 e 1995, respectivamente.

O recrutamento na $C B$ e CA1 deveu-se somente às espécies pioneiras e oportunistas, com maior intensidade para as espécies pioneiras (Tabela 6). Apenas 1 indivíduo de uma espécie reprodutora à sombra (Chrysophyllum gonocarpum) recrutou 
na CA1 no periodo. O alto recrutamento de espécies pioneiras em ambas ecounidades foi devido principalmente à Aloysia virgata e Bauhinia forficata. Apenas estas duas espécies contribuíram com $68,18 \%$ e $68,86 \%$ do recrutamento total na CB e CA1, respectivamente. A MM e CA2 se diferenciaram da $C B$ e CA1 por apresentarem recrutamento de espécies tolerantes e reprodutoras à sombra, embora tenha havido recrutamento maior para as espécies pioneiras e oportunistas na CA2 e MM (Tabela 6). A influência de outras eco-unidades na área limite com a $\mathrm{MM}$ influenciou o recrutamento de espécies pioneiras nesta eco-unidade. No entanto, enquanto a CA2 apresentou alto recrutamento de espécies pioneiras e oportunistas, na MM o recrutamento destas espécies foi inferior comparativamente às outras eco-unidades (Tabela 6). Onze individuos das espécies pioneiras, Alcornea urucurana, Cecropia ololeuca e Urera baccifera, e uma espécie tolerante, Citronella paniculata, e três espécies reprodutoras à sombra, Chrysophyllum gonocarpum, Guarea macrophylla e Metrodorea nigra, recrutaram na MM. Na CA2, uma espécie tolerante, Holocalyx balansae e duas espécies reprodutoras à sombra, Chrysophyllum gonocarpum e Trichilia pallida recrutaram individuos.

Tabela 6 - Número de indivíduos por hectare recrutados nas 4 eco-unidades entre 1991 e 1995.

\begin{tabular}{ccccc}
\hline \hline Eco & Pioneiras & Oportunistas & Tolerantes & Rep. à Sombra \\
\hline CB & 236,11 & 69,44 & 0 & 0 \\
CA1 & 284,58 & 56,25 & 0 & 3,31 \\
CA2 & 214,29 & 160,71 & 8,93 & 26,78 \\
MM & 117,02 & 31,91 & 10,64 & 31,91 \\
\hline \hline
\end{tabular}

\section{3 - Indivíduos Jovens ( indivíduos $\geq 50 \mathrm{~cm}$ de altura e $<5 \mathrm{~cm}$ de DAP)}

\subsection{1 - Densidade, Riqueza e Diversidade de Espécies em 1995 e 1996.}

Para 1995 e 1996, houve diferença significativa com relação ao número de individuos entre as eco-unidades (Análise de Variância de Kruskal-Wallis, $P=0,014$ e $P=0,013$, respectivamente), variando de 1,00 a 3,83 indivíduos/parcela e de 1,00 a 4,25 individuos/parcela, respectivamente (Tabela 7). A menor densidade de regeneração em 1995 e 1996 foi obtida na CB, não havendo diferença significativa entre esta e a CA1 (Tabela 7). Entre a CA2 e MM também não houve diferenças significativas, as 
quais obtiveram as maiores densidades (Tabela 7). Como o número de individuos mínimo obtido pela $C B$ foi muito baixo, consideramos então um número padrão de $29 \mathrm{e}$ 33 indivíduos, referentes ao número de indivíduos obtido pela MM em 1995 e 1996, respectivamente, para a estimativa do número esperado de espécies. A MM, CA1 e CA2 obtiveram os números esperado de espécies próximos. Este padrão pode ser constatado pelo índice de Simpson, que apresentou também valores semelhantes nestas três eco-unidades (Tabela 7). Tanto a riqueza quanto a diversidade foram menores para a $\mathrm{CB}$, onde apenas quatro espécies foram encontradas, e $\mathrm{o}$ índice de Simpson foi cerca de $50 \%$ menor comparativamente às outras eco-unidades (Tabela 7).

Tabela 7 - Número de indivíduos por parcela (média \pm desvio padrão), número total de espécies, número esperado de espécies $\left(E\left(S_{n}\right)\right.$ ) e índice de diversidade de Simpson (1/ $\lambda$ ) para árvores $\geq 50 \mathrm{~cm}$ de altura e $<5 \mathrm{~cm}$ de DAP nas 4 eco-unidades em $1995 \mathrm{e}$ 1996. Médias do número de indivíduo/parcela seguidas pela mesma letra, dentro do mesmo ano, não diferem estatisticamente pelo teste de Wilcoxon considerando um nível de probabilidade $P>0,05$. Números entre parênteses refere-se aos valores absolutos $d a$ densidade.

\begin{tabular}{ccc|cc|cc|cc}
\hline \hline & \multicolumn{2}{c}{ No. indivíduos/ } & \multicolumn{2}{|c|}{ No. espécies } & $\bar{E}\left(\mathrm{~S}_{29}\right)$ & $\mathrm{E}\left(\mathrm{S}_{33}\right)$ & \multicolumn{2}{|c}{$1 / \lambda$} \\
parcela $\left(9 \mathrm{~m}^{2}\right)$ & & & & & & \\
Eco & 1995 & 1996 & 1995 & 1996 & 1995 & 1996 & 1995 & 1996 \\
\hline CB & $1,00 \pm 1,00^{\mathrm{a}}$ & $1,00 \pm 1,00^{\mathrm{a}}$ & 4 & 4 & - & - & 5,26 & 5,26 \\
$(\mathrm{n}=7)$ & $(7)$ & $(7)$ & & & & & & \\
CA1 & $2,21 \pm 2,49^{\mathrm{ab}}$ & $2,60 \pm 2,75^{\mathrm{ab}}$ & 18 & 21 & 12 & 15 & 10,51 & 10,77 \\
$(\mathrm{n}=28)$ & $(61)$ & $(73)$ & & & & & & \\
CA2 & $3,83 \pm 3,76^{\mathrm{bc}}$ & $4,25 \pm 4,07^{\mathrm{bc}}$ & 17 & 20 & 14 & 16 & 11,23 & 11,08 \\
$(n=12)$ & $(45)$ & $(51)$ & & & & & & \\
$M M$ & $3,62 \pm 1,18^{\mathrm{c}}$ & $4,12 \pm 1,80^{\mathrm{c}}$ & 12 & 14 & 12 & 14 & 12,19 & 12,88 \\
$(n=8)$ & $(29)$ & $(33)$ & & & & & & \\
\hline \hline
\end{tabular}

\subsection{2 - Representatividade dos Grupos Ecológicos em 1995 e 1996.}

Os grupos das espécies oportunistas e reprodutoras à sombra foram os mais ricos em espécies nas parcelas de regeneração natural, com 13 e 11 espécies, compreeendendo $40,6 \%$ e $34,4 \%$ do total das espécies, respectivamente (Apêndice 2). 
Da mesma forma, o grupo das tolerantes foi o mais pobre em espécies, com apenas 2 espécies.

Apesar da riqueza e diversidade da $M M$ terem sido semelhantes à $C A 1$ e CA2, a representatividade dos grupos ecológicos entre estas eco-unidades diferiram muito (Tabela 8). Estas eco-unidades diferenciaram-se quanto à representatividade das espécies pioneiras e oportunistas. $\mathrm{Na} \mathrm{MM}$ não foi encontrada espécies pioneiras e as espécies oportunistas tiveram baixa representatividade, enquanto que as espécies reprodutoras à sombra tiveram alta representatividade, com 9 das 11 espécies registradas, sendo as responsáveis pelo maior percentual das espécies da MM. Ao contrário, espécies pioneiras e oportunistas foram bem representadas na CA1 e CA2. A CA1 e CA2 abrangeram 5 e 3 espécies pioneiras e 8 e 7 espécies oportunistas, respectivamente, do total de 6 espécies pioneiras e 13 espécies oportunistas registradas, sendo estas espécies responsáveis por mais da metade do total das espécies destas eco-unidades (Tabela 8).

Tabela 8 - Percentual de espécies de cada grupo ecológico nas 4 eco-unidades em 1995 e 1996. Números entre parênteses refere-se ao numero absoluto de espécies.

\begin{tabular}{ccc|cc|cc|cc}
\hline \multirow{2}{*}{ Econeiras } & \multicolumn{2}{c|}{ Oportunistas } & \multicolumn{2}{|c|}{ Tolerantes } & \multicolumn{2}{|c}{ Rep. à Sombra } \\
Eco & 1995 & 1996 & 1995 & 1996 & 1995 & 1996 & 1995 & 1996 \\
\hline CB & $25,0(1)$ & $25,0(1)$ & $50,0(2)$ & $50,0(2)$ & 0 & 0 & $25,0(1)$ & $25,0(1)$ \\
CA1 & $16,7(3)$ & $23,8(5)$ & $44,4(8)$ & $38,1(8)$ & $5,6(1)$ & $4,8(1)$ & $33,3(6)$ & $33,3(7)$ \\
CA2 & $17,6(3)$ & $15,0(3)$ & $35,3(6)$ & $35,0(7)$ & $5,9(1)$ & $5,0(1)$ & $41,2(7)$ & $45,0(9)$ \\
MM & 0 & 0 & $18,2(2)$ & $15,4(2)$ & $9,1(1)$ & $15,4(2)$ & $72,7(8)$ & $69,2(9)$ \\
\hline \hline
\end{tabular}

A representatividade grupo das espécies reprodutoras à sombra na $\mathrm{MM}$ pode ser sentida não apenas em número de espécies como também com relação à sua densidade (Tabela 9). Estas perfizeram $72,4 \%$ e $72,7 \%$ dos indivíduos nesta ecounidade em 1995 e 1996, respectivamente. Ao contrário, as espécies pioneiras e oportunistas abrangeram o maior percentual dos individuos na $\mathrm{CA} 1 \mathrm{e} \mathrm{CB}$, perfazendo ambas $75,4 \%$ e $85,8 \%$ em 1995 e $72,5 \%$ e $85,8 \%$ em 1996. A CA2, por sua vez, apresentou uma maior eqüidade dos grupos ecológicos. Como ocorreu para a classe > $5 \mathrm{~cm}$ de DAP, também as distribuições observadas de todos os grupos ecológicos diferiram das distribuições esperadas entre as eco-unidades em ambos os períodos 
(Tabela 9).

Tabela 9 - Densidade relativa de cada grupo ecológico nas 4 eco-unidades em 1995 e 1996. Números entre parênteses refere-se à estimativa do número de indivíduos por hectare. Os valores de $\mathrm{G}$ são mostrados para os quatro grupos ecológicos (" $\mathrm{P}<0,01$, $0,01<P<0,05)$.

\begin{tabular}{ccc|cc|cc|cc}
\hline \multicolumn{4}{c}{ Pioneiras } & \multicolumn{2}{c|}{ Oportunistas } & \multicolumn{2}{c|}{ Tolerantes } & \multicolumn{2}{c}{ Rep. à Sombra } \\
Eco & 1995 & 1996 & 1995 & 1996 & 1995 & 1996 & 1995 & 1996 \\
\hline CB & 42,9 & 42,9 & 42,9 & 42,9 & 0 & 0 & 14,2 & 14,2 \\
& $(476,2)$ & $(476,2)$ & $(476,2)$ & $(476,2)$ & & & $(158,7)$ & $(158,7)$ \\
CA1 & 38,6 & 29,0 & 36,8 & 43,5 & 8,8 & 7,3 & 15,8 & 20,3 \\
& $(873,0)$ & $(793,7)$ & $(833,3)$ & $(1190,5)$ & $(198,4)$ & $(198,4)$ & $(357,1)$ & $(555,55)$ \\
CA2 & 13,3 & 9,8 & 26,7 & 29,4 & 24,4 & 25,5 & 35,6 & 35,3 \\
& $(555,5)$ & $(463,0)$ & $(1111,1)$ & $(1388,9)$ & $(1111,1)$ & $(1203,7)$ & $(1481,4)$ & $(1666,7)$ \\
MM & 0 & 0 & 6,9 & 6,1 & 3,5 & 6,1 & 72,4 & 72,7 \\
& & & $(138,9)$ & $(277,8)$ & $(138,9)$ & $(277,8)$ & $(2916,7)$ & $(3333,3)$ \\
\hline$G$ & 10,58 & $10,51^{*}$ & $9,27^{*}$ & $11,61^{\prime \prime}$ & 16,61 & 19,76 & 37,36 & 36,74 \\
\hline \hline
\end{tabular}

\section{DISCUSSÃO}

Os resultados deste estudo indicam a existência de uma clara diferenciação na riqueza, diversidade e composição de espécies entre as quatro eco-unidades aqui identificadas.

A MM representa os locais mais bem conservados dentro do fragmento, seja do ponto de vista fisionômico, como em relação à riqueza, diversidade e composição de espécies. Analisando separadamente esta eco-unidade e a CA2, diferentes padrões de composição de espécies e processo sucessional entre estas eco-unidades podem ser avaliados. Diferentemente da CA2, que embora tenha apresentado semelhante riqueza e diversidade, a MM apresentou uma alta representatividade de espécies típicas de comunidades maduras (tolerantes e reprodutras à sombra). Considerando os indivíduos adultos (>=5 cm de DAP), a alta área basal desta eco-unidade é resultado da contribuição das espécies tolerantes (Figura 3), e as espécies reprodutoras à sombra contribuíram signicativamente com a densidade (Tabela 5). Ao contrário, na CA2 as espécies oportunistas foram responsáveis pela maior contribuição em áreal basal e estas espécies mais as espécies pioneiras pela densidade. Para os indivíduos 
jovens, da mesma forma, ambas eco-unidades diferenciaram-se quanto à representatividade dos grupos ecológicos. Este padrão é explicado pelo maior nivel de sombreamento que ocorre na MM, impedindo a germinação e crescimento de espécies pioneiras e oportunistas, podendo ser constatado pelo baixo recrutamento e baixa densidade de individuos jovens dessas espécies (tabelas 6 e 9). Na CA2, como um ambiente mais aberto, e conseqüentemente uma maior penetração de luz, espécies pioneiras e oportunistas são beneficiadas por esta condição. Para a regeneração de árvores em florestas tropicais, as diferentes condições de luz têm sido enfatizadas como o principal efeito sobre a germinação, estabelecimento e crescimento (Augspurger, 1984; Howe, 1990; Turner, 1990). Além disso, devido que a CA2 apresentam uma alta densidade de cipós, espécies pioneiras e oportunistas estão mais aptas a escapar da competição com os cipós por causa de suas altas taxas de crescimento em ambintes de maior luminosidade (Tabanez, 1995). Embora espécies tolerantes e reprodutoras à sombra possam também regenerar nesta eco-unidade, elas não crescem muito rápido e portanto sofrem mais a competição com os cipós, não favorecendo seu estabelecimento. Na MM, ao contrário, cipós são mais raros e dessa forma espécies de crescimento lento tem maior chance de sobrevivência.

B. forficata e A.virgata foram as responsáveis pela alta densidade em 1991 e 1995, além de perfazerem o maior percentual de recrutamento na CB e CA1. Além disso, $T$. micrantha apresentou uma densidade relativamente alta nestas eco-unidades em 1991. Catharino (1989) e Lorenzi (1992) relatam que B. forficata e A. virgata são espécies típicas de formações secundárias, como capoeiras, comuns no inicio da sucessão, sendo rara a ocorrência dessas espécies no interior de matas primárias densas e freqüente a ocorrência em bordas de mata. T. micrantha exerceu a maior dominância das espécies arbóreas logo após incêndio em uma floresta estacional semidecidual (Castellani \& Stubblebine 1993) e foi encontrada em capoeiras abandonadas na Amazônia Central que sofreram queimadas (Rankin-de-Merona \& Ackerly 1987, Uhl et al. 1988). Em outro fragmento aqui da região, esta espécie foi também encontrada dominando a área dois anos após um incêndio ocorrido em agosto de 1994 (H. E. M. Nascimento, observação pessoal). O poder germinativo de $A$. virgata aumenta significativamente quando suas sementes são submetidas à uma maior temperatura, com uso de fogo (André da S. Dias, comunicação pessoal). Portanto, 
baseado na presença de $T$. micrantha, na alta densidade e alto percentual de recrutamento de $B$. forficata e $A$. virgata e por os trechos de CB e CA1 serem vizinhos, sugere-se que as áreas que sofreram maiores intensidades dos incêndios ocorridos (cerca de 15-20 anos) evoluíram para o que aqui está sendo chamado de eco-unidades CB e CA1. Estas duas ecounidades diferenciam-se, como revelado anteriormente, quanto à fisionomia, que neste caso a CA1 se assemelha à CA2, com uma maior densidade de indivíduos, área basal e menor densidade e cobertura foliar de cipós que a CB.

Os resultados mostram que o processo de sucessão secundária após distúrbios parece não está atuando na CB e CA1. Isto pode ser constatado pelo alto recrutamento de espécies pioneiras (tabela 6), e pela baixa densidade de regeneração natural (tabela 7). Os distúrbios são considerados como agentes determinantes da estrutura de comunidade em florestas tropicais. A coexistência de grandes números de espécies arbóreas tropicais tem sido freqüentemente atribuida à resposta diferencial de regeneração das espécies ao distúrbio (Martinez -Ramos, 1985; Denslow, 1987). As características de distúrbios como o tipo e a frequência irão determinar o nível de heterogeneidade ambiental a ser formados pós-distúrbio (Bazzaz, 1983). Dessa forma, vários tipos de microhabitats podem ser formado após o distúrbio, os quais diferem em conteúdo de nutrientes, luminosidade, temperatura, umidade do solo, que em última análise irão recrutar espécies com diferentes requerimentos de regeneração (Orians, 1982). Dentro deste contexto, uma pequena clareira formada por queda de galhos é entendida como sendo menos heterogênea do que uma grande clareira formada por queda de árvores e os distúrbios severos, como o caso do fogo, criam ambientes ainda mais homogêneos (Bazzaz, 1983). A capacidade de rebrota a partir de tecidos subterrâneos tem sido documentada como uma das formas de regeneração após fogo para algumas espécies arbóreas tropicais na Amazônia Oriental (sensu Kauffman, 1991). De fato, Rodrigues et al. (1991) mostraram que $B$. forficata apresenta propagação vegetativa a partir de raizes gemiferas, com brotamento a até três metros da planta-mãe. Este estudo foi realizado também em uma floresta estacional semidecidua, cinco meses após a ocorrência de incêndio, evidenciando a capacidade de sobrevivência e estabelecimento desta espécie em áreas queimadas. 
A vizinhança biológica da área pertubada influencia na sua colonização. Alta diversidade da vizinhança biológica oferece uma variedade de colonizadores com diferentes capacidades e requerimentos de regeneração, enquanto uma vizinhança depauperada dificulta o processo de regeneração (Bazzaz, 1983). Desse modo, a colonização da $\mathrm{CB}$ e CA1 dependerá quase que exclusivamente da $\mathrm{MM}$, pois o isolamento que a Mata do Pomar apresenta de outras áreas de floresta torna praticamente inviável o fluxo de sementes vindo de outros fragmentos. Em pastagens abandonadas próximas à áreas de floresta que haviam sofrido corte e queimadas sucessivas, na Amazônia Oriental, Uhl et al. (1988) mostraram que, após oito anos de abandono destas pastagens, embora ainda houvesse uma dominância relativamente alta de cinco espécies pioneiras, já percebia-se uma estrutura florestal característica com relativa riqueza de espécies e alta densidade de regeneração (altura $<2 \mathrm{~m}$ ).

Se os distúrbios favorecerem a ocorrência de espécies"de cipós, o processo sucessional poderá ser retardado (sensu Uhl et al., 1988). Os cipós na CB cobrem completamente o solo, impedindo a germinação e estabelecimento de espécies arbóreas, constatado pela baixa densidade de individuos jovens nesta eco-unidade (tabela 7). Esta característica pode ser considerada como indicativo do estado de degradação desta eco-unidade. A presença marcante de cipós em florestas tropicais está relacionada à áreas tipicamente degradadas (Pinard \& Putz, 1994). Em fragmentos florestais, a falta de recrutamento de espécies arbóreas em certas áreas tem sido atribuída aos cipós (Tabanez, 1995; Turner et al., 1996). De fato, em áreas de CB que sofreram corte de cipós, Tabanez (1995) mostrou que, trinta dias após o corte, a densidade de plântulas $>5 \mathrm{~cm}$ e $<150 \mathrm{~cm}$ de altura triplicou em relação às áreas de $\mathrm{CB}$ que não tinham sofridos corte de cipós.

\section{CONCLUSÕES}

Atualmente, os fragmentos de floresta estacional semidecidual do interior de São Paulo não são simplesmente pequenos fragmentos isolados. Estes fragmentos foram $e$ são também resultado de pertubações antropogênicas, pincipalmente fogo, extração madereira e caça. Em função destas pertubações, o diagnóstico destes fragmentos, a partir da Avaliação Ecológica Rápida, permite caracterizá-los como um mosaico de ecounidades que indicam diferentes graus de conservação da estrutura florestal. Os 
resultados deste estudo mostram um alto empobrecimento biológico do fragmento Mata do Pomar, revelado pelo grande percentual de área ocupada por ecounidades degradadas. $O$ uso destas eco-unidades serve para definir diferentes estratégias de restauração nestes fragmentos florestais.

Um conjunto de características simples e facilmente reconheciveis permite avaliar o estado de conservação de um determinado fragmento de floresta estacional semidecidual. Este fato é importante na medida em que este método possa ser aplicado por pessoas sem conhecimentos teóricos, após algumas horas de treinamento. É especialmente importante também para organizações governamentais e não-governamentais engajadas na restauração e conservação destes fragmentos florestais. 
Apêndice 1 - Listagem das espécies e suas respectivas categorias sucessionais para os individuos $\geq 5 \mathrm{~cm}$ de DAP, referente aos levantamentos de 1991 e 1995 dos dois transectos.

\begin{tabular}{|l|l|}
\hline \hline \multicolumn{1}{|c|}{ PIONEIRAS } & \multicolumn{1}{c|}{ OPORTUNISTAS } \\
Alcornea urucurana & Acacia polyphylla \\
Aloysia virgata & Astronium graveolens \\
Bauhinia forficata & Bastardiopsis densiflora \\
Casearia sylvestris & Balfourodendron riedelianum \\
Cecropia hololeuca & Centrolobium tomentosum \\
Cestrum laevigatum & Chorisia speciosa \\
Croton urucurana & Cordia trichotoma \\
Guazuma ulmaefolia & Croton floribundus \\
Piper cf. aduncum & Croton salutaris \\
Solanum granulosum-leprosum & Enterolobium contortisiliquum \\
Solanum swartzianum & Lonchocarpus guilleminianus \\
Trema micrantha & Lonchocarpus muehlembergianus \\
Urera baccifera & Machaerium stipitatum \\
Vernonia polyanthes & Machaerium vestitum \\
Zanthoxylum cf. chiloperone & Matayba eleagnoides \\
Zanthoxylum rhoyfolium & Nectandra megapotamica \\
REPRODUTORAS SOMBRA & Patagonula americana \\
Campomanesia guazumifolia & Pseudobombax grandiflorum \\
Chrysophyllum gonocarpum & Piptadenia gonoacantha \\
Eugenia cf. moraviana & Schizolobium parahyba \\
Galipea multiflora & Seguieria langsdorffii \\
Guarea macrophylla & TOLERANTES \\
Metrodorea nigra & Citronella paniculata \\
Trichilia catigua & Copaifera langsdorfii \\
Trichilia pallida & Ficus sp. \\
\hline \hline & Gallesia integrifolia \\
& Holocalyx balansae \\
& NÄO CLASSIFICADA \\
\hline
\end{tabular}


Apêndice 2 - Listagem das espécies e suas respectivas categorias sucessionais para os individuos $\geq 50 \mathrm{~cm}$ de altura e $<5 \mathrm{~cm}$ de DAP na Mata do Pomar, referente aos levantamentos de 1995 e 1996.

\begin{tabular}{|c|c|}
\hline PIONEIRAS & $\overline{\text { OPORTUNISTAS }}$ \\
\hline Aloysia virgata & Bastardiopsis densiflora \\
\hline Bauhinia forficata & Centrolobium tomentosum \\
\hline Solanum swartzianum & Chorisia speciosa \\
\hline Trema micrantha & Croton floribundus \\
\hline Urera baccifera & Cupania vernalis \\
\hline Zanthoxylum rhoyfolium & Lonchocarpus guilleminianus \\
\hline REPRODUTORAS SOMBRA & Lonchocarpus muehlembergianus \\
\hline Campomanesia guazumifolia & Machaerium stipitatum \\
\hline Chrysophyllum gonocarpum & Machaerium vestitum \\
\hline Esenbeckia fefrifuga & Maytenus aquifolia \\
\hline Eugenia cf. moraviana & Nectandra megapotamica \\
\hline Galipea multiflora & Pseudobombax grandiflorum \\
\hline Guarea macrophylla & TOLERANTES \\
\hline Metrodorea nigra & Gallesia integrifolia \\
\hline Myrtaceae & Holocalyx balansae \\
\hline Trichilia catigua & NÄO CLASSIFICADA \\
\hline Trichilia elegans & Inga marginata \\
\hline Trichilia pallida & \\
\hline
\end{tabular}




\section{CAPITULO 3}

\section{SÍNDROMES DE DISPERSÃO E SUA RELAÇÃO COM A DINÂMICA DA VEGETAÇÃO ARBÓREA EM UM FRAGMENTO DE FLORESTA ESTACIONAL SEMIDECIDUAL.}

\section{1 - INTRODUÇÃO}

A dispersão de sementes envolve qualquer mecanismo por meio do qual as sementes são transportadas da planta-mãe até uma superfície (Chambers \& MacMahon, 1994). Nas florestas tropicais as espécies arbóreas produzem frutos e sementes com modificações para a dispersão através do vento (anemocoria), animais (zoocoria) e a auto-dispersão (autocoria) (Howe \& Smallwood, 1982). Os animais vertebrados, especialmente os pássaros, são os principais agentes da dispersão de sementes das espécies de árvores tropicais (Howe \& Smallwood, 1982; Levey et al., 1994).

É clara a importância dos frutos e das sementes tropicais como recurso alimentar para muitas espécies de pássaros e mamiferos bem como a importância destes para a dispersão de sementes (Howe \& Smallwood, 1982; Levey et al., 1994). A base teórica para explicar a alta diversidade de frutos e frugivoros está baseada na coevolução, isto é, existe um contínuo de dependência evolucionária e ecológica entre os frugivoros e as árvores (Howe, 1993; Levey et al., 1994). No início deste contínuo, estão as espécies especialistas. As plantas deste grupo, geralmente, devido a uma baixa fắcundidade, têm uma baixa produção de frutos e sementes grandes, altamente nutritivos (alto teor de lipídios e proteinas). Para estas espécies, a dispersão é crítica para o recrutamento. As longas estações de frutificação atraem um conjunto limitado de dispersores, de tamanho freqüentemente grande, que dependem quase que exclusivamente de frutos e de sementes na sua dieta, e utilizam poucas espécies de frutos por dia (Howe, 1993). No outro extremo, estão as espécies 
generalistas. Neste grupo as plantas têm uma alta produção de frutos e sementes pequenas, e com alto teor de água e açúcares. As curtas estações de frutificação destas espécies atraem pequenos frugivoros com grande tamanho populacional, que visitam muitas espécies de plantas por dia e para os quais os frutos e as sementes complementam a sua dieta (Howe, 1993).

Conforme os habitats naturais são destruidos pelo homem, eles tornam-se fragmentados e seus componentes populacionais são sub-divididos e reduzidos em tamanho (Bierregaard et al., 1992). Algumas espécies de animais são mais susceptíveis à rápida extinção em função da fragmentação do que outras. Alguns autores (Terborgh, 1986; Laurance, 1991a; Estrada et al. 1993) hipotetizam que animais frugivoros especialistas em recurso alimentar tendem a ser raros e, portanto, apresentam alta vulnerabilidade à fragmentação e isolamento do habitat, além de, poderem ser ameaçados por mudanças na composição florística dos fragmentos. Por outro lado, as espécies de frugivoros generalistas podem continuar a sobreviver em uma paisagem fragmentada. A extinção de animais frugivoros pode acarretar uma mudança imediata na composição das espécies da floresta, nas características demográficas das populações e na relação espacial dos indivíduos de cada espécie de planta (Janzen, 1980; Tumer, 1996).

Dessa forma, a forte relação de dependência entre algumas espécies de animais especialistas e as plantas em florestas tropicais sugere que o impacto da extinção local de uma determinada espécie de planta ou animal pode ser estendida para todo um "sistema" de dispersão (Howe, 1984, 1990). A extinção local de Casearia corymbosa na Costa Rica, por exemplo, pode por em risco as populações de algumas espécies de pássaros (Howe, 1984). Esta espécie é referida como "espécie-chave" pois fornece recurso alimentar para a avifauna em épocas de escassez de alimento na floresta (Howe, 1984). Se estas espécies de pássaros fossem extintas ou reduzissem seus tamanhos populacionais, o recrutamento de outras espécies de árvores que produzem frutos em outras épocas do ano estaria ameaçado (Howe, 1984, 1990).

A compreensão de como a fragmentação afeta processos ecológicos envolvendo populações de plantas e animais e como isto pode influenciar na persistência das espécies à longo prazo é um dos maiores desafios da biologia da 
conservação (Thébaud \& Strasberg, 1997). Na escolha de um determinado processo, foi assumido que a dispersão de sementes é essencial para a manutenção de populações de espécies arbóreas à longo prazo em fragmentos florestais. Especialmente em fragmentos isolados há muitas décadas, a densidade de plântulas e arvoretas e o ingresso de novos individuos podem fomecer importantes indícios sobre os possiveis efeitos da fragmentação sobre a interação planta-dispersor.

Neste trabalho, foi feita uma análise da relação entre as sindromes de dispersão e o recrutamento de indivíduos $\geq 5 \mathrm{~cm}$ de DAP e a densidade da regeneração natural (individuos $\geq 50 \mathrm{~cm}$ de altura e $<5 \mathrm{~cm}$ de DAP) de espécies arbóreas em um fragmento de Floresta Estacional Semidecidual de 9,5 ha, localizado em Piracicaba, SP. Foi analisada a seguinte questão: Existe relação entre as sindromes de dispersão de sementes com o recrutamento e a densidade de regeneração das espécies arbóreas ? A hipótese é que as síndromes diferem com relação ao número de indivíduos recrutados e densidade de regeneração. Se a fragmentação afeta a dispersão de propágulos e o posterior estabelecimento de espécies arbóreas, então as predições são de que as espécies que são dominantes na regeneração natural ou apresentaram recrutamento são: a) generalistas com relação aos animais dispersores, ou b) autocóricas ou anemocóricas.

\section{2 - MATERIAL E MÉTODOS}

\section{1 - Caracterização da área}

O municipio de Piracicaba localiza-se na depressão periférica do estado de São de Paulo, apresentando relevo suavemente ondulado, com altitude em torno de 500 metros, situando-se nas coordenadas $22^{\circ} 47^{\prime} \mathrm{S}$ e $47^{\circ} 49^{\prime} \mathrm{W}$. Segundo levantamento feito no Departamento de Meteorologia da Escola Superior de Agricultura Luiz de Queiroz (ESALQ/USP), para o periodo de 1990-1996, a pluviosidade média anual foi de cerca $1430 \mathrm{~mm}$, distribuidas irregularmente durante o ano. O período de maior precipitação coincide com o periodo mais quente, outubro a março (média de $184 \mathrm{~mm}$ ), e o periodo de menor precipitação coincide com o período mais frio, abril a setembro (média de $50 \mathrm{~mm}$ ). A temperatura média do período mais quente foi de $25^{\circ} \mathrm{C}$ e do periodo mais frio, $17^{\circ} \mathrm{C}$, para o intervalo de 1990 à 1996. 
A vegetação natural da região é classificada pelo Sistema Fitogeográfico Brasileiro como Floresta Estacional Semidecidual (IBGE, 1992). Caracteriza-se pela mistura de espécies caducifólias, que perdem suas folhas no período seco, e perenifólias. Entre as espécies típicas de dossel destacam-se: Aspidosperma polyneuron, Astronium graveolens, Balfourodendron riedelianum, Chorisia speciosa, Cariniana legalis e C. estrellensis. No sub-dossel tem-se Esenbeckia febrifuga, Galipea multiflora, Metrodorea nigra, Trichilia catigua, T. elegans e T. pallida como as espécies mais representativas.

A paisagem de Piracicaba está atualmente dominada pela monocultura da cana-de-açúcar, onde a vegetação original foi reduzida a pequenos fragmentos. Apenas $2,1 \%$ da cobertura florestal nativa ainda persiste, distribuidos em cerca de 102 fragmentos, sendo que os pequenos fragmentos (menor que 50 ha) compreendem $89,9 \%$ do total (Viana et al., 1997).

\section{2 - Descrição da área experimental}

$O$ fragmento em estudo está localizado dentro do campus da ESALQ/USP. Sua área é de aproximadamente 9,5 ha. Esta floresta é uma área de reserva da ESALQ, conhecida como Mata do Pomar. Em mapa datado de 1894, este fragmento era parte de uma maior área de floresta, que progressivamente foi sendo derrubada em diferentes épocas para dar lugar às culturas de café, cana-de açúcar e algodão e à instalação dos edifícios da ESALQ (Catharino, 1989).

Este fragmento sofreu, nas três últimas décadas, dois grandes incêndios, tendo o último ocorrido entre 15 e 20 anos atrás, queimando cerca de $20-30 \%$ de sua área, além de ter havido extração madeireira em passado relativamente recente, há cerca de 30 anos (Tabanez et al., 1997).

\section{3 - Obtenção dos dados}

O recrutamento das árvores foi obtido com o uso de dois transectos perpendiculares entre si, com 10 metros de largura, que vão de uma borda à outra do fragmento (Figura 1). Os dois transectos correspondem à uma área amostral de 5805 $\mathrm{m}^{2}(6,3 \%$ da área total do fragmento). No mês de julho do ano de 1991 , todas as 
ánores com DAP (diâmetro altura do peito) igual ou superior a $5 \mathrm{~cm}$ foram mapeadas, etiquetadas, identificadas, e tiveram seus DAP's medidos. No mês de julho de 1995, todas as árvores anteriormente existentes foram novamente medidas e os novos ingressos tiveram medidos seus DAP's, etiquetados, mapeados e identificados.

Para o estudo dos individuos jovens, 55 parcelas de $3 \times 3 \mathrm{~m}\left(9 \mathrm{~m}^{2}\right)$ foram instaladas a 1 metro da picada que divide os transectos ao meio (Figura 1). Nessas parcelas, alocadas sistematicamente em intervalos regulares, todos os individuos arbóreos maiores ou igual a $50 \mathrm{~cm}$ de altura e menores que $5 \mathrm{~cm}$ de DAP foram levantados em dois periodos. O primeiro levantamento foi realizado em dezembro de 1995 e o segundo, em dezembro de 1996, correspondendo a um intervalo de 1 ano.

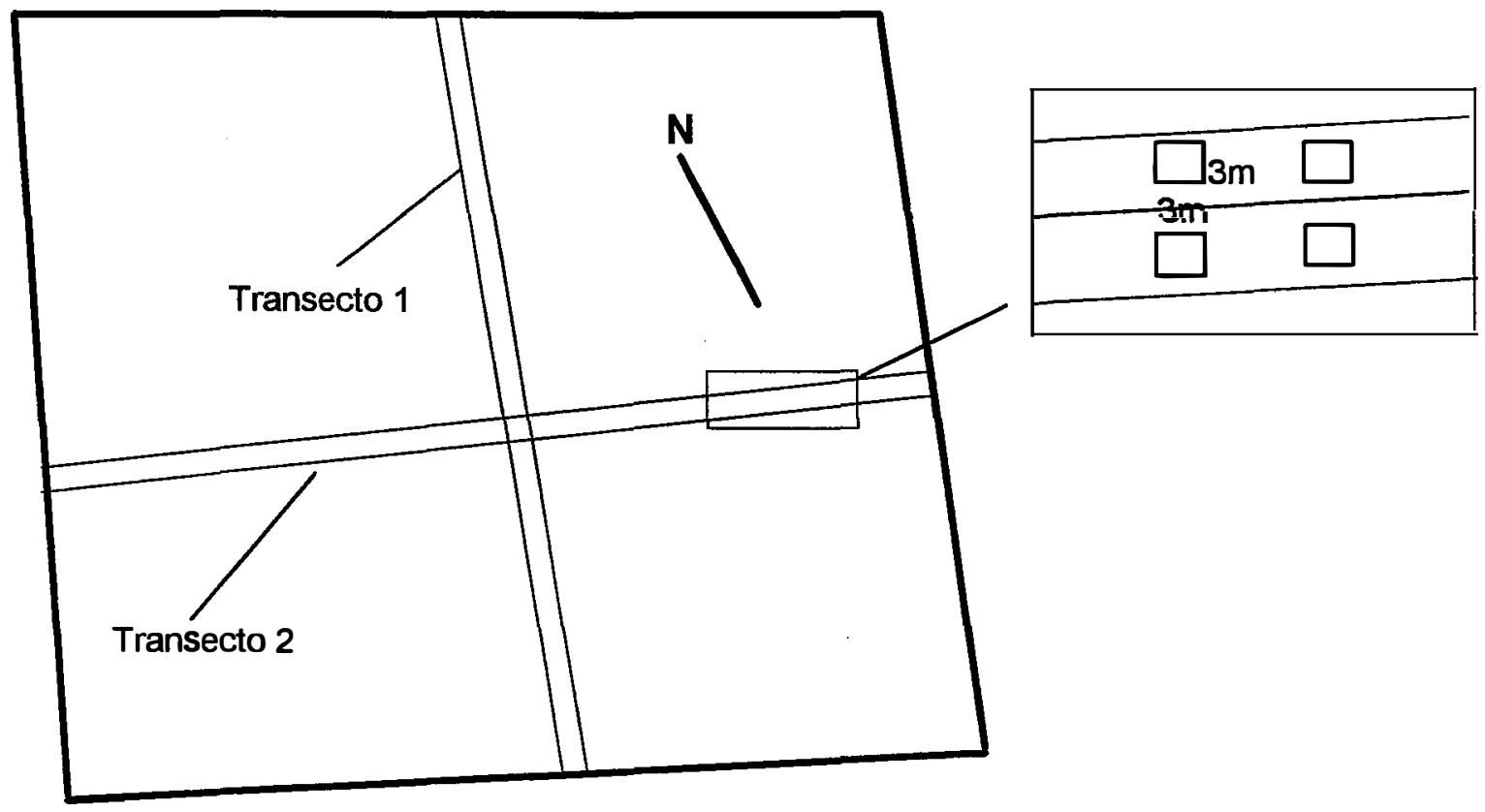

Figura 1 - Croqui da Mata do Pomar mostrando a localização dos dois transectos e as parcelas de regeneração natural.

As sindromes de dispersão para as espécies foram obtidas com base em levantamento bibliográfico. Para isto, foi utlizado o trabalho de Morelato (1991), que apresenta uma ampla caracterização dos principais mecanismos de dispersão de várias espécies arbóreas em outro fragmento de Floresta Estacional Semidecidual, baseado nas caracteristicas morfológicas dos frutos e sementes. Outros trabalhos 
consultados foram: Morelato \& Leitão-Filho (1992), Lorenzi (1992), Carvalho (1994). e de Hasui (1994) o qual apresenta uma lista de espécies arbóreas ornitocóricas de um fragmento de floresta estacional Semidecidual.

As espécies arbóreas encontradas no fragmento foram agrupadas em categorias sucessionais segundo a classificação proposta por Viana (1989). Este autor agrupou as espécies em pioneiras, oportunistas, tolerantes e reprodutoras à sombra. As pioneiras são espécies que normalmente têm sementes de grande longevidade e que exigem a formação de clareiras para germinação e dependem destas durante todo o seu ciclo de vida. As oportunistas são espécies com sementes que não requerem clareiras para germinar, com plântulas que sobrevivem à sombra, mas que dependem de aberturas do dossel para atingir o estágio reprodutivo. As tolerantes têm sementes que também não necessitam de clareiras para germinar, as plântulas podem crescer até o estágio juvenil sem a presença de clareiras, mas dependem destas para alcançar o estágio reprodutivo. As reprodutoras à sombra têm sementes que não necessitam de clareiras para germinar, crescem até o estágio adulto sob sombra e se reproduzem nesta mesma condição.

As espécies foram enquadradas nestas categorias sucessionais baseado no enquadramento em outras categorias realizado por diversos autores e por observações de campo. Esta não é uma classificação definitiva. O seu objetivo foi possibilitar uma análise da relação entre as diferentes sindromes de dispersão e os diferentes grupos ecológicos. A pequena quantidade de informações referentes à biologia de muitas espécies tropicais limita o enquadramento preciso das espécies em grupos ecológicos. Isso tem resultado numa classificação diferenciada entre autores para algumas espécies.

\section{3 - RESULTADOS}

\section{1 - Recrutamento (Indivíduos $\geq 5 \mathrm{~cm}$ de DAP que ingressaram em 1995).}

\subsection{1 - Proporção dos Grupos Ecológicos nas Síndromes.}

A anemocoria e zoocoria compreenderam o maior número das espécies que apresentaram recrutamento entre 1991 e 1995, com 13 e 14 espécies, respectivamente, ao passo que autocoria compreendeu apenas quatro espécies. As 
pioneiras e oportunistas foram os grupos sucessionais que mais recrutaram no periodo. Estes grupos compreenderam 24 espécies (11 pioneiras e 13 oportunistas), enquanto que apenas duas espécies tolerantes e quatro espécies reprodutoras sombra apresentaram recrutamento. Houve uma grande variação dos grupos ecológicos entre os modos de dispersão (Figura 2). A anemocoria compreendeu um grande número de espécies oportunistas, enquanto que as espécies pioneiras e reprodutoras sombra foram melhores representadas pela autocoria $e$, principalmente, pela zoocoria. Noventa e dois porcento das espécies anemocóricas são oportunistas (12 espécies) e 61,5\% das espécies zoocóricas são pioneiras (8 espécies) (Figura 2).

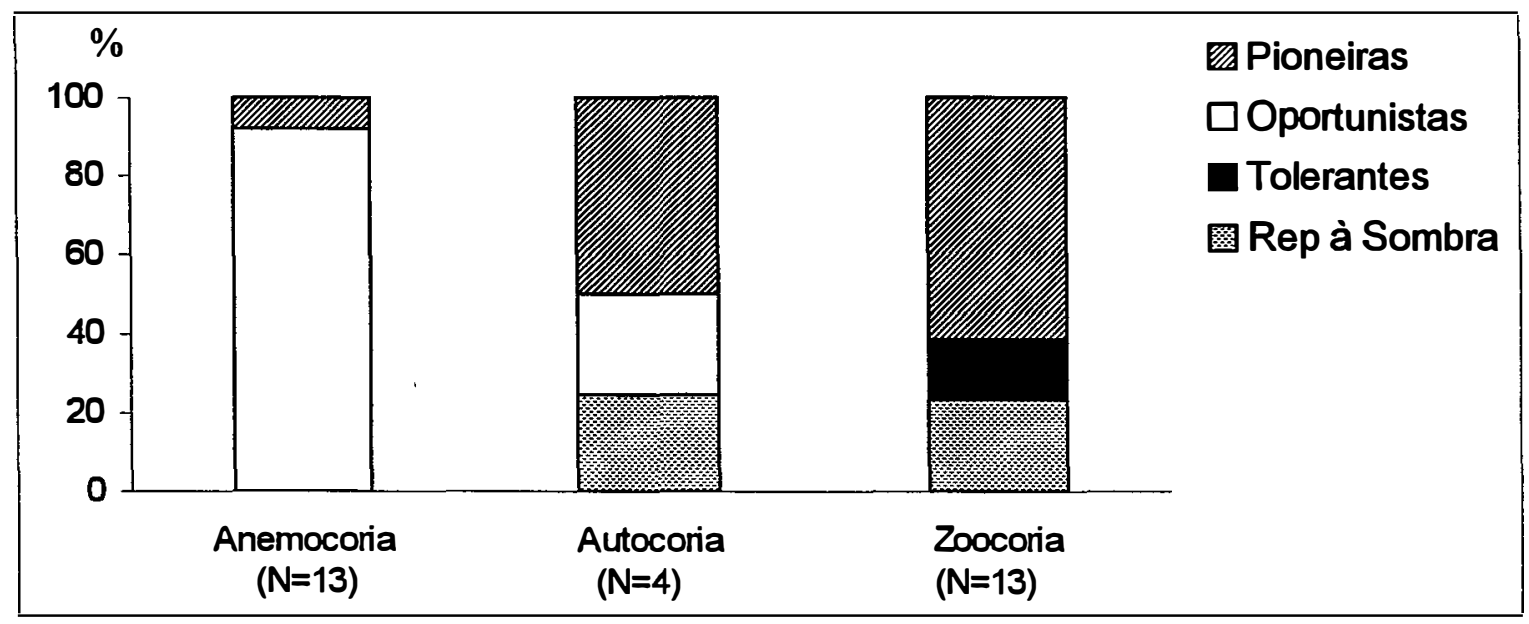

Figura 2 - Distribuição do percentual de espécies por grupo ecológico para cada sindrome de dispersão das espécies que recrutaram entre 1991 e 1995.

\subsection{2 - Número de Individuos Recrutados por Síndrome e Grupo Ecológico.}

Embora com um baixo número de espécies que recrutaram no periodo de 1991 a 1995, a autocoria foi bem representada em número de individuos recrutados (Figura 3). Para a autocoria, 39,1\% dos individuos recrutados pertencem esta sindrome, $36,9 \%$ anemocoria, ao passo que a zoocoria contribui com apenas $24,0 \%$ do total recrutamento.

Para cada sindrome, a contribuição das diferentes espécies e dos grupos sucessionais em termos de individuos recrutados foi bastante desigual (Figura 3). Para a anemocoria, uma espécie pioneira, Aloysia virgata, a segunda espécie mais comum no fragmento em 1991 e 1995 foi responsável por 23,3\% do recrutamento 
total no período. Uma espécie oportunista, Croton floribundus e uma espécie pioneira, Bahuinia forficata, a espécie mais comum no fragmento em 1991 e 1995 foram as espécies que contribuíram mais para o recrutamento dentro da autocoria. Duas espécies pioneiras, Urera baccifera e Cecropia ololeuca, obtiveram um alto recrutamento dentre as espécies zoocóricas (Figura 3). Com isso, as espécies pioneiras apresentaram o maior recrutamento na zoocoria, e estas espécies mais as espécies oportunistas, foram os grupos que mais contribuíram para o recrutamento das espécies anemocóricas e autocóricas (Figura 3).

\subsection{3 - Variação Temporal do Número de Indivíduos por Síndrome (1991 e 1995).}

Em 1991, as síndromes apresentavam semelhante número de indivíduos, não havendo diferença significativa entre as sindromes $\left(\chi^{2}=2,59,2\right.$ G.L., $\left.P=0,27\right)$. No entanto, como resultado do maior recrutamento obtido pela anemocoria e autocoria, em 1995 ocorreu um aumento no número de indivíduos pertencentes estas síndromes, ao passo que a zoocoria apresentou uma diminuição (Tabela 1). Neste ano, houve diferença altamente significativa entre as síndromes $\left(\chi^{2}=17,68,2\right.$ G.L., $P$ $=0,0001)$.

Tabela 1 - Percentual de indivíduos por síndromes de dispersão para o ano de 1991 e 1995.

\begin{tabular}{c|cc}
\hline Sindrome & 1991 & 1995 \\
\hline Anemocoria & 35,5 & 38,0 \\
Autocoria & 30,0 & 36,6 \\
Zoocoria & 34,5 & 25,4 \\
\hline
\end{tabular}




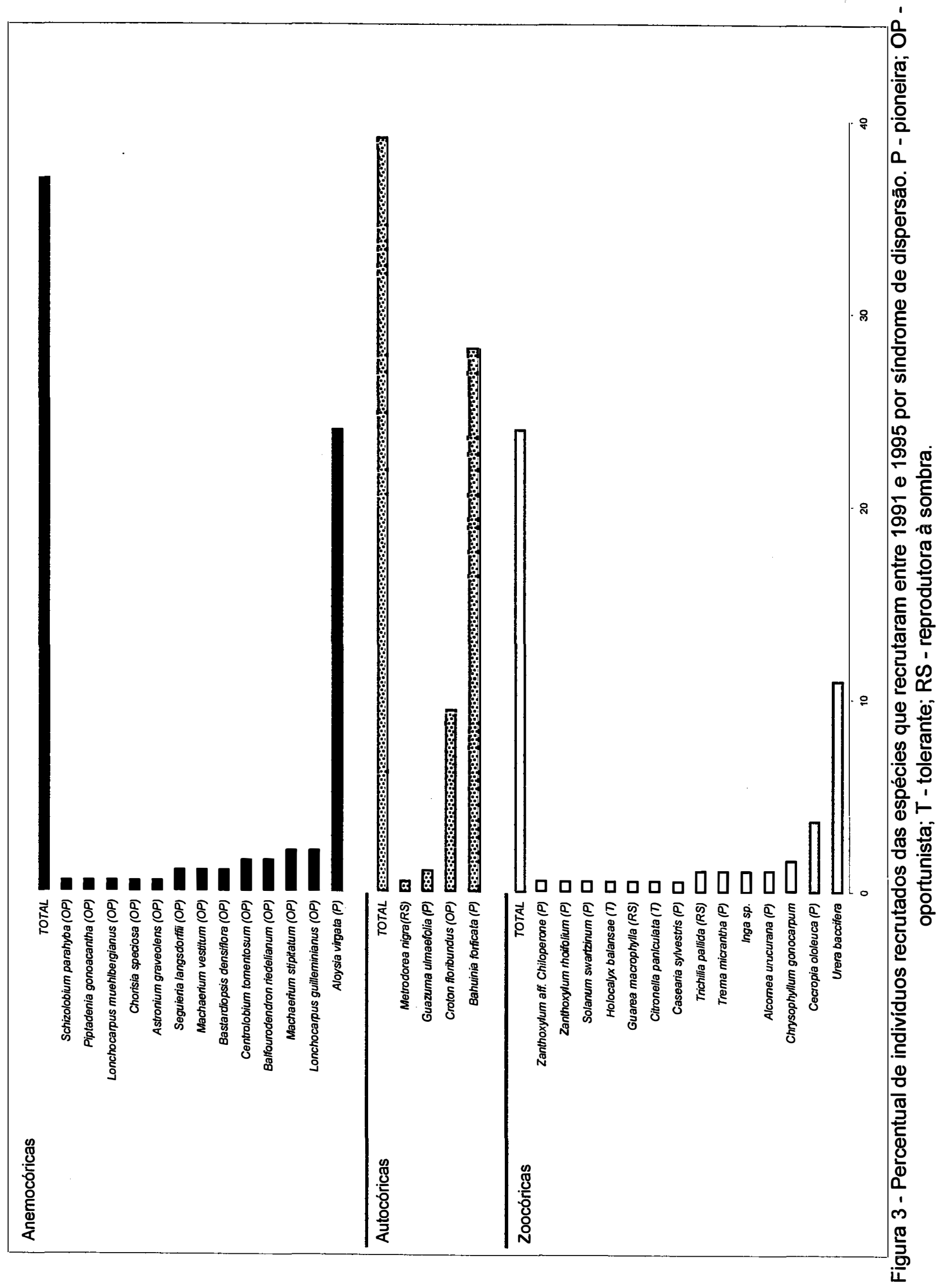




\section{2 - Individuos Jovens (Arvoretas).}

\subsection{1 - Proporção dos Grupos Ecológicos nas Síndromes.}

Padrão semelhante foi obtido pelas arvoretas (indivíduos $\geq 50 \mathrm{~cm}$ de altura $e<$ $5 \mathrm{~cm}$ de DAP presentes em 1995 e/ou 1996) comparativamente ao recrutamento. A anemocoria e a zoocoria compreenderam o maior número de espécies presentes em 1995 e/ou 1996, com 9 e 16 espécies, respectivamente, ao passo que autocoria compreendeu cinco espécies. As pioneiras, oportunistas e as reprodutoras à sombra foram os grupos sucessionais com maior número de espécies nos dois anos. Estes grupos compreenderam 28 espécies (6 pioneiras, 11 oportunistas e 11 rep. à sombra), enquanto que apenas duas espécies tolerantes estavam presentes em 1995 e/ou 1996. Houve uma grande variação dos grupos ecológicos entre os modos de dispersão (Figura 4). Tal como no recrutamento, a anemocoria perfez um grande número de espécies oportunistas, enquanto que as espécies pioneiras e reprodutoras à sombra foram melhores representadas pela autocoria e zoocoria. Setenta e oito por cento das espécies anemocóricas são oportunistas (7 espécies), 50,0\% e 25,0\% das espécies zoocóricas são reprodutoras à sombra (8) e pioneiras (4), respectivamente, e $60 \%$ das espécies autocóricas são reprodutoras à sombra (3 espécies).

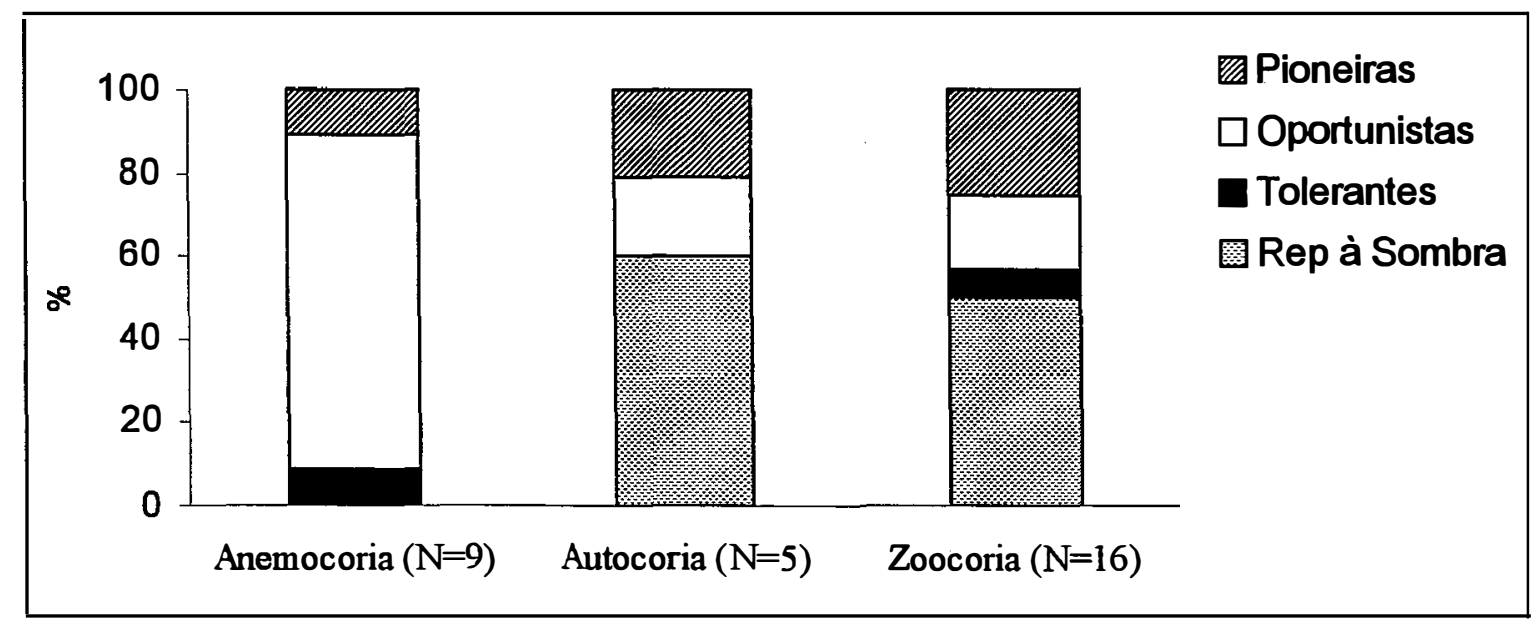

Figura 4 - Distribuição do percentual de espécies por grupo ecológico para cada síndrome de dispersão das espécies presentes nas parcelas de regeneração natural em 1995 e/ou 1996. 


\subsection{2 - Número de Indivíduos Recrutados por Síndrome e Grupo Ecológico.}

Embora com um baixo número de espécies que recrutaram no periodo de 1991 a 1995, a autocoria foi relativamente bem freqüente em termos de número de indivíduos (Tabela 2). A autocoria perfez $27,6 \%$ e $26,5 \%$ do total de indivíduos em 1995 e 1996, respectivamente, e representou $26,5 \%$ dos indivíduos recrutados entre 1995 e 1996. A anemocoria apresentou semelhante proporção de indivíduos em 1995 $(29,1 \%)$ e em $1996(27,1 \%)$ e também representou $26,5 \%$ do recrutamento. A zoocoria, ao contrário, foi a melhor representada com relação à abundância: $43,1 \%$ e 46,4\% dos indivíduos em 1995 e 1996, respectivamente pertencem à esta síndrome (Tabela 2).

Para cada síndrome, a contribuição das diferentes espécies e dos grupos sucessionais com relação à densidade em 1995 e 1996 também foi bastante desigual (Tabela 2). Para a anemocoria, apenas Lonchocarpus muhelbergianus, uma espécie oportunista, foi responsável por 12,8\% e 14,7\% dos indivíduos em 1995 e 1996, respectivamente, como também apresentou alto recrutamento comparativamente às outras espécies anemocóricas. Para a autocoria, Bauhinia forficata, e zoocoria, Holocalyx balansae e Trichilia pallida, foram as espécies que mais contribuíram para a abundância destas síndromes (Tabela 2). As espécies oportunistas apresentaram a maior densidade em 1995 e 1996 dentre as espécies anemcóricas. Por outro lado, as espécies pioneiras e as reprodutoras à sombra na autocoria e as espécies tolerantes e reprodutoras à sombra foram as mais abundantes dentre as espécies zoocóricas (Tabela 2). 
Tabela 2 - Densidades relativa (\%) em 1995 e 1996 e recrutamento por síndromes de dispersão das espécies presentes nas parcelas de regeneração natural. $P$ - pioneira, OP - oportunista, T - tolerante, RS - reprodutoras à sombra.

\begin{tabular}{|c|c|c|c|}
\hline \multirow[b]{2}{*}{ ESPÉCIE } & \multicolumn{2}{|c|}{ Densidade Relativa } & \multirow[b]{2}{*}{ Recrutamento } \\
\hline & 1995 & 1996 & \\
\hline \multicolumn{4}{|c|}{ ANEMOCÓRICAS } \\
\hline Aloysia virgata $(P)$ & 7,8 & 3,6 & 0 \\
\hline Bastardiopsis densiflora (OP) & 0,7 & 0 & 0 \\
\hline Centrolobium tomentosum (OP) & 0,7 & 0,6 & 0 \\
\hline Gallesia integrifolia $(\mathrm{T})$ & 0,7 & 0,6 & 0 \\
\hline Lonchocarpus guilleminianus (OP) & 0,7 & 0,6 & 0 \\
\hline L. muhelbergianus (OP) & 12,8 & 14,7 & 17,6 \\
\hline Machaerium stipitatum (OP) & 3,7 & 4,5 & 5,9 \\
\hline Machaerium vestitum (OP) & 2,2 & 1,9 & 0 \\
\hline Pseudobombax grandiflorum (OP) & 0 & 0,6 & 2,9 \\
\hline $\mathbf{P}$ & 7,8 & 3,6 & 0 \\
\hline OP & 20,8 & 22,9 & 26,4 \\
\hline $\mathbf{T}$ & 0,7 & 0,6 & 0 \\
\hline TOTAL & 29,1 & 27,1 & 26,5 \\
\hline \multicolumn{4}{|c|}{ AUTOCORICAS } \\
\hline Bauhinia forficata (P) & 14,8 & 11,8 & 8,8 \\
\hline Croton floribundus (OP) & 2,5 & 3,2 & 5,9 \\
\hline Esembeckia febrifuga (RS) & 2,2 & 4,5 & 11,8 \\
\hline Galipea multiflora (RS) & 3,7 & 3,2 & 0 \\
\hline Metrodorea nigra (RS) & 4,4 & 3,8 & 0 \\
\hline $\mathbf{P}$ & 14,8 & 11,8 & 8,8 \\
\hline OP & 2,5 & 3,2 & 5,9 \\
\hline RS & 10,3 & 11,5 & 11,8 \\
\hline TOTAL & 27,6 & 26,5 & 26,5 \\
\hline
\end{tabular}




\begin{tabular}{|c|c|c|c|}
\hline \multicolumn{4}{|c|}{ ZOOCÓRICAS } \\
\hline Campomanesia guazumifolia*(RS) & 2,2 & 2,5 & 2,9 \\
\hline Chrysophyllum gonocarpum (RS) & 2,9 & 2,5 & 0 \\
\hline Cupania vernalis (OP) & 0,7 & 0,6 & 0 \\
\hline Eugenia cf. moraviana (RS) & 1,4 & 1,9 & 2,9 \\
\hline Guarea macrophylla (RS) & 2,2 & 2,5 & 2,9 \\
\hline Holocalyx balansae (T) & 11,8 & 12,2 & 8,8 \\
\hline Maytenus aquifolium (OP) & 1,4 & 1,3 & 0 \\
\hline Myrtaceae (RS) & 0 & 1,3 & 5,9 \\
\hline Nectandra megapotamica (OP) & 2,2 & 3,2 & 5,9 \\
\hline Solanum swartzianum $(P)$ & 0,7 & 0,6 & 0 \\
\hline Trema micrantha $(\mathrm{P})$ & 0 & 1,3 & 5,9 \\
\hline Trichilia catigua (RS) & 2,9 & 2,5 & 0 \\
\hline Trichilia cf. elegans (RS) & 4,4 & 4,5 & 2,9 \\
\hline Trichilia pallida (RS) & 7,4 & 6,4 & 0 \\
\hline Urera baccifera $(\mathrm{P})$ & 2,9 & 2,5 & 5,9 \\
\hline Zanthoxylum rhoifolium $(\mathrm{P})$ & 0 & 0,6 & 2,9 \\
\hline $\mathbf{P}$ & 3,6 & 5,0 & 14,7 \\
\hline OP & 4,3 & 5,1 & 5,9 \\
\hline $\mathrm{T}$ & 11,8 & 12,2 & 8,8 \\
\hline RS & 23,4 & 24,1 & 17,5 \\
\hline TOTAL & 43,1 & 46,4 & 46,9 \\
\hline
\end{tabular}

\section{4 - DISCUSSÃO}

O número de indivíduos recrutados e a densidade de regeneração natural diferiram bastante entre as espécies, sugerindo que no fragmento a capacidade de regeneração se distingue entre as diferentes espécies. As diferenças de regeneração entre as espécies de planta é atribuída às características demográficas e quantidade de sítios apropriados para estabelecimento (Harper, 1977). Neste estudo, o número de indivíduos recrutados e a densidade de regeneração natural foram relacionados 
tanto aos grupos sucessionais como aos modos de dispersão. Em outras palavras, embora tenha sido encontrado um grande número de espécies e de indivíduos que independem de vetores animais para a dispersão de sementes (anemocóricas e autocóricas), estas espécies foram em maior número pioneiras e oportunistas. Por exemplo, as espécies pioneiras estavam presentes na anemocoria e na autocoria, como também na zoocoria. Portanto, independentemente das síndromes, as espécies pioneiras e oportunistas mostraram um grande número de indivíduos recrutados entre 1991 e 1995, como também uma alta densidade de regeneração natural em 1995 e 1996. Ou seja, a maioria das espécies e de individuos de espécies pioneiras e oportunistas que recrutou em 1995, foi responsável pelo maior número de espécies e indivíduos anemocóricos, autocóricos e zoocóricos recrutados, pois estas síndromes, são bem representadas pelas espécies pioneiras e oportunistas. Particularmente, uma espécie pioneira, B. forficata, e uma espécie oportunista, C. floribundus, ambas autocóricas, uma espécie pioneira anemocórica, $A$. virgata, e duas espécies pioneiras zoocóricas, $U$. baccifera e $C$. ololeuca, compreenderam $76,5 \%$ do recrutamento no periodo. Para a regeneração natural, o mesmo padrão pode ser observado. Tanto o número de espécies como o número de indivíduos do grupo das espécies pioneiras e oportunistas foram bem distribuidos entre as sindromes para esta classe de tamanho.

Surge então a seguinte pergunta: por que as espécies pioneiras e oportunistas apresentaram um maior número de indivíduos e de espécies? A explicação é que a Mata do Pomar, em função das perturbações antrópicas recentes (incêndios), se mostra como um ambiente mais favorável ao estabelecimento destes grupos de espécies (veja os Capitulos 1 e 2).

A fragmentação florestal, ao promover uma mudança nos padrões de abundância e composição dos vertebrados, coloca algumas dúvidas sobre a expectativa de sobrevivência à longo prazo de muitas espécies de plantas, incluindo aquelas espécies de planta dispersas por animais que ainda são localmente abundantes em fragmentos florestais (Laurance, 1997a). Aparentemente, as espécies dispersadas por animais devem ser incapazes de se ajustarem à perda de seus dispersores, e isto poderia afetar as suas possibilidades de sobrevivência à longo prazo. 
Os estudos têm demonstradoł que as diferentes espécies de vertebrados variam suas respostas à fragmentação. As populações de algumas espécies aumentam, outras declinam ou desaparecem e há ainda aquelas que não são afetadas (Laurance et al., 1997). Algumas caracteristicas ecológicas e peculiaridades de história de vida têm sido associadas à predisposição a extinção local de populações isoladas, incluindo à raridade natural, tamanho dos organismos, mobilidade restrita, baixa fecundidade e a baixa tolerância à matriz que circunda os fragmentos isolados (Laurance, 1991a; Estrada et al., 1993; Sieving \& Karr, 1997; Warbunton, 1997). Newmark (1991), em fragmentos isolados entre 50 a 100 anos na Tanzânia, encontrou uma correlação positiva entre a riqueza de espécies de pássaros e tamanho de fragmento. Um estudo que avaliou a diminuição significativa no número de espécies de pássaros ao longo dos anos e a alta dominância local de algumas espécies foi conduzido em outro fragmento de Floresta Estacional Semidecidual de 250 ha, localizado em Campinas, SP, por Aleixo \& Vielliard (1995). Este trabalho detectou um baixo número de espécies de pássaros (134 espécies), e 30 espécies típicas de interior de floresta foram consideradas extintas localmente. A dominância local das seis espécies mais comuns foi revelada pelos $39,3 \%$ do total dos contatos, percentual superior quando comparado com outro fragmento de maior área e menor grau de isolamento (Aleixo \& Vielliard, 1995). Em Los Tuxtlas, México, Estrada et al. (1993), mostraram que a fragmentação, ao mudar abruptamente o tipo da vizinhança ao redor dos fragmentos isolados, pode afetar diferentemente os grupos de vertebrados. Os grupos animais mais susceptivies à extinção local são aqueles que evitam as áreas de cultivo agrícola ao redor dos fragmentos, incluindo a maioria dos mamiferos terrestres. Na Singapura, uma região onde o processo da fragmentação é um dos mais antigos do mundo, Corlett \& Turner (1997) relataram a alta extinção que as comunidades de pássaros e mamíferos vêm sofrendo nos últimos 50 anos, comparativamente à taxa de extinção de espécies arbóreas de vida longa.

Dessa forma, a destruição e a fragmentação do habitat reduz significativamente a riqueza e abundância de espécies de pássaros e mamíferos. A maior ou menor capacidade de uma determinada espécie utilizar a vizinhança ao redor dos fragmentos isolados implicará na sua persistência no espaço e no tempo. A fragmentação florestal 
pode promover, ao longo dos anos, a dominância local de muitas espécies de pássaros e mamiferos generalistas que são mais tolerantes às mudanças da paisagem (Laurance, 1991a; Estrada et al., 1993, Warburton, 1997).

O fragmento Mata do Pomar, além do seu pequeno tamanho, alto grau de isolamento e as perturbações antrópicas recentes, está inserido numa matriz dominada pela agricultura e áreas urbanas. Além disso, o processo de fragmentação da Floresta Estacional Semidecidual do interior do Estado de São Paulo iniciou-se há várias décadas. A região de Piracicaba, por exemplo, está representada atualmente por apenas 2,1\% da cobertura florestal nativa (Viana et al., 1997). Então é provável que estes fatores, em conjunto, podem ter influenciado a perda de animais especialistas em recurso alimentar e de habitat e favorecido as espécies generalistas com alta tolerância às mudanças ambientais.

Um estudo semelhante foi realizado por Thébaud \& Strasberg (1997) na liha La Réunion, localizada no Oceano índico. Este estudo avaliou a taxa de colonização de espécies de plantas (incluindo árvores, arbustos e cipós) em áreas desmatadas abandonadas de diferentes idades que circundam os fragmentos. Houve diferença significativa da taxa de colonização entre a zoocoria e anemocoria. As espécies zoocóricas apresentaram menor taxa de colonização que as espécies anemocóricas Os autores apontam que esta diferença está provavelmente relacionada à extinção de muitas espécies animais dispersores de sementes, devido a elevada destruição do ecossistema nos útimos trezentos anos.

O maior recrutamento e a maior regeneração de individuos das espécies tolerantes e reprodutoras à sombra foram encontrados somente em áreas restritas dentro da Mata do Pomar, que ocupam cerca de apenas $16 \%$ da área total dos transectos (Nascimento \& Viana, submetido). $O$ fato dos fragmentos florestais serem continuamente afetados pelos efeitos de borda, tais como o aumento da abertura de clareiras em função da elevada turbulência de ventos e mudanças climáticas (Kapos, 1989; Laurance, 1997b), podem afetar a persistência mais a longo prazo destes grupos de espécies. $O$ desaparecimento destas espécies acarretará numa mudança da estrutura da comunidade, com as espécies pioneiras e oportunistas tendendo a aumentar ainda mais suas densidades. Como a maioria das espécies reprodutoras à 
sombra e tolerantes são zoocóricas e grande parte das espécies pioneiras e oportunistas são anemocóricas ou autocóricas, o desaparecimento das espécies tolerantes e reprodutoras à sombra implicará numa diminuição significativa da representatividade de espécies e indivíduos zoocóricos no fragmento. De fato, já ocorreu diminuição de indivíduos zoocóricos entre 1991 e 1995. Este processo deve resultar num contínuo empobrecimento biológico. São necessárias práticas de manejo conservacionista tanto no interior quanto na matriz da paisagem onde está inserido o fragmento. 


\section{REFERÉNCIAS BIBLIOGRÁFICAS}

ABATE, T. Environmental rapid-assessment programs have appeal and critics. Bioscience, v. 42, p. 486-489, 1992.

AIZEN, M. A.; FEINSINGER, P. Forest fragmentation, pollination, and plant reproduction in a chaco dry forest, Argentina. Ecology, v. 75, p. 330-351, 1994.

ALEIXO, A.; VIELLIARD, J. M. E. Composição e dinâmica da avifauna da Mata de Santa Genebra, Campinas, São Paulo, Brasil. Revista Brasileira de Zoologia, v.12, p. 493-511, 1995.

AUGSPURGER, C. K. Light requirements of neotropical tree seedlings: a comparative study of growth and survival. Journal of Ecology, p. 777-795, 1994.

BARRETT, S. C.; KOHN, J. R. Genetic and evolutionary consequences of small population size in plants: implications for conservation. In: FALK, D.; HOLSINGER, K. (Eds.). Genetics and conservation of rare plants. New York: Oxford University Press, 1991, p. 3-10.

BASSAB, W. O.; MIASAK, É. S.; ANDRADE, D. F. Introdução à análise de agrupamentos. In: $9^{\circ}$ SIMPÓSIO BRASILEIRO DE PROBABILIDADE E ESTATÍSTICA. São Paulo, 1990. Instituto de Matemática e Estatística Universidade de São Paulo. 105p.

BATISTA, J. L. F. Spatial dynamics of trees in a Brazilian Atlantic Tropical forest under natural and managed condition. Washington, 1994. 327p. Thesis (Ph.D.) University of Washigton.

BAWA, K. S. Plant-pollinator interactions in tropical forest. Annual Review Ecolology and Systematic, v. 21, p. 399-422, 1990.

BAZZAZ, F. A. Characteristic of population in relation to disturbance in natural and man-modified ecossystems. In: MOONEY, H. A.; GODRON, M. (Eds.) Disturbance and ecosystems. New York: Springer-Verlag, 1983. p. 259-275.

BECKER, P.; MOURE, J. S.; PERALTA, F. J. A. More about euglossine bees in Amazonian forest fragments. Biotropica, v. 23, p. 586-591, 1991.

BIERREGAARD, R. O.; LOVEJOY, T. E.; KAPOS, V.; SANTOS, A. A.; HUTCHINGS, $R$. W. The biological dynamics of tropical rainforest fragments. Bioscience, v. 42, $p$. 859-866, 1992.

CARVALHO, P. E. R. Espécies Florestais Brasileiras: recomendações silviculturais, potencialidades e uso da madeira. Curitiba: EMBRAPACNPFISPI, 1994, 640 p.

CASENAVE, J. L.; PELOTTO, J. P.; PROTOMASTRO, J. Edge-interior differences in vegetation structure and composition in a Chaco semi-arid forest, Argentina. Forest Ecology and Management, v. 72, p. 61-69, 1995.

CASTELLANI, T. T.; STUBBLEBINE, W. H. Sucessão secundária inicial em mata tropical mesófila após pertubação por fogo. Revista Brasileira de Botânica, v. 16, p. 181-203, 1993. 
CATHARINO, E. L. M. Estudos fisionômicos-florísticos e fitossociológicos em matas residuais secundárias no município de Piracicaba, SP. Campinas, 1989. 181p. Dissertação (M. S.) - Universidade Estadual de Campinas.

CHAMBERS, J. C.; MacMAHON, J. A. A day in the life of a seed: movements and fates of seeds and their implications for natural and managed systems. Annual Review Ecology and Systematic, v. 25, p. 263-292, 1994.

CORLETT, R. T.; TURNER, I. M. Long-term survival in tropical forest remnants in Singapore and Hong Kong. In: LAURANCE, W. F.; BIERREGAARD, R. O. (Eds.). Tropical forest remnants: ecology, management and conservation of fragmented communities. Chicago: University of Chicago Press, 1997, p. 3-12.

DENSLOW, J. S. Tropical rainforest gaps and tree species diversity. Annual Review of Ecology and Systematics, v. 18, p. 431-451, 1987.

DENSLOW, J. S. Functional group diversity and recovery from distubance. In: ORIANS, G. H.; DIRZO, R. (Eds.). Biodiversity and ecosystem processes in tropical forests. New York: Springer-Verlag, 1996, p. 127-152.

ESTRADA, A.; COATES-ESTRADA, R.; MERIT, D.; MONTIEL, S.;CURIEL, D. Patterns of frugivores species richness and abundance in forest islands and in agricultural habitats at Los Tuxtlas, Mexico. Vegetatio, 107/108: 245-257, 1993.

GILBERT, L. E. Food web organization and conservation of neotrpocal diversity., In: SOULÉ, M. E.; WILCOX, B. A. (Eds.). Conservation biology: an evolutionary and ecological perspective. Massachusetts: Sinauer Associates, 1980, p. 11-33.

GILPIN, M. E.; SOULÉ, M. E. Minimum viable populations: processes of species extintion. In: SOULÉ, M. E. (Ed.). Conservation biology: the science of scarcity and diversity. Massachusetts: Sinauer Press, 1986, p. 19-34.

HANSKI, I. Patch-occupancy dynamics in fragmented landscape. Trends in Ecology and Evolution, v. 9, p. 131-135, 1994.

HARPER, J. L. Population biology of plants. Londres: Academic Press, 1977. 715 p.

HASUI, É. O papel das aves frugivoras na dispersão de sementes em um fragmento de floresta estacional semidecídua secundária em São Paulo. São Paulo, Dissertação de Mestrado, IB/USP, 1994, 77 p.

HOWE, H. F. Implications of seed dispersal by animals for tropical reserve management. Biological Conservation, v. 30, p. 261-281, 1984.

HOWE, H. F. Specialized and generalized dispersal systems: where does "the paradigm" stand ? Vegetatio, v. 107/108, p. 3-13, 1993.

HOWE, H. F. Seed dispersal by birds and mammls: implications for seedlings demografy In: Bawa, K. S. (ed.). Reproductive Ecology of Tropical Forest Plants. The Parthenon Publishing Group, v. 8, 1990.

HOWE, H. F. Survival and growth of juvenile Virola surinamensis in Panama: effects of herbivory and canopy closure. Journal of Tropical Ecology, v. 6, p. 259-280, 1990. 
HOWE, H. F.; SMALLWOOD, J. Ecology of seed dispersal. Annual Review Ecology and Systematic, v. 13, p. 201-228, 1982.

HUBBELL, S. P.; FOSTER, R. B. Commonness and rarity in a neotropical forest: implications for tree conservation. In: SOULÉ, M. E. (Ed.). Conservation biology: the science of scarcity and diversity. Massachusetts: Sinauer Press, 1986, pp. 205-231.

IBGE. Manual Técnico da Vegetação Brasileira. Rio de Janeiro: IBGE, 1992. no. 1, 92p.

JANZEN, D. H. Ecologia vagetal nos trópicos. São Paulo: EDUSP, 1980.

JANZEN, D. H. No park is $\mathrm{f}$ (d island: increase in interference from outside as park decreases. Oikos, v. 41, p. 402-410, 1983.

JANZEN, D. H. The future of tropical biology. Annual Review of Ecology and Systematic, v. 17, p. 305-324, 1986.

JENNERSTON, O. Pollinator in Dianthes deltoides (Caryophullaceae) : effects of habitat fragmentation on visitation and seed set. Conservation Biology, v. 2, p. 359-366, 1988.

KAPOS, V. Effects of isolation on the water status of forest patches in the Brazilian Amazon. Journal of Tropical Ecology, v. 5, p. 173-185, 1989.

KAUFFMAN, J. B. Survival by Sprouting following fire in tropical forests of the eastern amazon. Biotropica, v. 23, p. 219-224, 1991.

KOOP, H.; RIJKSEN, H.; WIND, J. Tools to diagnose forest integrity: an appraisal method substantiated by silvi-star assessment of diversity and forest structure. In: BOYLE, T. J. B.; BOONTAWEE, B. (Eds.). Measuring and monitoring biodiversity in tropical and temperate forests. Tailândia: CIFOR/IUFRO, 1994. p. 309-334.

KREBS, C. J. Ecological methodology. New York: Harper Collins Publishers, 1985. 654p.

LANDE, R. Genetics and demography in biological conservation. Science, v. 241, p. 1455-1461, 1988.

LAURANCE, W. F. Ecological correlates of extinction proneness in Australian tropical rain forest mammals. Conservation Biology, v. 5, p. 79-89, 1991 a.

LAURANCE, W. F. Edge effects in tropical forest fragments: application of a model for the design of nature reserves. Biological Conservation, v. 57, p. 205-219, $1991 \mathrm{~b}$.

LAURANCE, W. F. Plants and plant-animal interactions. In: LAURANCE, W. F.; BIERREGAARD, R. O. (Eds.). Tropical forest remnants: ecology, management and conservation of fragmented communities. Chicago: University of Chicago Press, 1997a, p. 275-280. 
LAURANCE, W. F. Hyper-disturbed parks: edge effects and the ecology of isolated rainforest reserves in tropical Australia. In: LAURANCE, W. F.; BIERREGAARD, R. O. (Eds.). Tropical forest remnants: ecology, management and conservation of fragmented communities. Chicago: University of Chicago Press, 1997b, p. 71-83.

LAURANCE, W. F.; BIERREGAARD, R. O.; GASCON, C.; DIDHAM, R. K.; SMITH, A. P.; LYNAM, A. J.; VIANA, V. M.; LOVEJOY, T. E.; SIEVING, K. E.; SITES, J. W.; ANDERSEN, M.;TOCHER, M. D.; KRAMER, E. A.; RESTREPO, C.; MORITZ, C. Tropical forest fragmentation: synthesis of a diverse and dynamic discipline. In: LAURANCE, W. F.; BIERREGAARD, R. O. (Eds.). Tropical forest remnants: ecology, management and conservation of fragmented communities. Chicago: University of Chicago Press, 1997, p. 502-525.

LEPSCH-CUNHA, N. Rare tropical tree species: demographic and genetic responses of a very heterogeneous group. In: BIERREGAARD, R. O.; GASCON, C., LOVEJOY, T. E. (Eds.). The ecology and conservation of a fragmented forest: lessons from Amazonia. No prelo.

LEVEY, D. J., MOERMOND, T.C., DENSLOW, J.S. Frugivory: an overview. In: McDADE, L. A.; BAWA, K. S.; HESPENHEIDE, H. A.; HARTSHORN, G. S. (Eds.). La Selva: ecology and natural history of a neotropical rain forest. Chicago: University of Chicago Press, 1994. p. 282-294.

LIEBERMAN, M.; LIEBERMAN, D. Patterns of density and dispersion of forest trees. In: McDADE, L. A..; BAWA, K. S.; HESPENHEIDE, H. A.; HARTSHORN, G. S. (Eds.). La Selva: ecology and natural history of a tropical rainforest. Chicago: University of Chicago Press, 1994. p. 106-119.

LIEBERMAN, M.; LIEBERMAN, D.; PERALTA, R. Forests are not just swiss cheese: canopy stereogeometry of non-gaps in tropical forest. Ecology, v. 70, p. 550-552, 1989.

LORENZI, H. Árvores Brasileiras. Nova Odessa: Editora Plantarium, 1992, 352p.

LOVEJOY, T. E.; BIERREGAARD, R. O.; RYLANDS, A. B.; MALCON, J. R.;

QUINTELA, C. E.; HARPER, L. H.; BROWN, K. S.; POWELL, A. H.; POWELL, G. V. N.; SCHUBART, H. O. R.; HAYS, M. B. Edge and other effects of isolation on Amazon forest fragments. In: SOULE, M. E. (Ed.). Conservation biology: the science of scarcity and diversity. Massachusetts: Sinauer Press, 1986, p. 257285.

LYNAM, A. J. Rapid decline of small mammal diversity in Monsoon Evergreen forest fragments in Thailand. In: LAURANCE, W. F.; BIERREGAARD, R. O. (Eds.).

Tropical forest remnants: ecology, management and conservation of fragmented communities. Chicago: University of Chicago Press, 1997, p. 222239.

LUDWIG, J. A., REYNOLDS, J. F. Statistical ecology. New York: John Wiley \& Sons, 1988. 337p.

MAGURRAN, A. E. Ecological diversity and its measurement. New Jersey: Princeton University Press, 1988. 179p. 
MANOKARAN, N.; KOCHUMMEN, M. Recruitment, growth and mortality of tree species in a lowland dipterocarp forest in Peninsular Malaysia. Journal of Tropical Ecology, v. 3, p. 315-330, 1987.

MARTINEZ-RAMOS, M. Claros, ciclo vitales de los arboles tropicales y regeneracion natural de las selvas altas perennifoliadas. In: GOMEZ-POMPA, A. (Ed.). Investigaciones sobre la regeneracion de selvas altas en Veracruz, Mexico. Mexico: Editorial Alhambra Mexicana, v. 2, 1985, p. 191-239.

MENGES, E. S. Seed germination percentage increases with population size in a fragmented praire species. Conservation Biology, v. 5, p. 158-164, 1991a.

MENGES, E. S. The application of minimum viable population theory to plants. In:. FALK, D.A. \& HOLSINGER, K.E., (Eds.). Genetics and conservation of rare plants. Oxford University Press. 1991b, p. 45-61.

MORELLATO, P. C. Estudo da fenologia de árvores, arbustos e lianas de uma floresta semidecidua no sudeste do Brasil. Campinas, 1991. 176p. Tese (Doutorado), Universidade Estadual de Campinas.

MORELLATO, P. C., LEITÃO-FILHO, H. F. Padrões de frutificação e dispersão na Serra do Japi. In: MORELLATO, P. C. (Org.). História natural da Serra do Japi: ecologia e preservação de uma área florestal no sudeste do Brasil. Campinas: Editora da UNICAMP, 1992, p. 112-139.

MURCIA, C. Edge effects in fragmented forests: implications for conservation. Trends in Ecology and Evolution, v. 10, p. 58-62, 1995.

NASCIMENTO, H. E. M.; TABANEZ, A. A. J.; VIANA, V. M. Estrutura e dinâmica de dois fragmentos de floresta estacional semidecidual na região de Piracicaba, SP. In: $3^{\circ}$ CONGRESSO DE ECOLOGIA DO BRASIL, Brasilia, 1996. Resumos. Universidade de Brasília. p. 132.

NASCIMENTO, H. E. M.; VIANA, V. M. Estrutura e dinâmica de eco-unidades em um fragmento de floresta estacional semidecidual na região de Piracicaba, SP. Scientia Forestalis. Submetido.

NASON, J. D.; ALDRICH, P. R.; HAMRICK, J. L. Dispersal and the dynamics of genetic structure in fragmented tropical tree populations. In: LAURANCE, W. F.; BIERREGAARD, R. O. (Eds.). Tropical forest remnants: ecology, management and conservation of fragmented communities. Chicago: University of Chicago Press, 1997, p. 304-320.

NEWMARK, W. D. Tropical forest fragmentation and the local extictions of understory birds in the eastern usambara mountains, Tanzania. Conservation Biology, 5:67$78,1991$.

OLDEMAN, R. A. A. Tropical rain forest, architecture, silvigenesis, and diversity. In: SUTTON, S. L.; WHITMORE, T. C.; CHADWICK, A. C. (Eds.). Tropical rain forest: ecology and management. Oxford: Blackwell Scientific Publication, 1983. p.131150. 
OLDEMAN, R. A. A. Dynamics in tropical rain forests. In: HOLM-NIELSEN, L. B., NIELSEN, I. C.; BALSLEV, H. (Eds.). Tropical forest: botanical dynamics, speciation and diversity. London: Academic Press, 1989. p. 3-21.

ORIANS, G. H. The influence of trefalls on the tropical forest tree species richness. Tropical Ecology, v. 23, p. 255-279, 1982.

PRIMACK, R. B. Essentials of conservation biology. Massachusetts: Sinauer Press, 1993. 564 p.

PRIMACK, R. B.; HALL, P. Biodiversity and forest change in Malaysian Borneo. Bioscience, v. 42, p. 829-837, 1992.

PUTZ, F. E. The natural history of lianas on Barro Colorado Island, Panama. Biotropica, v. 19, p. 334-341, 1984.

RANKIN-DE-MERONA, J. M.; ACKERLEY, D. D. Estudos populacionais de árvores em florestas fragmentadas e as implicações para conservação in situ das mesmas na floresta tropical da Amazônia Central. Revista IPEF, v. 35, p. 47-59, 1987.

RICHARDS, P. W. The tropical rain forest. London: Cambridge University Press, 1979. 450p.

RODRIGUES, R. R.; MATTHES, L. A.; TORRES, B. B. Espécies arbóreas - distribuiçăo agregada ou reprodução vegetativa? In: V CONGRESSO LATINOAMERICANO DE BOTÂNICA, 1990. Resumos. p. 54.

SAUNDERS, D. A.; HOBBS, R. J.; MARGULES, C. R. Biological consequences of ecosystem fragmentation: a review. Conservation Biology, v. 5, p. 518-532, 1991.

SHAFFER, M. L. Minimum population sizes for species conservation. Bioscience, v. 31, p. 131-134, 1981.

SIEVING, K. E.; KARR, J. R. Avian extinction and Persistance Mechanisms in lowland Panama. In: LAURANCE, W. F.; BIERREGAARD, R. O. (Eds.). Tropical forest remnants: ecology, management and conservation of fragmented communities. Chicago: University of Chicago Press, 1997, p. 156-170.

SIMBERLOFF, D. Do species-area curves predict extinction in fragmented forest?. In: WHITMORE, T. C.; SAYER, J. A. (Eds.). Tropical deforestation and species extinction. London: Chapman Hall, 1992, p. 75-89.

SILVA, J. M. C.; UHL, C.; MURRAY, G. Plant sucession, landscape management, and the ecology of frugivorous birds in abandoned amazonian pastures. Conservation Biology, v. 10, p. 491-503, 1996.

SOKAL, R. R.; ROHLF, F. J. Biometry. New York: W. H. Freeman and Company, $1981.859 \mathrm{p}$.

SWAINE, M. D.; LIEBERMAN, D.; PUTZ, F. E. The dynamics of tree populations in tropical forest: a review. Journal of Tropical Ecology, v. 3, p. 359-366, 1987. 
TABANEZ, A. A. J. Ecologia e Manejo de Ecounidades em um Fragmento Florestal na Região de Piracicaba. Piracicaba, 1995. 85p. Disertação (M.S.) - Escola Superior de Agricultura "Luiz de Queiroz", Universidade de São Paulo.

TABANEZ, A. A. J.; VIANA, V. M.; DIAS, A. da S. Consequências da fragmentação e do efeito de borda sobre a estrutura, diversidade e sustentabilidade de um fragmento de floresta de planalto. Revista Brasileira de Biologia, v. 57, p. 47-60, 1997.

TERBORGH, J. Keystone plant resources in the tropical forest: In: SOULÉ, M. E. (Ed.). Conservation biology: the science of scarcity and diversity. Massachusetts: Sinauer Press, 1986, p. 330-354.

THÉBAUD, C.; STRASBERG, D. Plant dispersal in fragmented landscapes: a field study of wood colonization in rainforest remnants of the Mascarene Archipelago. In: LAURANCE, W. F.; BIERREGAARD, R. O. (Eds.). Tropical forest remnants: ecology, management and conservation of fragmented communities. Chicago: University of Chicago Press, 1997, p. 321-332.

TURNER, I. M. The seedling survivorship and growth of three Shorea species in a Malasian tropical rain forest. Journal of Tropical Ecology, v. 6, p. 469-478, 1990.

TURNER, I. M. Species loss in fragments of tropical rain forests: a review of the evidence. Journal of Applied Ecology, v. 33, p. 200-209, 1996.

TURNER, I. M.; CORLETT, R. T. The conservation value of small, isolated fragments of lowland tropical rain forest. TREE, v. 11, p. 330-333.

TURNER, I. M.; CHUA, K. S.; ONG, J. S. Y.; SOONG, B. C.; TAN, H. T. W. A century of plant species loss from an isolated fragment of lowland tropical rain forest. Conservation Biolology, v. 10, p. 1229-1244, 1996.

UHL, C.; CLARK, K.; DEZZEO, N.; MAQUIRINO, P. Vegetation dynamics in Amazonian treefall gaps. Ecology, v. 69, p. 751-763, 1988a.

UHL, C.; BUSCHBACHER, R.; SERRÃO, E. A. S. Abandoned pastures in eastern Amazonia. I. Patterns of plant succession. Journal of Ecology, v. 76, p. 663-681, 1988b.

UHL, C.; BARRETO, P.; VERISSIMO, A.; VIDAL, E.; AMARAL, P.; BARROS, A. C.; SOUZA, C.; JOHNS, J.; GERWING, J. Natural resource management in the brazilian amazon. Bioscience, v. 47, p. 160-168, 1997.

VIANA, V. M. Seed dispersal and gap regeneration: the case of three Amazonia tree species. Cambridge, 1989. 270p. Thesis (Ph. D.) - Harvard University.

VIANA, V. M. Conservação da biodiversidade de fragmentos florestais em paisagens tropicais intensamente cultivadas. In: ABORDAGENS INTERDISCIPLINARES PARA A CONSERVAÇÃO DA BIODIVERSIDADE BIOLÓGICA E DINÂMICA DO USO DA TERRA, Belo Horizonte, 1995. Anais. p. 135-154.

VIANA, V. M. \& TABANEZ, A. A. J. Biology and conservation of forest fragments in the brazilian atlantic moist forest. In: SCHELLAS, J.; GREENBERG, R. (Eds.). Forest patches in tropical landscapes. Washington: Island Press, 1996, p. 151-167. 
VIANA, V. M.; TABANEZ, A. A. J.; MARTINEZ, J. L. A. Restauração e manejo de fragmentos florestais. In: II CONGRESSO NACIONAL SOBRE ESSÊNCIAS NATIVAS, São Paulo, 1992. Anais. Instituto Florestal de São Paulo. p. 400-407.

VIANA, V. M.; TABANEZ, A. A. J.; BATISTA, J. L. F. Dynamics and restoration of forest fragments in the Brazilian Atlantic Moist forest. . In: LAURANCE, W. F.; BIERREGAARD, R. O. (Eds.). Tropical forest remnants: ecology, management and conservation of fragmented communities. Chicago: University of Chicago Press, 1997, p. 351-365.

VIDAL, E.; JOHNS, J.; GERWING, J.; BARRETO, P.; UHL, C. Vine management for reduced-impact logging in eastern Amazonia. Forest Ecology and Management, v. 98, p. 105-114, 1997.

WHITMORE, T. C. Canopy gaps and the two major groups of forest trees. Ecology, v. 70, p. 536-538, 1989.

WHITMORE, T. C. Tropical forest disturbance, disappearance, and species loss. In: LAURANCE, W. F.; BIERREGAARD, R. O. (Eds.). Tropical forest remnants: ecology, management and conservation of fragmented communities. Chicago: University of Chicago Press, 1997, p. 3-12.

WARBUNTON, N. H. Structure and Conservation of forest avifauna in isolated rainforest remnants in tropical Australia. In: LAURANCE, W. F.; BIERREGAARD, R. O. (Eds.). Tropical forest remnants: ecology, management and conservation of fragmented communities. Chicago: University of Chicago Press, 1997, p. 190206.

WILSON, E. O. The current state of biological diversity. In: WILSON, E. O.; PETER, F. M. (Eds.). Biodiversity. Washington: National Academy Press, 1988, p. 3-18.

YOUNG, A.; BOYLE, T.; BROWN, A. The population genetic consequences of habitat fragmentation. Trends in Ecology and Evolution, v. 11, p. 413-418, 1996.

ZUIDEMA, P. A.; SAYER, J. A.; DIJKMAN, W. Forest fragmentation and biodiversity: the case for intermediate-sized conservation areas. Environmental Conservation, v. 23, p. 290-297, 1996. 